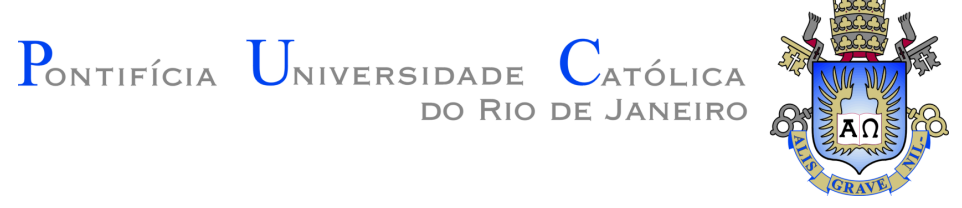

Maria Leandra Guateque Jaramillo

\title{
Redes neurais de aprendizado profundo para a identificação de despertares relacionados a eventos respiratórios usando sinais EEG polissonográficos
}

Dissertação apresentada como requisito parcial para obtenção do grau de Mestre pelo Programa de Pós-graduação em Engenharia Elétrica do Departamento de Engenharia Elétrica da PUC-Rio .

Orientador : Prof. Marco Aurélio Calvanti Pacheco Co-orientador: Profa. Elisabeth Costa Monteiro Co-orientador: Prof. Alvaro David Orjuela Cañón 

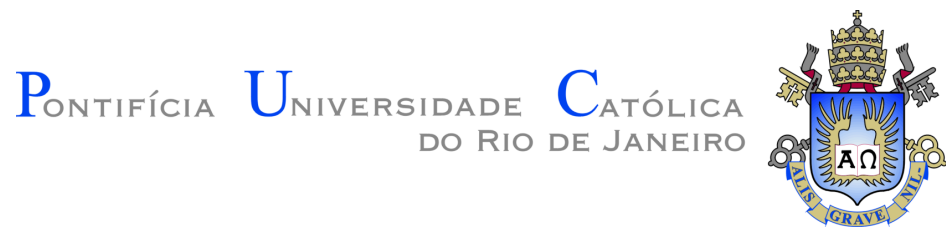

Maria Leandra Guateque Jaramillo

\begin{abstract}
Redes neurais de aprendizado profundo para a identificação de despertares relacionados a eventos respiratórios usando sinais EEG polissonográficos
\end{abstract}

Dissertação apresentada como requisito parcial para obtenção do grau de Mestre pelo Programa de Pós-graduação em Engenharia Elétrica do Departamento de Engenharia Elétrica da PUC-Rio Aprovada pela Comissão Examinadora abaixo assinada.

Prof. Marco Aurélio Calvanti Pacheco

Orientador

Departamento de Engenharia Elétrica - PUC-Rio

Profa. Elisabeth Costa Monteiro

Co-orientador

Programa de Pós-Graduação em Metrologia - PUC-Rio

\title{
Prof. Alvaro David Orjuela Cañón \\ Co-orientador \\ Unversidad del Rosario - URosario
}

Prof. Antônio Maurício Ferreira Leite Miranda de Sá

Universidade Federal do Rio de Janeiro - UFRJ

Prof. Carlos Roberto Hall Barbosa

Programa de Pós-Graduação em Metrologia - PUC Rio

Rio de Janeiro, 16 de Outubro de 2020 
Todos os direitos reservados. A reprodução, total ou parcial, do trabalho é proibida sem autorização da universidade, da autora e do orientador.

Maria Leandra Guateque Jaramillo

Graduou-se em Engenharia Biomédica na Universidade António Nariño (UAN) na cidade de Bogotá,Colômbia.

Ficha Catalográfica

Guateque Jaramillo, Maria Leandra

Redes neurais de aprendizado profundo para a identificação de despertares relacionados a eventos respiratórios usando sinais EEG polissonográficos / Maria Leandra Guateque Jaramillo; orientador: Marco Aurélio Calvanti Pacheco ; coorientadores: Elisabeth Costa Monteiro, Alvaro David Orjuela Cañón - 2020.

109 f: il. color. ; $30 \mathrm{~cm}$

Dissertação (mestrado) - Pontifícia Universidade Católica do Rio de Janeiro, Departamento de Engenharia Elétrica.

Inclui bibliografia

1. Engenharia Elétrica - Teses.2. Redes Neurais de Aprendizado Profundo,. 3. Extração de Características,. 4. Distúrbios respiratórios do sono,. 5. Sinais EEG polissonográficos,. 6. Sono. I. Calvanti, Marco Aurélio Pacheco. II. Costa Monteiro, Elisabeth.III. Orjuela Cañón, Alvaro David.IV. Pontifícia Universidade Católica do Rio de Janeiro. Departamento de Engenharia Elétrica.V. Título.

CDD: 621.3 
Aos meus pais, irmão e família pelo apoio e amor brindado ao longo desta etapa. 


\section{Agradecimentos}

Graças a Deus pela vida, fortaleza, experiencias e a sabedoria .

Ao meu orientador o Dr. Marco Aurélio Pacheco pela oportunidade, confiança e apoio durante o desenvolvimento dessa pesquisa e ao Dr. Smith Arauco, por compartilhar seu conhecimento, tempo e pela ajuda oferecida.

Aos meus Co-orientadores, a Dra. Elisabeth Costa Monteiro por sua ajuda, confiança e apoio incondicional, gratidão infinita pela dedicação e ajuda brindada, e ao Dr. Alvaro David Orjuela Cañón por ser meu amigo, tutor de graduação, um excelente professor e se tornar meu apoio. Ao Dr. Paulo Ivson pela ajuda, tempo, compreensão e apoio brindado.

O presente trabalho foi realizado com apoio da Coordenação de Aperfeiçoamento de Pessoal de Nível Superior - Brasil (CAPES) - Código de Financiamento 001. À PUC-Rio, pela bolsa de isenção das anuidades e pelo acesso à uma infraestrutura de pesquisa e a um enriquecedor ambiente acadêmico.

Ao meus pais pelo apoio, amor e paciência, gratidão por me ensinar que os obstáculos da vida podem ser a melhor escola e por me educar com muito amor e carinho. Ao meu irmão por ser meu amigo e minha motivação pra ser a melhor versão de mim cada dia. Ao meu namorado Juan David Caicedo Vásquez pelo amor, apoio, paciência, compreensão e por tornar minha vida simplesmente maravilhosa com seu sorriso e enorme coração, e a nossa gatinha Sombra, por nos dar luz e amor nos dias escuros.

Às minhas amigas, Olga, Vicky e Leidy pelo apoio emocional e sua amizade ao longo destes anos. Também a meus amigos de mestrado Yessica, Esteban, Allan, Andrés e Priscila pelas lembranças, risadas e as brincadeiras compartilhadas, em especial a meu amigo Salvador Pacheco pelos ensinamentos, companhia e ajuda nos momentos mais difíceis, gratidão amigão!!. 


\section{Resumo}

Guateque Jaramillo, Maria Leandra; Calvanti, Marco Aurélio Pacheco; Costa Monteiro, Elisabeth; Orjuela Cañón, Alvaro David. Redes neurais de aprendizado profundo para a identificação de despertares relacionados a eventos respiratórios usando sinais EEG polissonográficos. Rio de Janeiro, 2020. 109p. Dissertação de Mestrado - Departamento de Engenharia Elétrica, Pontifícia Universidade Católica do Rio de Janeiro.

Para o diagnóstico de distúrbios do sono, um dos exames mais usado é a polissonografia (PSG), na qual é registrada uma variedade de sinais fisiológicos. O exame de PSG é observado por um especialista do sono, processo que pode levar muito tempo e incorrer em erros de interpretação. $\mathrm{O}$ presente trabalho desenvolve e compara o desempenho de quatro sistemas baseados em arquiteturas de redes neurais de aprendizado profundo, mais especificamente, redes convolutivas $(\mathrm{CNN})$ e redes recorrentes Long-Short Term Memory (LSTM), para a identificação de despertares relacionados ao esforço respiratório (Respiratory Effort-Related Arousal-RERA) e a eventos de despertar relacionados à apneia/hipopneia. Para o desenvolvimento desta pesquisa, foram usadas as informações de apenas seis canais eletroencefalográficos (EEG) provenientes de 994 registros de PSG noturna da base de dados PhysioNet CinC Challenge2018, além disso, foi considerado o uso de class weight e Focal Loss para lidar com o desbalanceamento de classes. Para a avaliação de cada um dos sistemas foram usadas a Accuracy, AUROC e AUPRC como métricas de desempenho. Os melhores resultados para o conjunto de teste foram obtidos com os modelos CNN1 obtendo-se uma Accuracy, AUROC e AUPRC de 0,8404, 0,8885 e 0,8141 respetivamente, e CNN2 obtendo-se uma Accuracy, AUROC e AUPRC de 0,8214, 0,8915 e 0,8097 respetivamente. Os resultados restantes confirmaram que as redes neurais de aprendizado profundo permitem lidar com dados temporais de EEG melhor que os algoritmos de aprendizado de máquina tradicional, e o uso de técnicas como class weight e Focal Loss melhoram o desempenho dos sistemas.

\section{Palavras-chave}

Redes Neurais de Aprendizado Profundo, Extração de Características, Distúrbios respiratórios do sono, Sinais EEG polissonográficos, Sono 


\section{Abstract}

Guateque Jaramillo, Maria Leandra; Calvanti, Marco Aurélio Pacheco (Advisor); Costa Monteiro, Elisabeth (Co-Advisor); Orjuela Cañón, Alvaro David (Co-Advisor). Deep Learning Neural Networks for the Identification of Arousals Related to Respiratory Events using polysomnographic EEG signals. Rio de Janeiro, 2020. 109p. Master Dissertation - Departamento de Engenharia Elétrica, Pontifícia Universidade Católica do Rio de Janeiro.

For the diagnosis of sleep disorders, one of the most commonly used tests is polysomnography (PSG), in which a variety of physiological signs are recorded. The study of PSG is observed by a sleep therapist, This process may take a long time and may incur misinterpretation. This work develops and compares the performance of four classification systems based on deep learning neural networks, more specifically, convolutional neural networks (CNN) and recurrent networks Long-Short Term Memory (LSTM), for the identification of Respiratory Effort-Related Arousal (RERA) and to events related to apnea/hypopnea. For the development of this research, it was used the Electroencephalogram (EEG) data of six channels from 994 night polysomnography records from the database PhysioNet CinC Challenge2018, the use of class weight and Focal Loss was considered to deal with class unbalance. Accuracy, AUROC, and AUPRC were used as performance metrics for evaluating each system. The best results for the test set were obtained with the CNN1 models obtaining an accuracy, AUROC and AUPRC of 0.8404, 0.8885 and 0.8141 respectively, and RCNN2 obtaining an accuracy, AUROC and AUPRC of 0.8214, 0.8915 and 0.8097 respectively. The remaining results confirmed that deep learning neural networks allow dealing with EEG time data better than traditional machine learning algorithms, and the use of techniques such as class weight and Focal Loss improve system performance.

\section{Keywords}

Deep Neural Networks, Features Extraction, Breathing sleep disorders, polysomnographic EEG signals, Sleep 


\section{Sumário}

$\begin{array}{lll}1 & \text { Introdução } & 17\end{array}$

$\begin{array}{lll}1.1 & \text { Motivação } & 18\end{array}$

$\begin{array}{lll}1.2 & \text { Objetivos } & 19\end{array}$

$\begin{array}{ll}1.3 \text { Desenho da Pesquisa } & 19\end{array}$

1.4 Organização do documento 20

2 Estado da Arte $\quad 22$

3 Fisiologia do Sono $\quad 26$

$\begin{array}{ll}3.1 & \text { Atividade Eletroencefalográfica } \\ 3.1 .1 & 26\end{array}$

$\begin{array}{ll}3.1 .1 & \text { Ondas Alfa } \\ 3.1 .2 & 27\end{array}$

3.1.2 Ondas Teta 27

3.1.3 Ondas Delta 28

3.1.4 Fusos do sono 28

3.1.5 Complexos k 28

$\begin{array}{ll}3.1 .6 & \text { Ondas Beta } \\ 3.2 & 28\end{array}$

3.2 Estágios de sono 29

$\begin{array}{lll}3.2 .1 & \text { Vigília } & 29\end{array}$

3.2.2 Sono NREM 30

3.2.3 Sono REM 31

3.3 Processo Respiratório durante o sono 31

3.4 Distúrbios Respiratórios associados ao sono 31

3.4.1 Apneia 32

3.4.2 Hipopneia 32

3.4.3 Despertares relacionados ao Esforço Respiratório (RERA) 32

4 Polissonografia $\quad 33$

$\begin{array}{lll}4.1 & \text { Hipnograma } & 33\end{array}$

4.2 Parâmetros Fisiológicos da Polissonografia 34

4.2.1 Parâmetros Neurofisiológicos 34

4.2.1.1 Electroencefalograma $\quad 35$

4.2.1.2 Eletro-oculograma 36

4.2.1.3 Eletromiografia de Queixo 36

$\begin{array}{lll}\text { 4.2.1.4 Eletromiografia da Perna } & 37\end{array}$

4.2.2 Parâmetros Cardiorrespiratórios 38

4.2.2.1 Electrocardiograma (ECG) 38

4.2.2.2 Fluxo de $\mathrm{Ar} \quad 39$

4.2.2.3 Oximetria de Pulso $\quad 39$

4.2.2.4 Esforço Respiratório 40

4.2.3 Parâmetros Auxiliares 41

4.2.3.1 Sensor de Ronco 41

4.2.3.2 Sensor de Posição 41

4.2.3.3 Sensor de movimento das extremidades 42

4.3 Identificação de RERA 42 
4.4 Identificação de Hipopneia 42

5 Fundamentos de Inteligência Artificial $\quad 44$

5.1 Machine Learning (ML) 44

5.1.1 Random Forest (RF) 44

5.1.2 Naive Bayes (NB) 45

$\begin{array}{lll}5.1 .3 & \text { K-Nearest Neighbor (KNN) } & 46\end{array}$

$\begin{array}{lll}\text { 5.1.4 Redes Neurais Artificiais (RNA) } & 47\end{array}$

$\begin{array}{lll}5.1 .5 & \text { Funções de ativação } & 48\end{array}$

5.2 Deep Learning (DL) 48

5.2.1 Redes Neurais Convolucionais (CNN) 48

5.2.1.1 Camada Convolutiva $\quad 50$

5.2.1.2 Camada de Amostragem (Pooling Layer) 50

5.2.1.3 Fully Connected Layer $\quad 51$

5.2.2 Batch Normalization (BN) 51

5.2.3 Dropout 52

5.2.4 Redes Neurais Recorrentes (RNN) 52

5.2.5 Redes Long Short-Term Memory(LSTM) 53

$\begin{array}{ll}\text { 5.2.6 Class Weight } & 56\end{array}$

5.2.7 Focal Loss (FL) 56

6 Materiais e Métodos $\quad 58$

6.1 Materiais $\quad 58$

6.1.1 Equipamento/software 58

6.1.2 Base de Dados $\quad 59$

6.2 Métodos 61

6.2.1 FASE I: Estudo da base de dados 62

6.2.1.1 Normal 62

6.2.1.2 Evento RERA 63

6.2.1.3 Eventos associados à apneia/hipopneia 64

6.2.2 FASE II: Desenvolvimento e Implementação de sistemas 65

6.2.2.1 Notação dos dados 65

6.2.2.2 Sistema $1 \quad 66$

6.2.2.3 Sistema 2: CNN1 70

6.2.2.4 Sistema 3: RCNN1 70

6.2.2.5 Sistema 4: CNN2 71

6.2.2.6 Sistema 5: RCNN2 72

6.2.3 FASE III: Validação dos resultados 73

6.2.3.1 Matriz de confusão 73

6.2.3.2 Área sob a Curva de característica de operação do receptor (AUROC) 73

6.2.3.3 Precision 74

6.2.3.4 Recall 74

6.2.3.5 Área sob a curva de Recall de Precisão (AUPRC)

6.2.3.6 Acuracy

$\begin{array}{lll}\text { 6.2.3.7 Especificidade } & 75\end{array}$

7 Resultados: apresentação, análise e discussão $\quad \mathbf{7 6}$

$\begin{array}{lll}7.1 & \text { Resultados Sistema } 1 & 76\end{array}$

$\begin{array}{lll}7.2 & \text { Resultados Sistema 2 } & 79\end{array}$ 
$\begin{array}{lll}7.3 & \text { Resultados Sistema } 3 & 82\end{array}$

$\begin{array}{lll}7.4 & \text { Resultados Sistema } 4 & 85\end{array}$

$\begin{array}{lll}7.5 & \text { Resultados Sistema } 5 & 88\end{array}$

$\begin{array}{lll}7.6 & \text { Discussão dos resultados } & 91\end{array}$

8 Conclusões $\quad 96$

$\begin{array}{lll}8.1 & \text { Trabalhos Futuros } & 98\end{array}$

$\begin{array}{lr}\text { Referências bibliográficas } & 99\end{array}$

$\begin{array}{lll}\text { A Glossário } & 109\end{array}$ 


\section{Lista de figuras}

$\begin{array}{lll}\text { Figura 1.1 Desenho da pesquisa } & 21\end{array}$

$\begin{array}{lll}\text { Figura 3.1 } & \text { Formas de onda da atividade EEG. } & 27\end{array}$

Figura 4.1 Gráfico de um Hipnograma para uma noite de sono de um adulto saudável obtido usando Python, no qual cada um das cores representa a transição de um para outro dos estágios do sono.

Figura 4.2 Sistema 10-20 para adquisição de EEG.(a) Derivações EEG recomendadas e (b) derivações EEG ideais para PSG. Em cor azul podem-se observar as derivações frontais, em verde as centrais e em laranja as posteriores.

Figura 4.3 Eletro-oculografia: (a) Diferença de potencial córnearetina e (b) Posição dos eletrodos para adquisição do sinal.

Figura 4.4 Posição dos eletrodos para adquisição do sinal de EMG de queixo.

Figura 4.5 Eletromiografia de perna para PSG (a) em vermelho localização do músculo tibial anterior e (b) posição dos eletrodos para a adquisição do EMG durante a PSG podendo ser usada configuração EMG_D, EMG_I ou ambas.

Figura 4.6 Posição dos eletrodos para adquisição do sinal de eletrocardiografia. Em (a) emprega-se o terra do EEG e em (b) o terra do ECG (RL)

Figura 4.7 Posicionamento do sensor para medição do fluxo de ar:

(a) Vista frontal e (b) lateral do termistor.

Figura 5.1 Representação esquemática de um modelo Random Forest 45

Figura 5.2 Arquitetura padrão de uma Rede Neural Artificial. 47

Figura 5.3 Funções de ativação e sua definição matemática. 48

Figura 5.4 Exemplo Básico de uma Rede Neural Convolutiva 49

Figura 5.5 Processo de convolução entre a entrada de forma matricial (quadro amarelo) e o kernel (quadro azul) do neurônio da camada oculta (ponto azul escuro)

Figura 5.6 Exemplo de amostragem usando uma camada tipo Maxpooling, onde é usado um kernel de tamanho 2x2 (quadrado vermelho) para encontrar os valores máximos presentes nas submatrizes da entrada (arreglos de $2 \times 2$ cor rouxo, verde, amarelo e azul).

Figura 5.7 Esquema geral de uma Rede LSTM.

Figura 5.8 Primeira porta da rede LSTM destacada em cor rosa. $\quad 54$

Figura 5.9 Segunda porta de uma rede LSTM destacada em cor laranja claro

Figura 5.10 Terceira porta de uma rede LSTM destacada em verde $\quad 55$

Figura 5.11 Porta de saída de uma rede LSTM destacada em azul $\quad 55$ 
Figura 6.1 Equipamento e software usado para o desenvolvimento da pesquisa: (a) interface gráfica SSH Power Shell Client usada para conexão ao nodo GPU da máquina remota e (b) Laptop usado para conexão remota e atividades relacionadas ao desenvolvimento de algoritmos

Figura 6.2 Registro polissonográfico para um segmento de 30 segundos 60 Figura 6.3 Quantidade de exemplos para cada um dos distúrbios de sono presentes na base de dados

Figura 6.4 Fases da Metodologia

Figura 6.5 Exemplo de um segmento de Polissonografia da classe Normal

Figura 6.6 Exemplo de um segmento de Polissonografia de um Evento RERA

Figura 6.7 Exemplo de um segmento de Polissonografia associado a um evento de apneia/hipopneia

Figura 6.8 Diagrama de fluxo dos passos para o desenvolvimento e implementação do sistema 1

Figura 6.9 Derivações EEG contidas nos registros PSG da base de dados

Figura 6.10 Periodograma de Welch: (a) Gráfico do periodograma de Welch, no qual o eixo x apresenta os bins de frequência contidas no segmento de sinal e o eixo y, a densidade de potência espectral (Power Spectral Density (PSD)

Figura 6.11 Matriz de dados polissonográficos para um individuo.

Figura 6.12 Arquiteturas usadas para o (a) Sistema 2 e (b) Sistema 3. 71

Figura 6.13 (a) Bloco CBR e arquiteturas usadas para o (b) Sistema 4 e (c) Sistema 5.

Figura 6.14 Matriz de confusão

Figura 7.1 Valores de Accuracy obtidos para o Sistema 2: (a) Comparação da Accuracy alcançada por cada configuração de hiperparâmetros e (b) Zoom dos melhores resultados de Accuracy obtidos para o sistema.

Figura 7.2 Valores de AUROC obtidos para o Sistema 2: (a) Comparação da AUROC alcançada por cada configuração de hiperparâmetros e (b) Zoom dos melhores resultados de AUROC obtidos para o sistema.

Figura 7.3 Valores de AUPRC obtidos para o Sistema 2: (a) Comparação da AUPRC alcançada por cada configuração de hiperparâmetros e (b) Zoom dos melhores resultados de AUPRC obtidos para o sistema.

Figura 7.4 Valores de Accuracy obtidos para o Sistema 3: (a) Comparação da Accuracy alcançada por cada configuração de hiperparâmetros e (b) Zoom dos melhores resultados de Accuracy obtidos para o sistema.

Figura 7.5 Valores de AUROC obtidos para o Sistema 3: (a) Comparação da AUROC alcançada por cada configuração de hiperparâmetros e (b) Zoom dos melhores resultados de AUROC obtidos para o sistema 
Figura 7.6 Valores de AUPRC obtidos para o Sistema 3: (a) Comparação da AUPRC alcançada por cada configuração de hiperparâmetros e (b) Zoom dos melhores resultados de AUPRC obtidos para o sistema

Figura 7.7 Valores de Accuracy obtidos para o Sistema 4: (a) Comparação da Accuracy alcançada por cada configuração de hiperparâmetros e (b) Zoom dos melhores resultados de Accuracy obtidos para o sistema

Figura 7.8 Valores de AUROC obtidos para o Sistema 4: (a) Comparação da AUROC alcançada por cada configuração de hiperparâmetros e (b) Zoom dos melhores resultados de AUROC obtidos para o sistema

Figura 7.9 Valores de AUPRC obtidos para o Sistema 4: (a) Comparação da AUPRC alcançada por cada configuração de hiperparâmetros e (b) Zoom dos melhores resultados de AUPRC obtidos para o sistema

Figura 7.10 Valores de Accuracy obtidos para o Sistema 5: (a) Comparação da Accuracy alcançada por cada configuração de hiperparâmetros e (b) Zoom dos melhores resultados de Accuracyobtidos para o sistema

Figura 7.11 Valores de AUROC obtidos para o Sistema 5: (a) Comparação da AUROC alcançada por cada configuração de hiperparâmetros e (b) Zoom dos melhores resultados de AUROC obtidos para o sistema

Figura 7.12 Valores de AUPRC obtidos para o Sistema 5: (a) Comparação da AUPRC alcançada por cada configuração de hiperparâmetros e (b) Zoom dos melhores resultados de AUPRC obtidos para o sistema

Figura 7.13 Comparação entre o presente trabalho e os trabalhos da literatura em função da Accuracy

Figura 7.14 Comparação entre o presente trabalho e os trabalhos da literatura em função da AUROC

Figura 7.15 Comparação entre o presente trabalho e os trabalhos da literatura em função da AUPRC 


\section{Lista de tabelas}

Tabela 3.1 Alterações fisiológicos presentes durante o sono 29

Tabela 4.1 Parâmetros medidos na PSG. 34

Tabela 6.1 Sinais contidas em cada um dos registros polissonográficos da base de dados $\quad 59$

Tabela 6.2 Notação dos dados para o Sistema $1 \quad 65$

Tabela 6.3 Notação dos dados para os sistemas 2, 3, 4 e $5 \quad 66$

Tabela 7.1 Resultados obtidos pelo Sistema 1 usando Random Forest. 77

Tabela 7.2 Resultados obtidos pelo Sistema 1 usando Naive Bayes 77

Tabela 7.3 Resultados obtidos pelo Sistema 1 usando KNN $\quad 77$

Tabela 7.4 Configurações de Hiperparâmetros para o Sistema 2. 79

Tabela 7.5 Resultados obtidos avaliando o Sistema 2. 79

Tabela 7.6 Configurações de Hiperparâmetros para o Sistema $3 . \quad 82$

Tabela 7.7 Resultados obtidos avaliando o Sistema 3. 82

Tabela 7.8 Configurações de Hiperparâmetros para o Sistema $4 \quad 85$

Tabela 7.9 Resultados obtidos avaliando o Sistema 4.

Tabela 7.10 Configurações de Hiperparâmetros para o Sistema $5 . \quad 88$

Tabela 7.11 Resultados obtidos avaliando o Sistema 5.

Tabela 7.12 Resumo dos melhores resultados obtidos para os sistemas $2,3,4$ e $5 \quad 91$

Tabela 7.13 Resumo das melhores configurações para os sistemas 2, 3, 4 e 5.

Tabela 7.14 Comparação trabalhos da Literatura com os sistemas propostos 92

Tabela 7.15 Comparação entre os desempenhos alcançados pelos sistemas 2 e 5 e os trabalhos da literatura 95 


\section{Lista de Abreviaturas e Siglas}

AASM - - Americam Academy of Sleep Medicine

AOS - - Apneia Obstrutiva do Sono

AUROC - - Area Under the Receiver Operating Characteristic

AUPRC- - Area Under the Precision-Recall Curve

Bi-LSTM - - Bidirectional Long-short Term Memory

CAP - - Períodos de Alternância do Ciclo

CCNL - - Computational Clinical Neurophysiology Laboratory

CDAC - - Clinical Data Animation Laboratory

CE - - Entropia Cruzada

CNN - - Convolutional Neural Networks

CPAP - - Pressão positiva contínua nas vias aéreas

DRS - - Distúrbios Respiratórios do Sono

EEG - - Electroencefalografia

ECG - - Eletrocardiografia

EMG - - Electromiografia

EL - - Ensamble Learning

EOG - - Eletro-oculagrafia

FFT - - Transformada Rápida de Fourier

FL - - Focal Loss

FN - Falsos Negativos

FP - - Falsos Positivos

KNN - - k-Nearest Neighbor

LSTM - - Long-Short Term Memory

MGH - - Massachusetts General Hospital's

MLP - - Multi-Layer Perceptron

MPES - - Movimentos Periódicos das extremidades durante o Sono

mRMR - - Minimum Redundancy Maximum Relevance

NREM - - Non Rapid Eye Moviment

PSD - - Potential Spectral Density

PSG - - Polissonografia

REM - - Rapid Eye Moviment

RERA - - Respiratory Effort-Related Arousal

RNA - - Redes Neurais Artificiais 
RNN - - Redes Neurais Recorrentes

RMS - - Raiz da Média Quadrática

SAHOS - - Síndrome da Apneia-Hipopneia Obstrutiva do Sono

SaO2 - - Saturação de Oxigênio

SDE - - Sonolência Diurna Excessiva

SNC - - Sistema Nervoso Central

SRVAS - - Síndrome de Resistência das Vias Aéreas Superiores

SVM - - Support Vector Machine

tanh - - Tangente Hiperbólica

TN - - Verdadeiros Positivos

TP - - Verdadeiros Negativos 


\section{Introdução}

Segundo a Organização Mundial da Saúde (OMS), aproximadamente $40 \%$ da população mundial dorme mal por causa de algum distúrbio do sono. A qualidade de sono relaciona-se com o estado mental, físico e psicológico do individuo, ao seu bem-estar e saúde em geral, razão pela qual, o sonho inadequado pode causar doenças mentais e físicas, que incluem problemas de memória e aprendizado, obesidade, hipotensão, disfunção cardiovascular, entre outras [1-5]. Existem aproximadamente 90 distúrbios do sono que são classificados nas categorias de insônia, distúrbios respiratórios, distúrbios do movimento relacionados ao sono, hipersonias de origem central, parassomias e transtornos do ritmo circadiano [6]. Os distúrbios de sono são classificados de acordo com critérios clínicos e neurofisiológicos, com fundamento nesses critérios, é possível avaliar a causa primária do distúrbio. As principais causas são: i) mecanismo do controle de sono, e ii) função inadequada de um órgão (e.g as vias superiores e os pulmões). Para o diagnóstico destes transtornos um dos testes mais usados é a Polissonografia clinica (PSG) [7].

No início da década de 1990, foram feitas tentativas para rastrear a população com distúrbios respiratórios de sono (DRS), para isso foram realizados três grandes estudos nos EUA: o Wisconsin Sleep Cohort Study, o Sleep Heart Health Study e o Penn State Cohort. Estes estudos evidenciaram que a prevalência de distúrbios respiratórios do sono nas mulher é de $6,5 \%$ a 9 $\%$ e nos homens de $17 \%$ a $31 \%$ [8]. Como resultado desses estudos aumentou-se o reconhecimento e conscientização dos DRS e sua associação a grandes taxas de morbidade e mortalidade. Assim, foi percebido que uma alta proporção dos indivíduos suspeitos de ter algum tipo de DRS têm fatores comórbidos (e.g. Síndrome de obesidade-hipoventilação) [8-10].

Destaca-se que o foco desta pesquisa é a identificação de despertares (Arousals) induzidos por três DRS específicos: apneia, hipopneia e despertares relacionados ao esforço respiratório (Respiratory Effort-Related ArousalRERA), dado que os despertares de sono podem ocorrer por transições entre os estados de sono, de forma espontânea ou em associação com outros distúrbios de sono ou estímulos ambientais [11]. De acordo com a American Academy Medicine of Sleep [12], os despertares de sono estão caraterizados pelas mu- 
danças repentinas na frequência do sinal cerebral, que são evidenciadas numa eletroencefalografia (EEG). Porém, dependendo do tipo de distúrbio de sono, outros sinais fisiológicas podem sofrer mudanças abruptas ou alterações nas suas formas de onda; Por exemplo, no caso da apneia, a hipopneia e os eventos RERA, são apresentadas alterações na forma de onda do EEG, fluxo de ar e a saturação de oxigênio (SaO2) [7]. Portanto, a análise dos padrões das séries temporais clínicas, anteriormente mencionadas, junto com outros biossinais, como eletro-oculografia (EOG) e eletrocardiografia (ECG), que são registrados durante um teste típico de polissonografia (PSG), fornecem importantes informações para detecção do despertar do sono $[4,13]$.

Diante disso, esta pesquisa propus o uso de redes neurais de aprendizado profundo para a identificação automática dos despertares associados a distúrbios respiratórios mencionados acima (detectados em gravações PSG da base de dados PhysioNet/Computing in Cardiology (CinC) Challenge 2018). Para isso, foram desenvolvidos quatro sistemas baseados em arquiteturas de redes neurais de aprendizado profundo, mais especificamente, redes neurais convolutivas (CNN) e redes neurais recorrentes Long-Short Term Memory (LSTM). Nesse contexto, esta pesquisa de mestrado visa contribuir para a optimização de processo de identificação dos distúrbios respiratórios do sono.

\section{1 \\ Motivação}

$\mathrm{Na}$ atualidade muitos indivíduos podem ser portadores de distúrbios do sono previamente diagnosticados ou não reconhecidos, embora, em muitas situações eles permanecem sem diagnóstico, resulta importante a obtenção no auxilio do diagnóstico dos distúrbios de forma eficiente e exata [10]. Portanto, há uma oportunidade de utilizar a avaliação do sono para descobrir doenças como apneia, hipopneia, eventos RERA, bruxismo, obstrução das vias aéreas, dentre outras, por meio de avaliação clínica e de testes de sono

Um dos desafios dos Conjuntos de dados PSG clínicos é o volume de informação que possuem, dado que podem consistir em centenas a milhares de registros PSG, e cada registro PSG contém mais de uma dúzia de séries temporais clínicas com cerca de oito horas de duração. A análise manual de tais conjuntos de dados é um processo lento e trabalhoso, que depende altamente da experiência e habilidade do tecnólogo do sono [14] e, consequentemente, limita os estudos relacionados ao sono baseados em PSG.

Por outro lado, a maioria dos trabalhos relacionados á identificação de distúrbios de sono focam-se só na identificação de uma única doença ou de parâmetros específicos como estágios de sono. Dessa forma, configura-se um 
espaço para investigação sobre a possibilidade de classificação dos registros quanto à ocorrência de despertares (arousals) com base apenas nos registros de EEG, minimizando complexidade e custos da avaliação diagnóstica. Por outro lado, considerando que a realização de registros de EEG em crianças são realizados durante o sono, por ser o período no qual ocorrem as alterações epilépticas, a possibilidade de identificação de arousals com base exclusivamente no registro eletroencefalográfico pode trazer benefícios diagnósticos adicionais ao EEG infantil, tais como a diminuição dos sensores usados para aquisição dos sinais fisiológicos, que em consequência melhoraria o conforto das crianças na hora do exame.

\section{2}

\section{Objetivos}

O objetivo principal deste projeto é a identificação automática de despertares por eventos respiratórios, especificamente por eventos RERA (Respiratory Effort-Related Arousal) e eventos associados a apnea/hipopneia usando sinais polissonográficos de EEG.

Os objetivos específicos que fazem parte desta pesquisa são:

- Implementar técnicas para lidar com o desbalanceamento dos dados e melhorar o desempenho dos sistemas na identificação de eventos Respiratórios.

- Desenhar e Implementar diferentes sistemas de classificação para a identificação de despertares relacionados a eventos respiratórios usando sinais de EEG polissonográficos.

- Analisar o desempenho obtido para cada um dos classificadores implementados frente aos modelos apresentados na literatura.

\section{3}

\section{Desenho da Pesquisa}

Esta pesquisa abrange três etapas principais: (I) exploratória e descritiva, (II) pesquisa aplicada e (III) conclusiva. A Figura 1.1 apresenta o desenho da pesquisa, destacando seus componentes e os métodos usados. Quanto aos meios de investigação, a metodologia compreende:

- Pesquisa bibliográfica e documental sobre os temas centrais da pesquisa (Fase I Figura 1.1).

- Analise exploratório dos dados visando identificar a distribuição dos dados e as relações existentes entre as variáveis. 
- Desenvolvimento de algoritmos para o pré processamento dos dados, a extração de características e a avaliação das técnicas de aprendizado de maquina.

\section{4}

\section{Organização do documento}

A presente dissertação está organizada em oito capítulos. O primeiro capítulo consiste desta introdução, que inclui a motivação, os objetivos do projeto e descreve-se o desenho da pesquisa usado para a identificação de despertares relacionados a eventos respiratórios. Já no capítulo 2 é apresentada uma revisão dos trabalhos desenvolvidos para a identificação de eventos e distúrbios respiratórios.

Os capítulos 3, 4 e 5 contêm todos os fundamentos teóricos desta pesquisa e estão divididos em fisiologia do sono, a base teórica da polissonografia e alguns dos fundamentos de Inteligência Artificial estudados para o desenvolvimento desta pesquisa.

O sexto capítulo apresenta as diferentes etapas desenvolvidas durante a pesquisa, assim como as técnicas usadas.

O sétimo capítulo apresenta e discute os resultados. Neste capítulo, são expostas as vantagens e desvantagens de cada técnica experimental, assim como sua eficiência na identificação dos eventos por esforço respiratório.

Finalmente, o oitavo capítulo apresenta as conclusões da pesquisa e as propostas para trabalhos futuros. 

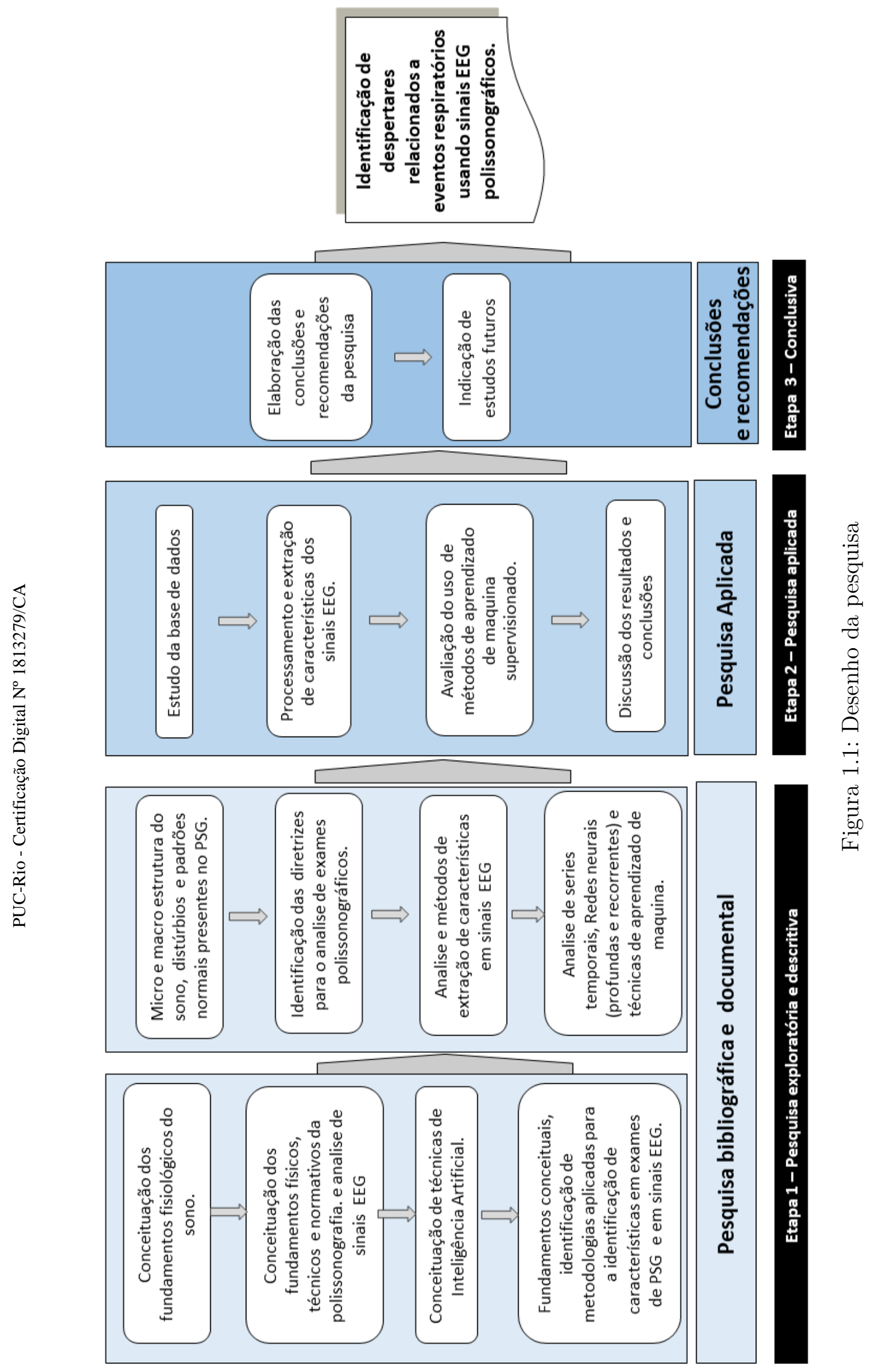


\section{2}

\section{Estado da Arte}

Neste capítulo é apresentada uma revisão bibliográfica de trabalhos desenvolvidos para a identificação tanto de despertares causados por eventos RERA como de distúrbios do sono associados apneia e hipopneia em registros de PSG.

Nos últimos anos, com o propósito de fornecer uma análise rápida e confiável dos registros de PSG, diferentes técnicas foram desenvolvidas nas áreas de informática, processamento de sinais e inteligência artificial. Por exemplo, em trabalhos como [15-17] são propostos sistemas para automatizar a classificação dos estágios de sono a partir dos registros PSG e em outros trabalhos o alvo principal é o diagnóstico de distúrbios de sono, como por exemplo, em $[18,19]$. Por outro lado, existem distúrbios de sono que vão acompanhados da aparição de despertares (Arousals), produzidos por uma mudança abrupta da frequência no EEG, que podem ter origem neurológica ou cardiorrespiratória, além disso, são fenômenos transitórios que resultam em um sono fragmentado sem despertar comportamental [11,20,21]. Visando a oferecer métodos de identificação desses eventos, em [22] foi proposto um sistema que usa dois canais de sinais de EEG e um de eletromiografia (EMG), extraídos dos registros PSG de 20 indivíduos. Os sinais foram pré-processados usando duas janelas temporais móveis, sobre cada canal, a fim de fazer uma comparação entre os segmentos passados e futuros do sinal. Após, cada época do sinal foi normalizada com base na amplitude total, em um intervalo de $[-1,1]$. Seguidamente, foram extraídas as épocas com presença de despertares para alimentar quatro classificadores baseados em discriminantes lineares e quadráticos de Fisher, Support Vector Machine (SVM) e redes neurais artificiais (RNA). Nesse trabalho foi obtida um sensibilidade, especificidade e uma Área sob a curva de operação do receptor(AUCROC) (Seção 6.2.3.2) médias de $0,868,0,765$ e 0,816 respetivamente.

Em 2015 [23], foi desenvolvido um algoritmo para a detecção automática de diferentes despertares do sono, para isso foram usados os registros noturnos de PSG de 9 indivíduos (seis homens, três mulheres), com faixa etária de 34 a 69 anos e diferentes estados de saúde (4 pacientes com apneia obstrutiva do sono, 4 saudáveise 1 paciente com distúrbio periódico do movimento dos membros), 
desses registros foram extraídos os sinais EEG, EMG e eletrocardiográfica (ECG). Seguidamente, cada um dos sinais foi segmentado em épocas de 30 segundos, foi calculada a porcentagem de banda usando a densidade de potencia espectral (PSD), obtida pelo algoritmo de Welch do sinal EEG. Já para o sinal de EMG, foi calculada a raiz da média quadrática (RMS), seguido de uma transformação para o domínio da frequência usando o algoritmo de Welch e finalmente foram extraídos a média dos valores espectrais de potência e é calculado o Minimum Noise Fraction (MNF). Também, a média, o desvio padrão, a amplitude do pico e o valor máximo do espectro de energia foram extraídos do sinal de fluxo de ar, finalizando a extração de características com o calculo da frequência cardíaca Heart Rate. Utilizou-se um classificador $k$ nearest neighbors (KNN) e o desempenho do algoritmo foi avaliado por Cross Validation Leave-One-Out. A sensibilidade, especificidade e precisão médias do algoritmo foram de $79 \%, 95,5 \%$ e $93 \%$, respectivamente.

Já em [24] foi proposto um algoritmo de extração de características genéricas e específicas de domínio para sinais de EEG, ECG, EMG, eletrooculografia (EOG), saturação de oxigênio (SaO2) e fluxo de ar do conjunto de dados da Physionet Challenge [25]. Cada um dos sinais foi segmentado em janelas de 20 segundos, com uma sobreposição do 10\%. Por outro lado, a fim de mudar o desequilíbrio em favor da classe minoritária, são manipulados os rótulos de classe, mantendo a marcação do segmento se pelo menos o $80 \%$ pertence á classe positiva (Classe 1), caso contrário ele é substituído pela classe negativa (Classe 0). Neste trabalho foram extraídas 50 características significativas, previamente selecionadas com o algoritmo de Minimum Redundancy Maximum Relevance (mRMR), e para realizar a classificação dos despertares associados a eventos RERA, foi usado um Multiple Unbiased Random Forests. O algoritmo obteve uma área sob a curva de precisão de recuperação (AUPRC) que é uma métrica de desempenho para respostas binárias [26] (Seção 6.2.3.5) de 0,29 ao usar 5 conjuntos de validação cruzada.

Nos últimos anos, o Deep Learning tem permitido trabalhar com dados não estruturados e com grandes volumes de informações [27]. Seu uso na identificação de despertares do sono e doenças, especificamente de despertares por eventos RERA e relacionados a apneia e hipopneia, pode ser observado em alguns trabalhos, como [28], no qual propõem-se duas abordagens para a classificação de eventos RERA a partir de sinais de EMG de queixo e peito, ECG e o fluxo de ar. Para a primeira abordagem, usa-se um modelo de Ensemble Learning (EL) composto por classificadores de regressão logística para cada um dos sinais de entrada, a partir deles obtêm se a classificação final pelo método de plurating voting. Na segunda abordagem, é usada uma rede 
Long Short Term Memory bidirecional (Bi-LSTM) para o analise dos sinais. Esse trabalho obteve um AUPRC de 0,081 para o conjunto de teste no caso do modelo de EL, e de 0,295 usando a rede Bi-LSTM e 10 conjuntos de validação cruzada.

Também em [29], foi proposto um sistema de aprendizado multitarefa, cuja estrutura está composta por Multiple Dense Convolutional Units (DCU) seguidas de uma rede Bi-LSTM. Esse sistema visou a obter a identificação de três alvos: (i) estágios de sono, (ii) regiões com presença de despertares e (iii) múltiplas tipos de apneia e hipopneia. Foram usados os sinais de EOG, EEG, EMG, fluxo de ar e SaO2, segmentadas em janelas de 20 minutos com sobreposição de 18 minutos, após cada canal e transformado ao domínio da frequência usando a Transformada Rápida de Fourier (FFT). Esse trabalho obteve um AUPRC de 0,505 e AUROC de 0,922 para a detecção de despertares.

Em [30], usam uma combinação de redes neurais recorrentes e convolucionais (RCNN) para o aprendizado supervisionado de rótulos clínicos que designam estágios do sono, eventos de apneia do sono e movimentos dos membros. Os dados para teste e treinamento foram derivados de 10.000 polissonografias clínicos e 5804 polissonografias de pesquisa. Após de treinado no conjunto de dados clínicos, a rede RCNN reproduz a pontuação do diagnóstico PSG para o estadiamento de sono, distúrbios respiratórios do sono e movimentos dos membros com precisão de $87,6 \%, 88,2 \%$ e $84,7 \%$ respectivamente.

Já em [31], propõe-se uma arquitetura de redes neurais profundas para a identificação de eventos RERA. Ramos separados da rede neural extraem os recursos dos sinais de EEG, EOG, EMG, Fluxo de ar e SaO2, os recursos extraídos passam por uma rede totalmente conectada que estima a probabilidade de ocorrência em cada uma das regiões de interesse. Além disso, é explorada uma arquitetura siamesa para obter uma calibração de recursos eficaz, nesta, cada passagem para frente e para trás da rede é concatenada á entrada de um sinal de modelo especifico de um indivíduo, que por sua vez é processado por uma cópia idêntica da rede. A arquitetura proposta neste trabalho obteve uma pontoação AUPRC de 0,40 para o conjunto de teste, e obteve um AUPRC de 0,45 usando 10 conjuntos de validação cruzada ao avaliar o conjunto de treinamento.

Em [32] propõem-se cinco modelos de redes convolucionais baseadas em blocos residuais para avaliar os sinais de EEG central (Derivação C3-M2 sistema 10-20 de colocação de eletrodos), EOG, EMG do movimento abdominal, fluxo de ar respiratório e Sao2. Cada série de tempo foi normalizada, em seguida foi aplicado um filtro anti-aliasing e foi reamostrada a $100 \mathrm{~Hz}$. Seguidamente cada sinal foi segmentado em janelas de 30 segundos, com sobreposição de 25 
segundos, seguidamente os rótulos de classe foram definidos como: segmentos com despertares ("1") e em segmentos sem despertares ("0"). Neste trabalho [32] foi obtida um AUPRC média de 0,31 e um AUROC média de 0,84. Já em [33], é proposto um algoritmo baseados em redes Bi-LSTM, usando 6 canais EEG, EOG, 3 canais EMG, fluxo de ar e saturação de oxigênio da base de dados Physionet Challengue 2018 [25] para isso todos os sinais foram filtrados usando um filtro rejeita faixa de $60 \mathrm{~Hz}$, foram removidos os artefatos dos sinais e cada sinal foi segmentado em janelas de 5 segundos, sem sobreposição usando uma janela triangular. Além disso, foram adicionadas 900 características extraídas do domínio temporal, da frequência, tempo-frequência e o espaço de fase, seguidamente usando um classificador Random Forest, foram selecionadas as melhores características de entrada para o sistema. O sistema obteve uma AUPRC de 0,50 e um AUROC de 0,92. 


\section{3}

\section{Fisiologia do Sono}

Neste capítulo são apresentados alguns dos elementos da macroestrutura e microestrutura do sono, seus estágios, assim como os eventos e distúrbios respiratórios associados ao sono.

O sono é um estado biológico comportamental, periódico e espontâneo, que é acompanhado por uma redução reversível do nível de consciência. Está dividido em dois estágios: (i) sono com movimento rápido dos olhos (REM) e (ii) sono com movimento não-rápido dos olhos (NREM ou Não-REM), dividido em três fases denominadas NREM1, NREM2 e NREM3 [10,34] . Também, tem associados ciclos biológicos e circadianos (ciclo luz e escuridão) [35-37]]. Além disso, intervém uma complexa rede neuronal com participação de várias áreas do sistema nervoso central, junto com neurotransmissores como a serotonina, noradrenalina, dopamina, acetilcolina, dentre outras [38].

A periodicidade do sono é alternada de forma cíclica, que se inicia com um estado de alerta ou de vigília, seguido de outro de sono (ciclos de vigília-sono). Durante o sono de um adulto em estado de saúde normal, ocorrem vários ciclos de sono, variando entre três e cinco ciclos por noite. Cada ciclo é constituído por períodos Não-REM e REM (sono superficial - sono profundo - sono REM). O primeiro ciclo começa com sonolência e termina com o final da primeira fase REM. Quando termina, há um breve despertar que às vezes não inclui estado de consciência. Após o ciclo reinicia-se no estágio do sono NREM2, seguido de um segundo ciclo de sono que terminará no final do estágio REM. [39,40].

Quanto à estrutura do sono, pode ser dividida em macrostrutura e uma microestrutura. A macrostrutura do sono é baseada em padrões cíclicos dos estágios NREM e REM, enquanto a microestrutura do sono consiste principalmente de excitações (Arousals), períodos de alternância do ciclo (CAP- pelas siglas no inglês de Cyclic alternating pattern) e períodos sem CAP [10].

\section{1}

\section{Atividade Eletroencefalográfica}

A atividade eletroencefalográfica (EEG) é caracterizada por padrões de onda em frequências específicas, e que possuem origem em diferentes áreas do 
cérebro. Essas ondas são nomeadas de acordo com a frequência e a amplitude da forma de onda, subdividindo-se em: delta, teta, alfa e beta. Além disso, pode incluir formas de onda de curta duração denominadas como complexos $\mathrm{k}$ e fusos de sono [41,42]. Na Figura 3.1 é apresentado um exemplo dos padrões de onda caraterísticos do EEG para um adulto saudável ao longo de uma noite.

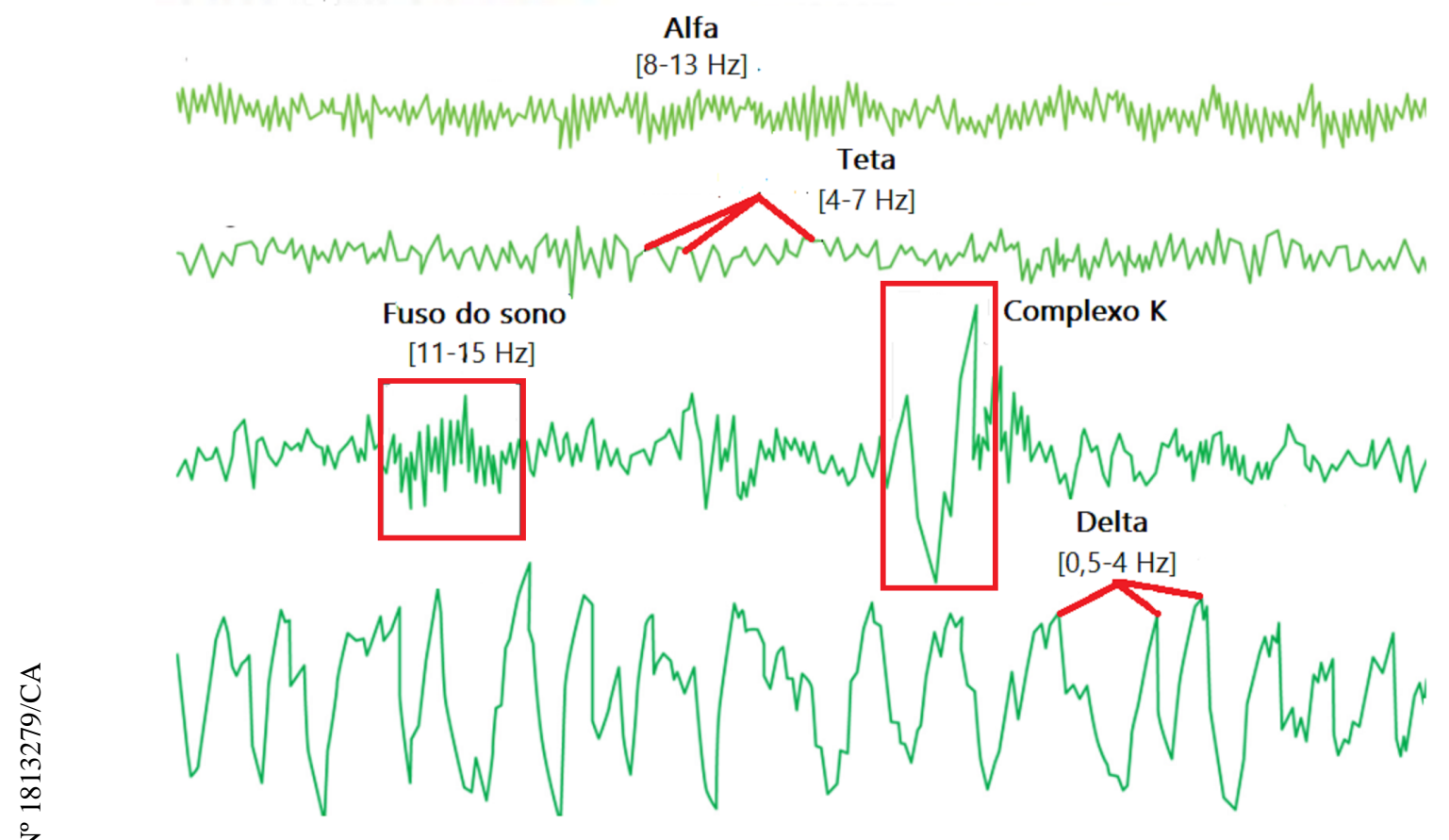

Figura 3.1: Formas de onda da atividade EEG.

\subsection{1}

\section{Ondas Alfa}

Atividade EEG na faixa de frequência de 8-13 Hz, com origem na região occipital e nas derivações occipitais (derivações O1 - M2 ou O2 - M1). Usada como um marcador para vigília relaxada, despertares do sistema nervoso central (SNC), sonolência. Durante a abertura de olhos suprime-se a atividade alfa, presentando um aumento durante o fechamento dos olhos [41, 43].

\subsection{2}

\section{Ondas Teta}

Atividade EEG na faixa de frequência de 4-7 Hz, particularmente proeminente nas derivações centrais e temporais. Durante o estágio de sono REM, pode-se observar em forma de atividade dente de serra, que é uma variante única da atividade teta, caracterizada por conter formas de onda com uma aparência entalhada ou em formato de dente de serra [41]. 
Em adultos, o aparecimento de atividade teta frontal pode ser facilitado por um determinado estado emocional ou processos mentais como a resolução de problemas. Além disso, quando um desaparecimento gradual do ritmo alfa é substituído pela atividade teta em um indivíduo acordado, pode ser indício de sonolência $[5,43]$.

\subsection{3}

\section{Ondas Delta}

Qualquer atividade EEG na faixa de frequência de $0.5-4 \mathrm{~Hz}$ e uma amplitude de sinal $\leq 75 \mu \mathrm{V}$. São predominantes na fase do sono N3 e sua incidência máxima se produz na região frontal (os complexos k também têm incidência nesta região) [43].

\subsection{4}

\section{Fusos do sono}

Têm uma frequência de $\mathbf{1 2 - 1 4} \mathrm{Hz}$, possuem uma duração entre $\mathbf{0 , 5 - 1 , 5}$ segundos. Assim como os complexos k, os fusos estão presentes na fase NREM2 do sono. Sua incidência máxima se produz na região central (C4-M1, C3M2). Os fusos do sono (ou Spindles) surgem de oscilações tálamo-corticais, especificamente no núcleo reticular do tálamo [5,41].

\subsection{5}

\section{Complexos k}

São ondas definidas, agudas e lentas, que possuem uma morfologia com deflexão negativa e positiva (morfologia bifásica). Sua duração total é $\geq$ 0,5 segundos, geralmente em amplitude máxima quando registrada usando derivações frontais. A excitação deve ser simultânea com o complexo K ou começar no máximo 1 segundo após o término do complexo K para que possa ser associada a um complexo k, além disso, eles são usados como marcadores para o estagio de sono NREM2 [41,43].

\subsection{6}

\section{Ondas Beta}

Atividade EEG na faixa de frequência de $\mathbf{1 3}$ - $\mathbf{3 0} \mathrm{Hz}$, possui amplitudes $\leq 30 \mu V$, ela é normalmente registrada nas regiões fronto-centro-temporais no EEG acordado de adultos normais, mas pode-se alterar devido ao efeito de várias substâncias beta-ativadoras (barbitúricos, benzodiazepínicos, neurolépticos, anti-histamínicos, anfetaminas, cocaína etc.). Relaciona-se a processos mentais e cognitivos de vários tipos, à ansiedade e ao estado de alerta; e tam- 
bém é induzida ou aumentada por sonolência e sono leve. Devido a sua baixa amplitude pode ser confundida com a atividade muscular, e também pode ser mascarada pela amplitude e sincronização do ritmo alfa durante o fechamento dos olhos [43].

\section{2}

\section{Estágios de sono}

O sono está dividido em dois grandes estágios: o sono NREM (pelas sigas no inglês-Not Rapid Eye Moviments) e o sono REM (pelas siglas no inglêsRapid Eye Moviments) também nomeado como sono de ondas lentas. Cada estado está caracterizado pela aparição de padrões específicos no sinal EEG, o movimento de olhos e na atividade muscular (respostas fisiológicas dependentes da idade) $[38,39,42]$. Na Tabela 3.1 são apresentadas as características presentes nos sinais de EEG, EOG e EMG, durantes os estágios de vigília, sono NREM e sono REM [10].

Tabela 3.1: Alterações fisiológicos presentes durante o sono

\begin{tabular}{cccc}
\hline Sinal $^{*}$ & Vigília & Sono NREM & Sono REM \\
\hline EEG & $\begin{array}{c}\text { Ondas Alpha; } \\
\text { dessincronizado }\end{array}$ & Sincronizado & $\begin{array}{c}\text { Ondas Theta; } \\
\text { dessincronizado }\end{array}$ \\
\hline EMG & Normal & $\begin{array}{c}\text { ligeiramente reduzido; } \\
\text { dessincronizado }\end{array}$ & $\begin{array}{c}\text { Moderadamente a } \\
\text { sevamente reduzido } \\
\text { ou ausente }\end{array}$ \\
\hline EOG & $\begin{array}{c}\text { Movimento dos } \\
\text { olhos acordados }\end{array}$ & $\begin{array}{c}\text { Movimentos lentos } \\
\text { dos olhos }\end{array}$ & $\begin{array}{c}\text { Movimento rápido } \\
\text { de olhos }\end{array}$ \\
\hline Duração $(\%)^{* *}$ & --- & $75-80$ & $20-25$ \\
\hline
\end{tabular}

* EEG: Eletroencefalografia; EMG: Eletromiografia (Tônus muscular); EOG: Eletro-oculografia

** Porcentagem de duração em relação ao tempo total de sono

\subsection{1}

Vigília

Nomeado estado $\mathrm{W}$, pode ir acompanhado por movimentos conjugados dos olhos (movimentos oculares verticais, horizontais, oblíquos, lentos ou rápidos). Durante a vigília o ritmo alfa é o ritmo predominante $(8-13 \mathrm{~Hz})$, presente predominantemente na região posterior e é misturado com uma pequena quantidade do ritmo beta $(>\mathbf{1 3} \mathrm{Hz})$ proveniente das regiões anteriores da cabeça [10]. 


\subsection{2}

\section{Sono NREM}

O sono NREM é dividido em três estágios: NREM1, NREM2 e NREM3. Cada estagio está caracterizado por padrões específicos nas ondas cerebrais, do mesmo modo, pelas mudanças nos sinais cardíaca, respiratório, ocular e muscular. Neste estado de sono, a profundidade do sono aumenta, suprimindo os tônus muscular e a atividade reflexa, enquanto a frequência cardíaca diminui e as pupilas contraem-se $[38,39,44]$.

\section{Estágio 1 (NREM1)}

Equivale ao 3-8 \% do tempo de sono. Durante a vigília relaxada o EEG de um indivíduo mostra dois padrões básicos de atividade: a atividade alfa, que se gera quando descansa tranquilamente, com os olhos fechados e a atividade beta, quando o indivíduo fica alerta e atento [10,45].

\section{Estágio 2 (sono leve ou NREM2)}

Nesta fase diminui o ritmo alfa e aparecem ondas lentas $(0,5-2 \mathrm{~Hz})$ e ondas teta $(4-7 \mathrm{~Hz})$. Os olhos geralmente estão em repouso e as taxas de frequência cardíaca e respiratória diminuem. Equivale ao 45-55 \% do tempo de sono. Inicia aproximadamente 10-12 minutos após do estágio N1 com aparição de disparos das ondas conhecidas, como "fusos do sono" (11-16 Hz, principalmente de 12-14 Hz) e complexos $\mathrm{k}$ misturadas com ondas agudas de vértice, que são disparos de alta amplitude e aparecem antes e depois dos fusos do sono. Os fusos de sono podem ser de dois tipos: (i) Fusos Rápidos predominantes da região centro-parietal $(13-15 \mathrm{~Hz})$ e (ii) Fusos lentos provenientes da região frontal (11-13 Hz).Pode ter uma duração de 30-60 minutos [10,43].

\section{Estágio 3 (sono profundo ou NREM3)}

Aparecem ondas lentas delta $(\leq 4 \mathrm{~Hz})$. Neste estágio o sono é profundo, ocorrendo uma hora depois de adormecer. As ondas se tornam ainda mais lentas e as frequências cardíaca e respiratória diminuem entre 15-23\%, assim como a temperatura e pressão arterial. Equivale ao 15-23 \% do tempo total de sono $[43,44]$ 


\subsection{3}

\section{Sono REM}

Também conhecido como sono paradoxal, caracterizado por uma dessincronização do EEG, semelhante à fase de vigília (alta frequência e baixa amplitude devido à ativação cortical pelas estruturas cerebrais profundas), aumento da frequência cardíaca, atividade respiratória, movimentos oculares rápidos e atonia muscular (paralisia muscular temporária a exceção de pequenos músculos periféricos). O estágio cobre o $\mathbf{2 0 - 2 5} \%$ do sono total, com uma duração estimada de 20 minutos. Dentro deste período se observa a maior parte da atividade onírica, ou seja existe presença de sonhos emocionais ativos, além de estar associada com uma elevada atividade cerebral [36, 40,46].

\section{3}

\section{Processo Respiratório durante o sono}

A regulação da respiração apresenta diferenças singulares durante os estágios de sono, devido à ocorrência de alterações em diversos processos que regulam o controle respiratório, assim como às mudanças de posição e aos efeitos associados a estágios de sono, particularmente no sono REM, comparado com o sono NREM [47].

Durante o sono existe uma diminuição na resposta motora ventilatória, no volume tidal (volume de ar que se move para dentro ou para fora dos pulmões durante a respiração) e da frequência respiratória, acompanhada pela redução da atividade músculo dilatadora das vias aéreas superiores e aumento da resistência ao fluxo de ar. Por outro lado, destaca-se que, diferentemente do sono NREM, o sono REM é caracterizado pela variabilidade na ventilação, na resistência das vias aéreas superiores, embora, a quimiorresponsividade ventilatória hipercápnica e hipóxica diminuam, comparadas aos estágios de sono NREM e vigília [13,48].

\section{4}

\section{Distúrbios Respiratórios associados ao sono}

Caracterizados por alterações particulares da respiração durante o sono, causando a fragmentação do sono fisiológico, sintomas de privação do sono e alterações noturnas na troca de gases. Incluem o ronco habitual, o síndrome de resistência aumentada da via aérea superior (SRVA), as hipopneias obstrutivas, o síndrome de apneia-hipopneia obstrutiva do sono (SAHOS). RERA e outras alterações cronicas. Para o diagnostico é preciso realizar um exame de PSG $[37,49]$. 


\subsection{1}

\section{Apneia}

Definido como um transtorno que causa a ausência da fluxo de ar por pelo menos 10 segundos, em consequência, produz hipo-oxigenação e micro despertares que afetam a qualidade do sono. É caraterizada por ruídos e interrupções na respiração que se repetem múltiplas vezes num curto período de tempo [10]. Existem três tipos de apneias [12]:

- Apneia Obstrutiva: Refere-se à ausência de fluxo de ar por 10 segundos com evidência de esforço respiratório.

- Apneia Central: Refere-se à ausência de fluxo de ar por 10 segundos sem evidência de esforço respiratório.

- Apneia Mista: Refere-se à ausência de fluxo de ar por 10 segundos, com ausência inicial de esforço respiratório, seguida de retorno do esforço respiratório antes da retomada do fluxo de ar.

\section{4 .2 \\ Hipopneia}

De acordo com a American Academy of Sleep Medicine (AASM) a hipopneia em adultos é definida como um evento respiratório com duração de pelo menos 10 segundos, acompanhada de uma redução de pelo menos o $30 \%$ do movimento toráxico-abdominal ou fluxo de ar em comparação com a linha de base, que é seguida por um despertar do sono e pelo menos $4 \%$ de dessaturação de oxigênio. Além disso, as hipopneias podem estar associadas à obstrução das vias aéreas ou a uma redução parcial do esforço respiratório. Destaca-se que na prática, a distinção entre uma hipopneia central e uma obstrutiva é difícil a não ser que seja usado um sensor de pressão esofágica [12,43].

\subsection{3}

\section{Despertares relacionados ao Esforço Respiratório (RERA)}

Definido como um evento que causa um despertar e uma diminuição da saturação de oxigênio, sem se qualificar como uma apneia ou hipopneia, especificamente, são distúrbios respiratórios do sono que não provocaram uma dessaturação de oxihemoglobina de $4 \%$ (ou mais), mas foram encerrados por um despertar do sistema nervoso central (SNC). Os RERAs, são uma possível razão para sonolência diurna excessiva, fadiga e distúrbios do humor $[10,13]$. 


\section{4}

\section{Polissonografia}

A PSG é o registro gráfico e simultâneo da atividade de diversas variáveis fisiológicas durante o sono, além disso, é uma das ferramentas mais comuns para o estudo dos distúrbios do sono. Neste exame são registradas uma variedade de sinais fisiológicos como: eletroencefalografia (EEG), eletro-oculograma (EOG), eletromiografia (EMG) de abdome e extremidades, eletrocardiografia (ECG), saturação de oxigênio (SaO2), gravações de ronco, fluxo nasal, dentre outras $[5,36,37,40]$. Tradicionalmente, esses exames são realizados em ambientes laboratoriais do sono, onde a polissonografia, o áudio e a videografia do paciente adormecido podem ser cuidadosamente inspecionados por especialistas em sono para identificar os possíveis distúrbios do sono $[35,50]$.

Os especialistas empregam as gravações para avaliar informações detalhadas sobre características do sono, presença de distúrbios como insônias, transtornos circadianos do sono-vigília, transtornos respiratórios do sono (RERA, apneias e hipopneias), entre outros $[6,36,51,52]$. Também pode ser usada no diagnóstico de doenças psiquiátricas, tais como alucinações hipnagógicas que acontecem durante o passo da vigília ao sono ou no diagnóstico de demências, como ferramenta de diagnóstico diferencial entre os sintomas de depressão e os sintomas dos transtornos do sono [10].

\section{1}

\section{Hipnograma}

Definido como a representação gráfica das diferentes fases do sono durante uma noite (Figura 4.1). No decorrer da noite são apresentados vários ciclos de sono, com uma duração de 80-90 minutos no adulto, e nos que são alternados o estado de sono REM, NREM (N1, N2 e N3) além de possíveis artefatos (Art) [39].

Observando-se o registro de PSG é possível identificar a aparição de ondas cerebrais típicas, com os complexos $\mathrm{k}$ e os fusos do sono, as ondas delta (tipicas no sono profundo), as mudanças nos movimentos do registro EOG (lento para rápido), diminuição da atividade muscular e as variações da frequência cardíaca e/ou fluxo respiratório [101]. No caso da identificação dos estágios de sono, precisa-se da observação de características particulares para cada um [12,102]. 


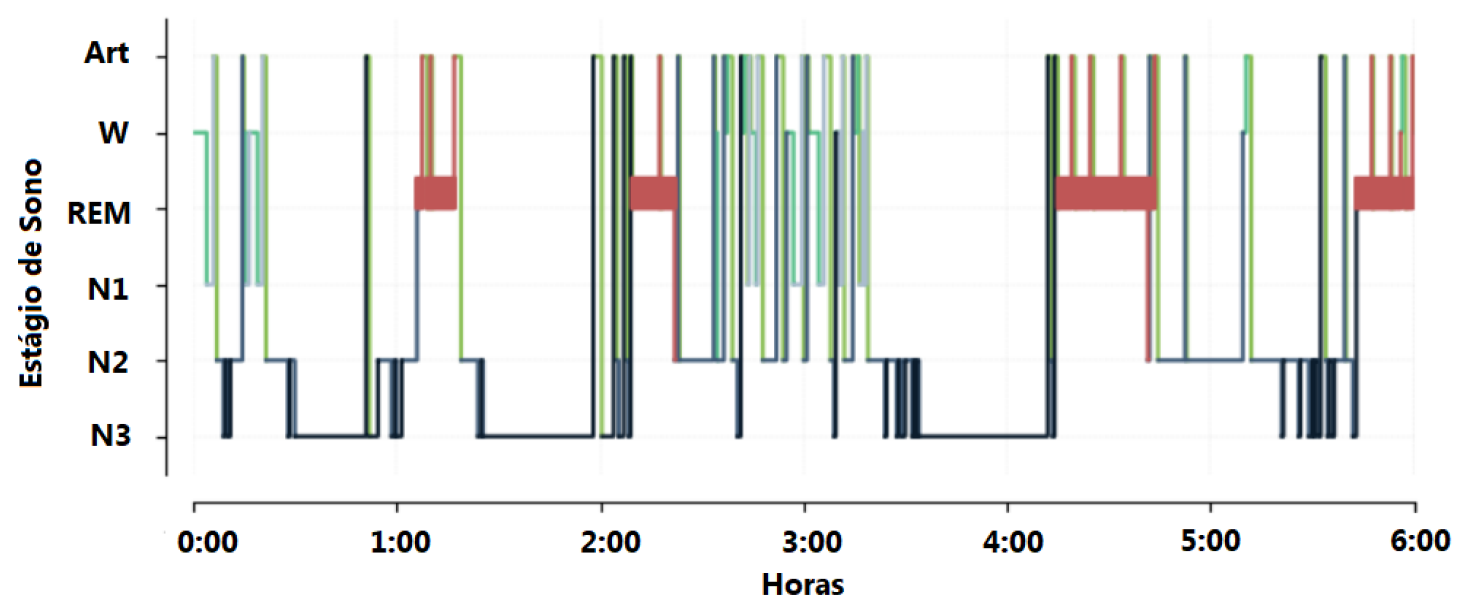

Figura 4.1: Gráfico de um Hipnograma para uma noite de sono de um adulto saudável obtido usando Python, no qual cada um das cores representa a transição de um para outro dos estágios do sono.

\section{2}

\section{Parâmetros Fisiológicos da Polissonografia}

Os sinais incluídos no estudo de PSG abrangem múltiplos parâmetros e características específicas, que devem ser considerados tanto para a aquisição dos sinais, quanto para a interpretação dos resultados [53,54]. No estudo de PSG, a caracterização dos estágios do sono é feita de acordo aos critérios estabelecidos em [12].

No estudo de PSG, especialmente na polissonografia clínica, são medidos três principais grupos de parâmetros: neurofisiológicos, cardiorrespiratórios e auxiliares [53-55]. Na Tabela 4.1 é apresentado o resumo dos sinais contidos em cada grupo de parâmetros e explicados nas secções a seguir.

Tabela 4.1: Parâmetros medidos na PSG.

\begin{tabular}{ccc}
\hline Parâmetros & Parâmetros & Parâmetros \\
Neurofisiológicas & Cardiorrespiratórios & Auxiliares \\
\hline Electroencefalograma & Eletrocardiograma & Sensor de ronco \\
Eletro-oculografia & Fluxo de Ar & Sensor de Posião \\
Eletromiografia & Oximetria de Pulso & Sensor de movimento \\
& Esforço respiratório & \\
\hline
\end{tabular}

\subsection{1}

\section{Parâmetros Neurofisiológicos}

Os parâmetros neurofisiológicos incluem três tipos de sinais: (i) Eletroencefalografia, (ii) Eletro-oculografia e (iii) Eletromiografia, descritas a seguir: 


\subsubsection{1}

\section{Electroencefalograma}

No registro do EEG, mede-se a atividade cerebral em regiões específicas do cérebro. Para isso, os eletrodos são colocados no couro cabeludo seguindo um padrão simétrico como se ilustra na Figura 4.2. Os eletrodos são localizados de acordo com o sistema internacional de aplicação 10-20, na qual podem-se observar as (a) derivações recomendadas e as (b) derivações ideais para a PSG para o eletroencefalograma (EEG) durante a polissonografia (PSG) [51, 97]. Como resultado, os dados do EEG são apresentados por formas de onda, classificadas de acordo com sua amplitude e frequência [56].
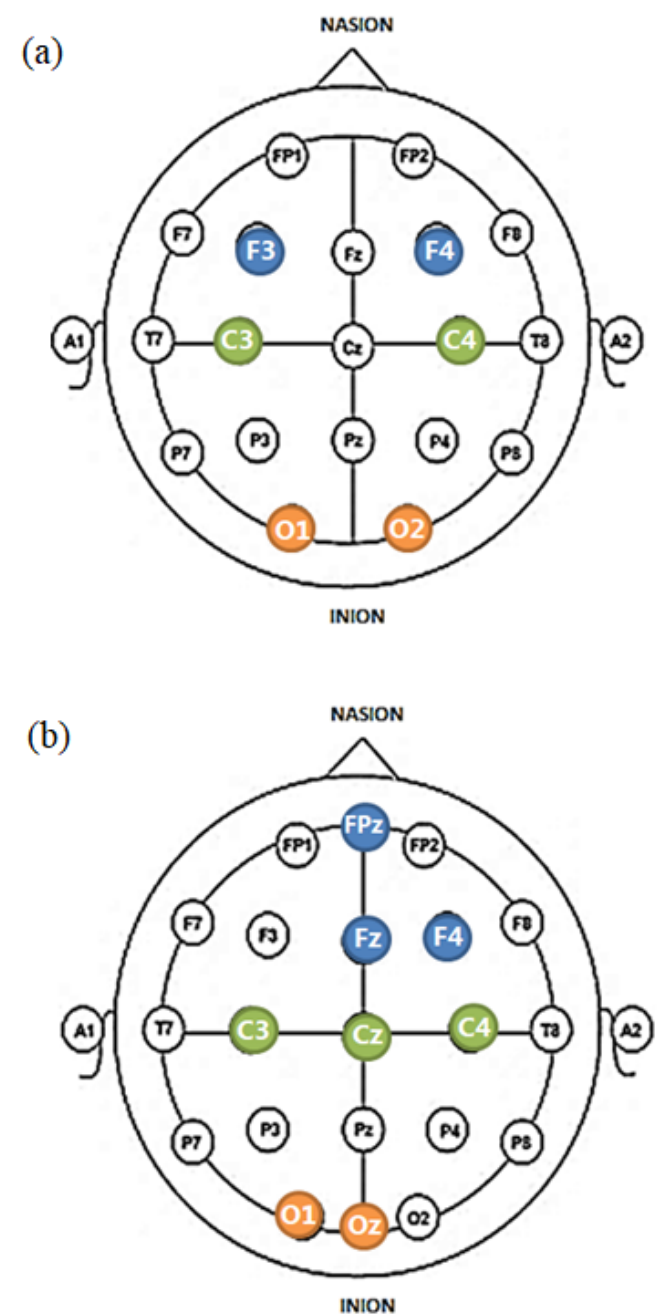

Figura 4.2: Sistema 10-20 para adquisição de EEG.(a) Derivações EEG recomendadas e (b) derivações EEG ideais para PSG. Em cor azul podem-se observar as derivações frontais, em verde as centrais e em laranja as posteriores. 
As derivações C4-M1, C3-M2 do sistema 10-20 são usadas para registrar a maioria das ondas cerebrais, distinguir entre as múltiplas fases do sono e é a principal derivação para efetuar pontuações de eventos respiratórios. Já no âmbito do estudo do sono, os resultados do EEG são usados para a identificação dos estágios do sono (vigília, sono REM e fases do sono NREM); porque as ondas alfa, teta e delta tornam-se visíveis e têm características específicas dependendo da fase do sono [96].

\subsubsection{2}

\section{Eletro-oculograma}

O registro do EOG auxilia na avaliação do início do sono REM e na identificação das fases do sono, que envolvem mudanças no movimento dos olhos. Neste registro é medida a atividade elétrica ocular, baseando-se na gravação da diferença de potencial elétrico entre a córnea e a retina. A córnea apresenta uma saída de tensão positiva e a retina tem uma polaridade negativa, como ilustra a Figura 4.3a. O movimento da retina gera uma diferença de potencial positiva ou negativa dependendo da direção do movimento do olho, embora uma diferença de potencial nula seja produzida em estado de repouso. Na Figura 4.3b, é apresentada a posição dos eletrodos para aquisição do sinal (E1-M2 e E2-M1), podendo-se utilizar a conexão a terra do EEG [55].
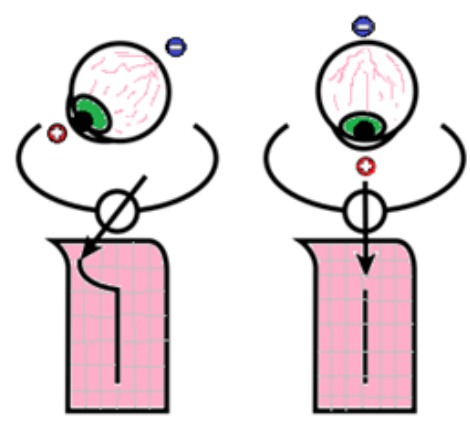

(a)

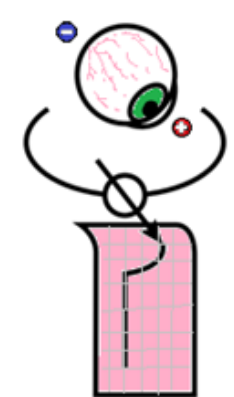

(E2)

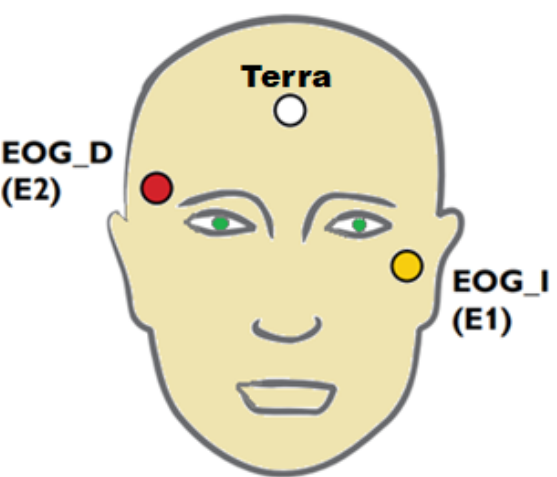

(b)

Figura 4.3: Eletro-oculografia: (a) Diferença de potencial córnea-retina e (b) Posição dos eletrodos para adquisição do sinal.

\subsubsection{3}

\section{Eletromiografia de Queixo}

A eletromiografia permite obter o tônus muscular do queixo. Este é um dos parâmetros que auxiliam ao especialista na determinação das fases do sono REM como o sono NREM, junto com o EEG e EOG. Durante o sono, o tônus 
muscular descresse e sua diminuição máxima se produz durante a fase REM. Neste caso, também existem muitas derivações possíveis. Segundo as diretrizes da AASM, devem-se colocar três eletrodos: dois para aquisição do sinal (Chin1, Chin2) e um terceiro como eletrodo auxiliar no caso de falha dos anteriores, como se ilustra Figura 4.4 [56].

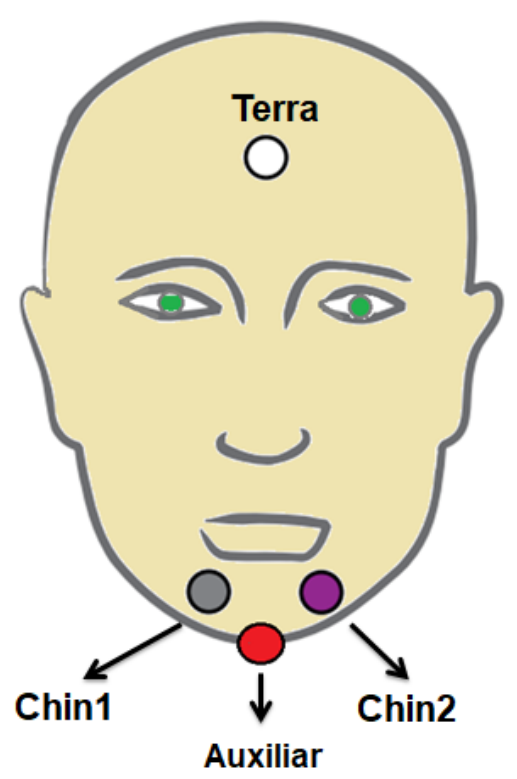

Figura 4.4: Posição dos eletrodos para adquisição do sinal de EMG de queixo.

\subsubsection{4 \\ Eletromiografia da Perna}

A monitorização do músculo tibial anterior (Figura 4.5a) é necessária para diagnosticar os movimentos periódicos das extremidades durante o sono (MPES). O histórico clínico por si só não é suficiente para determinar a presença de MPES durante o sono. Deixar os eletrodos de eletromiografia (EMG) desconectados da perna, significaria omitir pelo menos vários outros diagnósticos importantes de distúrbios relacionados ao sono. A atividade de movimento de ambas as pernas deve ser observada durante o exame de PSG, também os eletrodos podem ser posicionados em uma única perna, sem afetar a qualidade dos dados medidos [98, 99]. 


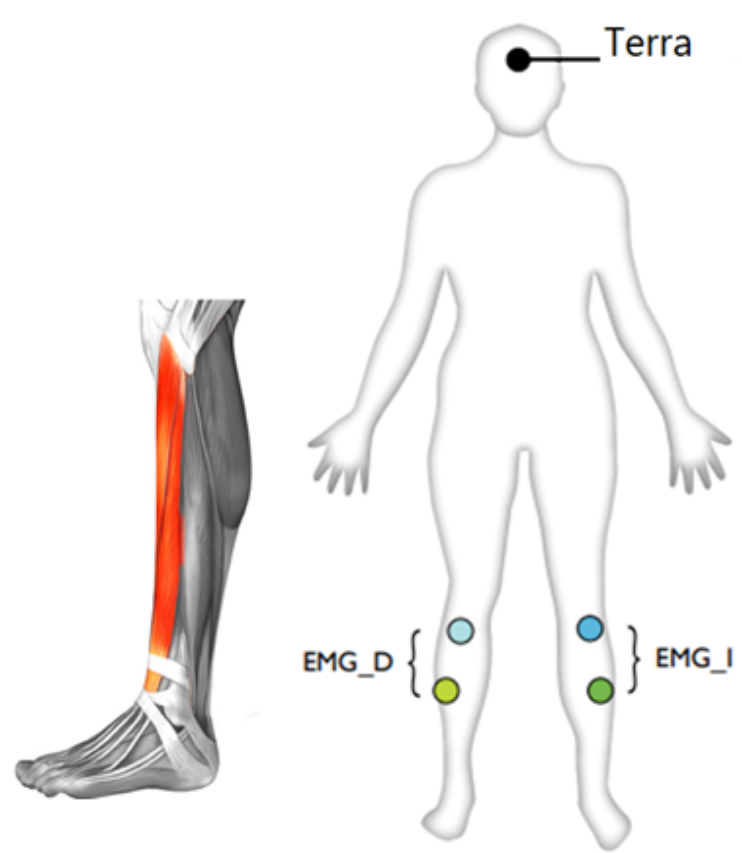

(a)

(b)

Figura 4.5: Eletromiografia de perna para PSG (a) em vermelho localização do músculo tibial anterior e (b) posição dos eletrodos para a adquisição do EMG durante a PSG podendo ser usada configuração EMG_D, EMG_I ou ambas.

\subsection{2}

\section{Parâmetros Cardiorrespiratórios}

Os parâmetros cardiorrespiratórios incluem quatro tipos de sinais: (i) Eletrocardiografia (ECG), (ii) Fluxo de Ar, (iii) Oximetria de pulso e (iv) Esforço respiratório descritas a seguir.

\subsubsection{1}

\section{Electrocardiograma (ECG)}

É o registro das mudanças elétricas nas células cardíacas usando eletrodos de superfície. O registro da atividade elétrica do coração tem vários propósitos $[56,100]$ :

- Medir a evolução da frequência cardíaca e detectar eventuais arritmias cardíacas que podem estar associadas aos transtornos do sono.

- Confirmar determinados eventos do sono, como os despertares cerebrais.

- Medir o tempo de transição da frequência cardíaca.

Os eletrodos são posicionados nas regiões do tórax e abdome, seguindo a colocação dos eletrodos periféricos (Triângulo de Einthoven) do ECG convencional (Figura 4.6), na qual são geralmente utilizados os membros superiores 
(RA, LA) e inferiores (RL, LL). Para o exame de PSG, podem ser usadas duas configurações: (i) usando os eletrodos RA, LL e como eletrodo de referência a terra usada para EEG (Figura 4.6a) e (ii) usando os eletrodos da perna esquerda (LL), o ombro direito e como eletrodo de referência a perna direita (RL) (Figura 4.6b) [99].

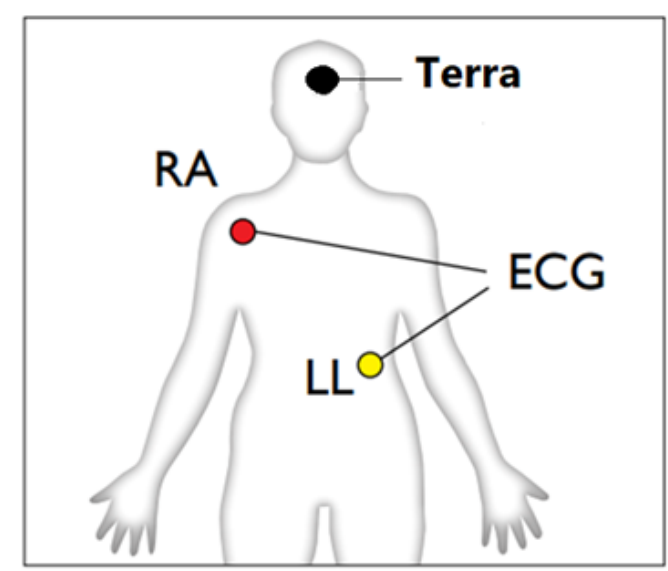

(a)

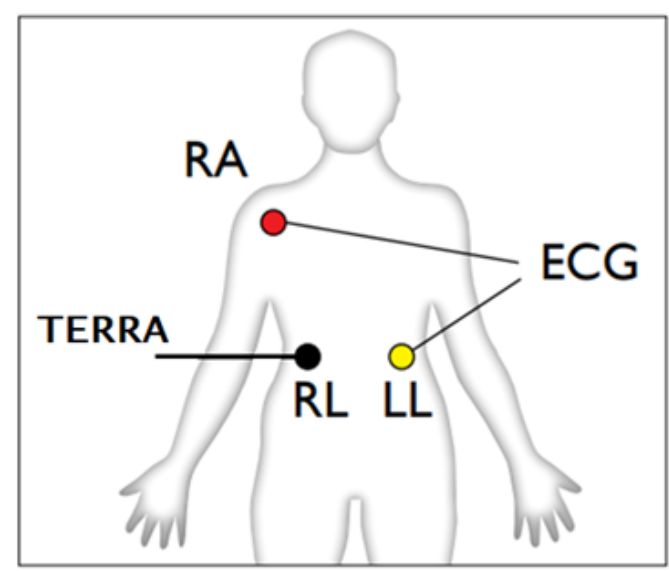

(b)

Figura 4.6: Posição dos eletrodos para adquisição do sinal de eletrocardiografia. Em (a) emprega-se o terra do EEG e em (b) o terra do ECG (RL)

\subsubsection{2}

\section{Fluxo de Ar}

Para medição do fluxo de ar, usam-se sensores térmicos como o apresentado na Figura 4.7. Os sinais não quantitativos estão baseados na variação de temperatura do ar inspirado e expirado. Comumente é usado um termistor ou termopar; esse sensor é posicionado acima do lábio superior, e possui fios, dos quais, dois são usados para cada uma das narinas e um terceiro na frente da boca. As mudanças da temperatura em função da inspiração e expiração são transformadas em um sinal que indica as flutuações do fluxo do ar [51,100].

\subsubsection{3}

\section{Oximetria de Pulso}

Registra o pulso cardíaco e a saturação de oxigênio (SaO2). Na PSG, algumas hipopneias são identificadas por meio da queda de saturação, além disso, é útil para acompanhar a frequência cardíaca [55]. 


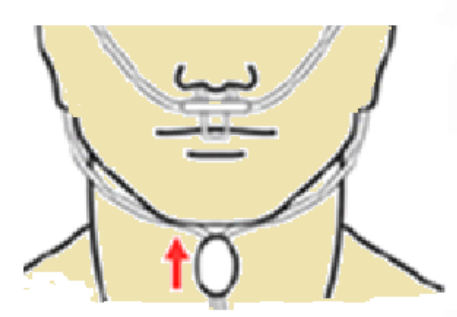

FRONTAL

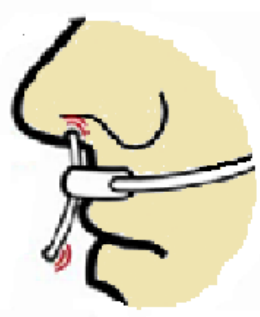

LATERAL

Figura 4.7: Posicionamento do sensor para medição do fluxo de ar: (a) Vista frontal e (b) lateral do termistor.

\subsubsection{4}

\section{Esforço Respiratório}

A respiração e eventos respiratórios podem ser avaliados medindo o movimento das paredes torácicas e abdominais. A tarefa essencial é identificar o esforço respiratório para distinguir entre uma apneia obstrutiva (esforço respiratório) e uma apneia central (ausência de esforço). No exame da PSG, existem vários métodos que são usados atualmente para avaliar o esforço respiratório como os seguintes $[55,57]$ :

- Manometria Esofágica: É um dos métodos mais precisos para medir o esforço respiratório. A pressão esofágica (PES) é medida pela inserção de um cateter de pressão através da cavidade nasal e duto esofágico, onde permanecerá durante o estudo do sono. Flutuações rítmicas da pressão torácica na ausência de fluxo aéreo nasal ou oral significativo constituem a indicação mais segura da existência de uma apneia obstrutiva [100]. No entanto, na prática clínica, este procedimento não é utilizado rotineiramente pelo fato de ser invasivo e muito desconfortável para a maioria dos pacientes. Além disso, a colocação do cateter oferece dificuldades e outro cálculo do esforço respiratório pode ser obtido medindo-se as mudanças no volume abdominal e torácico, o que é conhecido como pletismografia $[55]$.

- Pletismografia Elastomérica (piezelétrica): Consiste em ter uma cinta elástica em torno do tórax ou abdômen, a fin de registrar uma mudança de tensão quando o tórax ou o abdômen se expandem e se contraem. Esta mudança de tensão, é facilmente medida e convertida em uma tensão elétrica por meio de um sensor piezoelétrico. O sensor é um cristal que gera diretamente uma tensão elétrica quando é comprimido ou expandido [56]. 


\subsection{3}

\section{Parâmetros Auxiliares}

Os parâmetros auxiliares podem incluir sinais de: (i) Sensor de ronco, (ii) Sensor de posição e (iii) Sensor de movimento das extremidades, que são descritos a seguir.

\subsubsection{1}

\section{Sensor de Ronco}

O ronco é um som de baixa frequência produzido por vibrações da via aérea superior durante o sono. O ronco intenso é o sintoma mais comum identificado como Síndrome de Resistência da via aérea superior (SRVAS) e síndrome da apneia-hipopneia obstrutiva do sono (SAHOS). Para a medição do ronco, existem varias opções como $[55,56]$ :

- Microfone: pode gravar sons produzidos enquanto o paciente ronca.

- Sensor de Ronco piezoelétrico: Permite o registro das vibrações do ronco quando é colocado na parte lateral da garganta transformando as vibrações em tensões elétricas.

- Cânula de pressão nasal: Quando o sinal da cânula, do sensor de fluxo de ar não é filtrado, o ronco é sobreposto no sinal da onda do fluxo de ar, porque a frequência do ronco $(10-70 \mathrm{~Hz})$ é maior que a do fluxo de ar. A Frequência de fluxo de ar oscila entre $0,05-5 \mathrm{~Hz}$, o ronco pode ser obtido filtrando a forma de onda do fluxo de entrada de ar.

\subsubsection{2}

\section{Sensor de Posição}

A manifestação de alguns tipos de apneias obstrutivas dependem da posição do indivíduo, por isso é importante saber se o indivíduo dormiu em todas as posições, a fim de avaliar corretamente a verdadeira gravidade do problema e a dosagem adequada de CPAP (Continuos Positive airway pressure). Devido a uma mudança na gravidade, o sensor de posição do corpo envia um sinal diretamente proporcional à posição de repouso do indivíduo (supino, deitado, esquerdo, direito ou ereto). O sensor de posição do corpo é posicionado no cinturão torácico $[55,57]$. 


\subsubsection{3}

\section{Sensor de movimento das extremidades}

É útil para diagnosticar movimentos periódicos das extremidades durante o sono, como o movimento dos membros associado a eventos respiratórios e a atividade do membro associada a crises epilépticas noturnas. Este sensor é colocado no pulso ou no tornozelo e produz um sinal diretamente proporcional ao movimento da mão ou da perna. Não registra atividade muscular como a EMG $[58,96]$.

\section{3}

\section{Identificação de RERA}

De acordo com a American Academy of Sleep Medicine (AASM) [12], a identificação de episódios de RERA durante os estágios de sono N1, N2, N3 ou REM, pode ser indicada se existe um deslocamento abrupto da frequência do EEG, incluindo alfa, beta e/ou frequências maiores aos $16 \mathrm{~Hz}$ (mas não Spindles), além de possuir uma duração de pelo menos 3 segundos.

Mesmo assim, faz-se necessário considerar algumas posições especificas dos eletrodos utilizados na medição do EEG. As derivações recomendadas pela AASM, de acordo com o sistema de medição 10-20, são as correspondentes a F4-M1, C4-M1, 02-M1, mas os electrodos de backup em caso de que os electrodos presentem falhas durante o estudo são as derivações correspondentes a F3-C3, C3-M2 e O1-M2.

\section{4 \\ Identificação de Hipopneia}

De acordo com a AASM, um evento respiratório pode ser marcado se os critérios a seguir forem atendidos:

- As excursões do sinal de pico caem em $30 \%$ da linha de base pré-evento usando pressão nasal (estudo de diagnóstico), fluxo derivado de PAP (estudo de titulação) ou um sensor de hipopneia alternativo (estudo de diagnóstico).

- A duração da queda > 30 \% na excursão do sinal é > 10 segundos.

- Há uma dessaturação de oxigênio $>3 \%$ da linha de base pré-evento ou o evento está associado a um despertar.

Caso os critérios anteriores forem atendidos, uma hipopneia será pontuada se houver pelo menos uma dessaturação de oxigênio $\geq 3 \%$ da linha de base pré-evento ou o evento estiver associado a um despertar. Portanto, o 
evento pode estar associado a apenas uma dessaturação de oxigênio $\geq 3 \%$, apenas a um despertar ou a ambos. 


\section{5}

\section{Fundamentos de Inteligência Artificial}

Este capítulo descreve os conceitos relacionados a sistemas de classificação baseados em técnicas de Inteligência Artificial usados nesta pesquisa, mais especificamente, Machine Learning e Deep Learning.

\section{1}

\section{Machine Learning (ML)}

É um subcampo da inteligência artificial e da ciência cognitiva, definido como o conjunto de métodos que extraem padrões de dados automaticamente, e que podem ser usados na predição, classificação, regressão e outros tipos de tomada de decisão sob incerteza (como planejar, coletar mais dados, seleção de variáveis etc) [59]. Dividido em três ramos principais: i) aprendizado supervisionado, ii) aprendizado não supervisionado e iii) aprendizado por reforço. [60, 61].

O aprendizado supervisionado visa a aprender uma regra geral que permita mapear as entradas nas saídas, para isso, são apresentados exemplos de entradas e saídas desejadas para o computador.

Já o aprendizado não supervisionado tem por objetivo principal descobrir os padrões ocultos nos dados. Nesta forma de aprendizado os dados não têm rótulos atribuídos ao algoritmo de aprendizado, e o modelo é responsável de achar a estrutura dos dados e suas relações.

Por último, o aprendizado por reforço é um processo cíclico, que engloba a acumulação de experiências, porém pode ser custoso e demorado. A máquina interage com um ambiente dinâmico, no qual ela tenta cumprir um determinado objetivo. O programa recebe uma retroalimentação em termos de recompensas e punições à medida que navega no entorno simulado.

\subsection{1}

\section{Random Forest (RF)}

Técnica de aprendizado conjunto para classificação, regressão e outras tarefas, que operam construindo uma multidão de árvores de decisão (DT pelas siglas em inglês Decision Trees), com o objetivo de gerar uma única 
saída misturando diferentes variáveis de entrada como pode-se observar na Figura 5.1 [62].

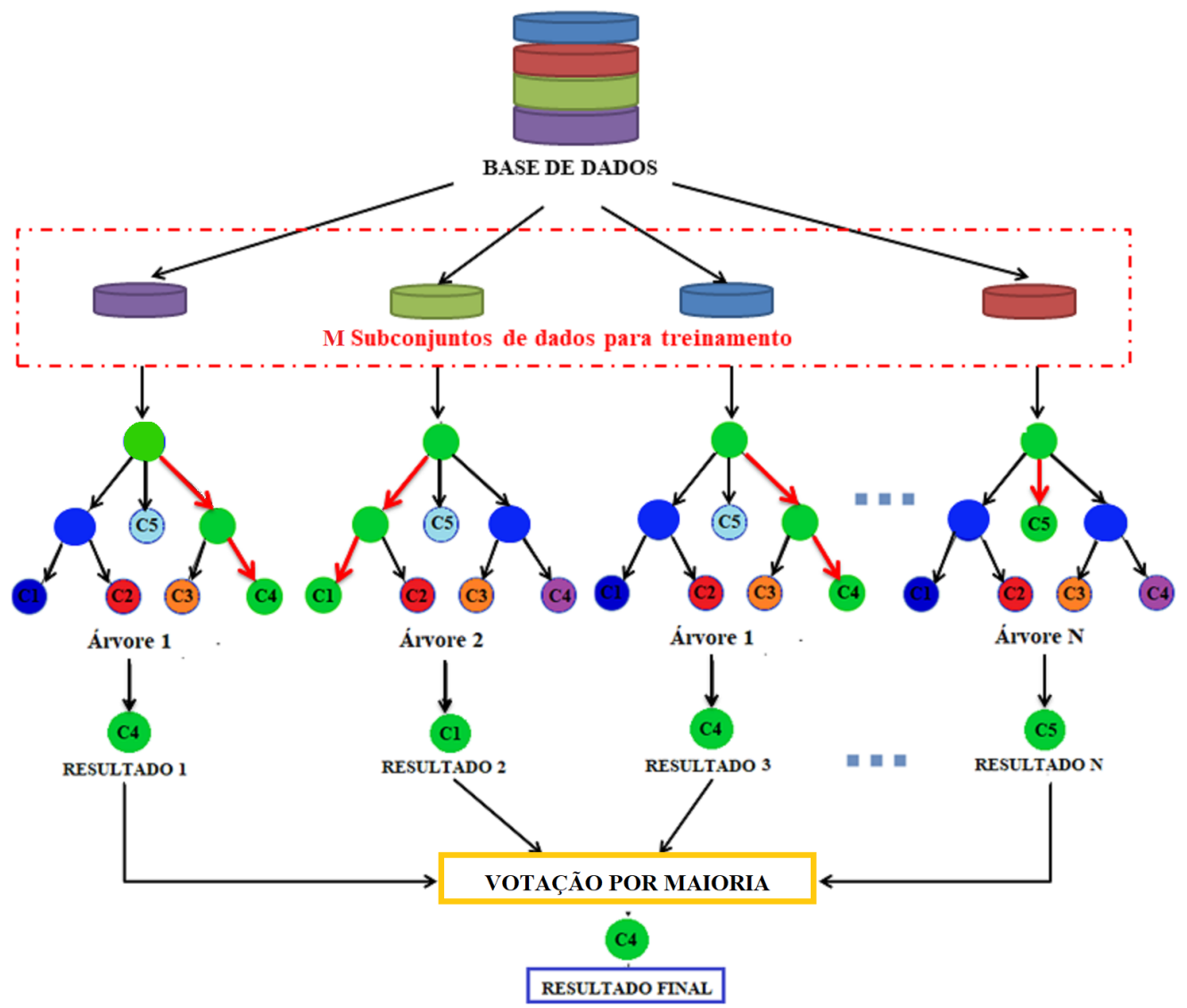

Figura 5.1: Representação esquemática de um modelo Random Forest

Na Figura 5.1 apresenta-se um modelo de RF para classificação, no qual os dados de entrada são divididos em $M$ diferentes subconjuntos com $i$ número de dados, para o treinamento de cada uma das $N$-Árvores de Decisão. Cada seta vermelha representa o fluxo da decisão para um nó (circulo verde), no entanto, as setas pretas representam os fluxos de decisão alterna para outros nós (círculos azuis). O fluxo de decisão representa a sequência de decisões que permitem identificar corretamente a classe (C1, C2, C3, C4 e C5) dada a entrada $X(i)$. Finalmente, a saída do modelo e o resultado de pegar a classe com a maior concordância [63].

\subsection{2}

\section{Naive Bayes (NB)}

Técnica de classificação baseada no Teorema de Bayes, no qual é assumida a independência de caraterísticas, o que significa que um sistema classificador NB, assume que a presença de um determinado recurso em uma classe 
não está relacionada à presença de qualquer outro recurso ou que todas essas propriedades têm contribuição independente para a probabilidade. Na Equação 5-1 é expresso o Teorema de Bayes, no qual, $P(t)$ é a probabilidade anterior de um determinado valor alvo (ou seja, o rótulo da classe), $P(f)$ é a probabilidade anterior de uma característica, $P(f \mid t)$ é a probabilidade da característica $f$ dada o alvo $t$, e $P(t \mid f)$ é a probabilidade do alvo $t$ dado apenas o recurso $f$.

$$
P(t \mid f)=\frac{P(f \mid t) P(t)}{P(f)}
$$

No caso do ML, precisa-se converter o Teorema de Bayes para ser usado com um vetor (n-dimensional) de recursos, para isso, a Equação 5-1 transformase no expresso na Equação 5-2 [63].

$$
P\left(t \mid f_{\text {all }}\right)=\frac{P\left(f_{1} \mid t\right) P\left(f_{2} \mid t\right) P\left(f_{3} \mid t\right) \ldots . . P\left(f_{n} \mid t\right) P(t)}{P\left(f_{\text {all }}\right)}
$$

\section{1 .3}

\section{K-Nearest Neighbor (KNN)}

Considerado um algoritmo simples e de fácil implementação, porém é uma ferramenta poderosa para a compreensão e resolução de problemas de classificação. Foi desenvolvido a partir da necessidade de realizar uma análise discriminante quando estimativas paramétricas confiáveis de densidades de probabilidade são desconhecidas ou difíceis de determinar (p.ex. a média e a covariância) [64]. Esse algoritmo assume que os dados agrupados são mais semelhantes aos seus vizinhos, e, portanto podem se classificar com o mesmo rótulo que seu vizinho. O termo $K$, refere-se ao número de vizinhos mais próximos que vão ser considerados, quando um elemento desconhecido esteja sendo classificado. O vizinho mais próximo ou mais afastado é medido pela distância entre o elemento desconhecido a ser classificado e o vizinho, embora, existam diferentes métricas, a distância euclidiana expressa na Equação 5-3 é a mais comum [63].

$$
\text { distância }=\sqrt{\sum_{i=1}^{n}\left(x_{i}-y_{i}\right)^{2}}
$$

Onde, $x_{i}$ e $y_{i}$ são as duas observações entre as quais estamos calculando a distância. $x_{i}$ é o valor do ponto $A$ na dimensão $d$ (podendo ser x ou y), $y_{i}$ é o valor para o segundo ponto na mesma dimensão. Para um problema bidimensional, a distância é expressa como na Equação 5-4, da qual, $i$ é o ponto conhecido e $j$ é o elemento de classe desconhecida.

$$
d i s t=\sqrt{\left(x_{i}-x_{j}\right)^{2}+\left(y_{i}-y_{j}\right)^{2}}
$$


Assim o sistema associa a classe desconhecida com a classe de seu vizinho mais próximo calculado.

\subsection{4}

\section{Redes Neurais Artificiais (RNA)}

São arquiteturas compostas por conjuntos de unidades de aprendizagem simples nomeadas neurônios, e inspiradas na interconexão de neurônios a nó organizados em camadas de entrada e saída que existe numa rede neural biológica. A Figura 5.2 ilustra uma arquitetura padrão de RNA que possui uma camada de entrada, uma camada oculta e uma camada de saída com todos seus neurônios inter-conetados (círculos em azul) com a camada seguinte.

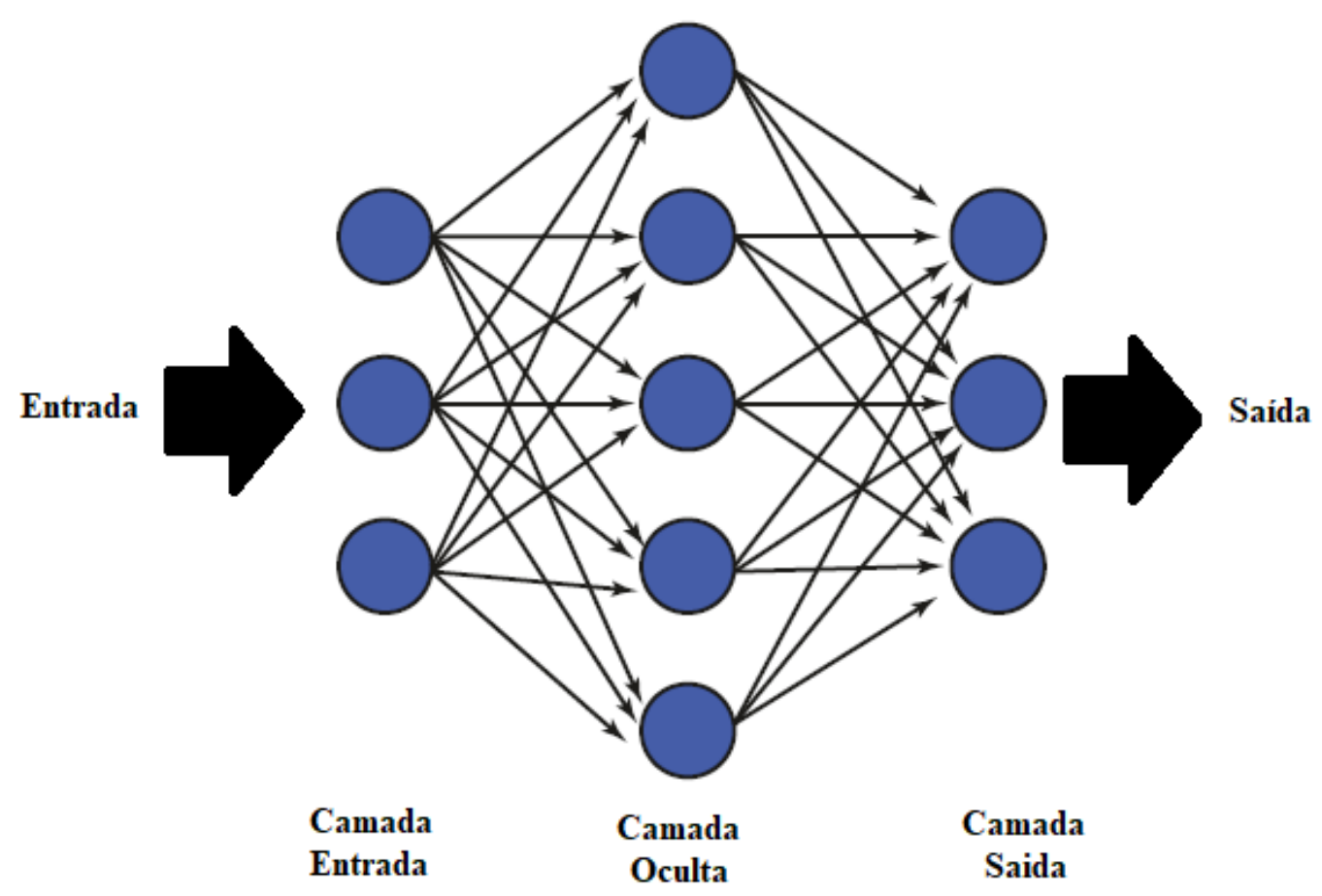

Figura 5.2: Arquitetura padrão de uma Rede Neural Artificial.

As RNA geralmente são criadas com todos os parâmetros inicializados como pequenos valores atingindo distribuições normais. Uma vez que uma observação é alimentada através da rede, o valor gerado é comparado com o valor real da observação usando uma função de perda ou função de erro. Isso é chamado de forward propagation. Em seguida, um algoritmo vai para trás pela rede tentando identificar o quanto cada parâmetro contribuiu para o erro entre os valores preditos e verdadeiros (backpropagation). Em cada parâmetro, o algoritmo de otimização determina quanto cada peso deve se ajustar para melhorar o resultado. As redes neurais aprendem repetindo os processos de forward propagation e backpropagation para cada observação nos 
dados de treinamento várias vezes, atualizando iterativamente os valores dos parâmetros $[62,63]$.

\subsection{5}

\section{Funções de ativação}

São operações matemáticas, não lineares, aplicadas na saída de camadas internas de uma rede neural multicamada. Essas funções introduzem não linearidades que fornecem a capacidade de rede para aproximar com precisão funções arbitrariamente complexas. Algumas das funções de ativação mais comuns são Sigmoid, tanh e Unidade Linear Retificada (ReLU) como é ilustrado na Figura 5.3 [65]. Por outro lado, as funções de ativação decidem se um neurônio deve ser ativado ou não, a traves do calculo da soma ponderada e a adição de ainda mais viés com ela [60].
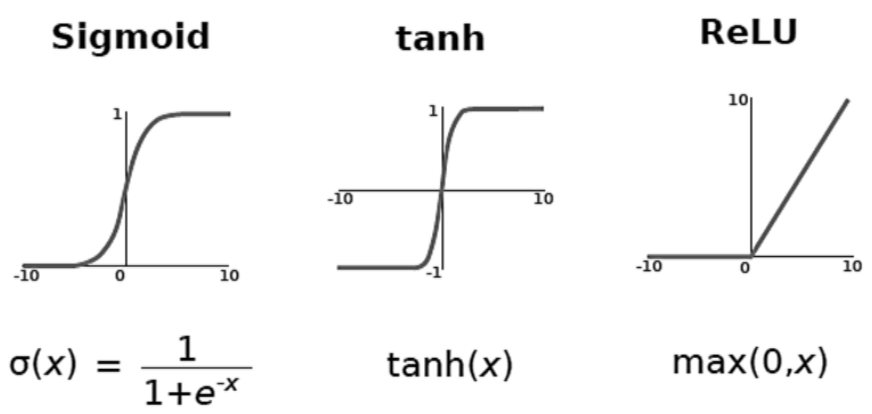

Figura 5.3: Funções de ativação e sua definição matemática.

\section{2}

\section{Deep Learning (DL)}

É uma subárea do ML que investiga técnicas para simular o comportamento do cérebro humano em tarefas como reconhecimento visual, reconhecimento de fala e processamento de linguagem natural. Está definido como um tipo particular de aprendizado de máquina que alcança grande poder e flexibilidade, aprendendo a representar o mundo como uma hierarquia aninhada de conceitos, com cada conceito definido em relação a conceitos mais simples e representações mais abstratas computadas em termos de menos abstratos [61].

\subsection{1}

\section{Redes Neurais Convolucionais (CNN)}

Uma CNN é uma sequência de camadas na qual cada camada transforma um volume de ativações em outro através de uma função diferenciável (função 
de ativação). A diferença das RNA que recebem entradas em forma de vetores, uma CNN, pressupõe entradas com forma matricial de $\mathrm{N}$ dimensões.

Para construir arquiteturas CNN como a ilustrada na Figura 5.4, são usados blocos compostos por três tipos de camadas principalmente: (i) camadas convolucional (Convolutional layer), (ii) camada de amostragem (Pooling layer) e uma camada totalmente conetada (Fully-Connected layer-(FC)) igual que em uma rede Multi-Layer perceptron (MLP) [60,61].

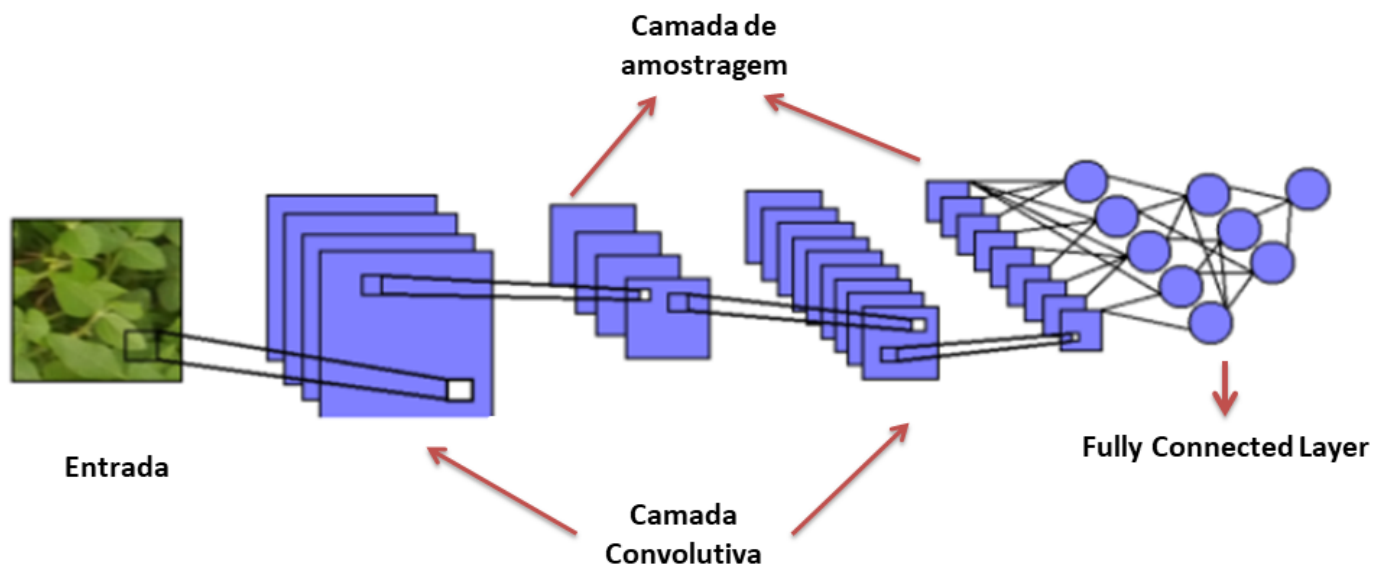

Figura 5.4: Exemplo Básico de uma Rede Neural Convolutiva

De forma geral, as camadas convolutiva e de amostragem, possuem um número $k$ de filtros (nomeados como kernels) cujas dimensões são $n \times n \times q$ (supondo uma matriz 3D), com $n$ e $q$ escolhidos de acordo com o objetivo. Cada filtro gera por convolução um mapa de características da entrada (Feature Map), de tamanho $(m-n+1) \mathrm{x}(m-n+1) \mathrm{x} p$, com altura $m$, largura $n$ e $p$ que equivale ao número de filtros. Em seguida, cada mapa é sub-amostrado na camada de amostragem, em regiões contíguas de tamanho $p \times x$ com valores entre 2 e 5. Finalmente, na camada FC, uma função de ativação, mais um viés para cada mapa de características é aplicado para obter a saída [66-68]. Destaca-se que três hiper parâmetros controlam o tamanho do mapa de características de saída: filtros, Stride e padding.

- Filtros: Refere-se à o número de filtros que vai ser usado.

- Stride: É a distância em pixels, que vai separar cada bloco extraído sem sobreposição para o caso da camada de amostragem e sobreposto para as camadas convolutivas.

- Padding: Refere-se ao preenchimento do mapa de características ao redor da borda, em geral é usado o Zero-padding, dado que ele permite controlar e preservar o tamanho espacial dos volumes de saída. 


\subsubsection{1}

\section{Camada Convolutiva}

É a camada que permite reduzir o número de elementos que compõem a rede, através da operação de convolução entre a matriz de entrada e um kernel. Nesta camada, o número de conexões possíveis entre o neurônio da camada oculta e os elementos da imagem de entrada é restrito, dessa forma cada neurônio oculto será conectado a um pequeno subconjunto de elementos da imagem total, como ilustra-se na Figura 5.5.

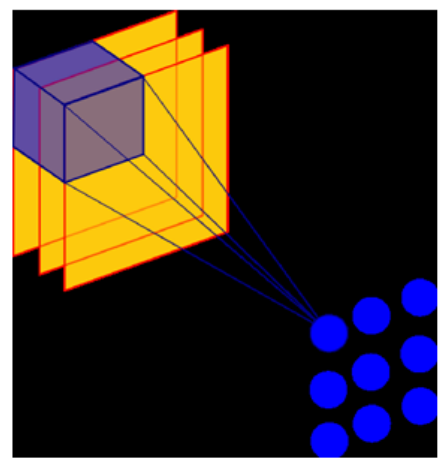

Neurônios

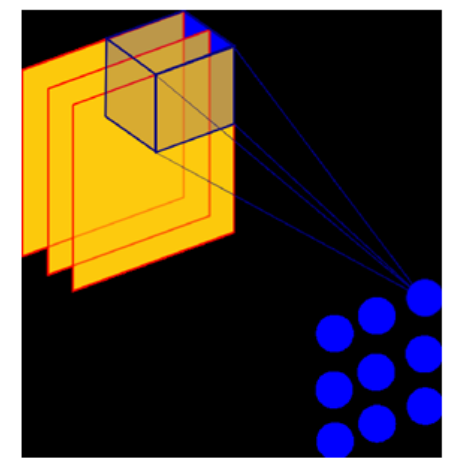

Kernel

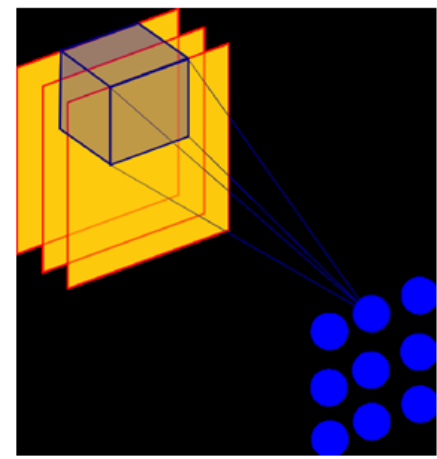

Camada convolutiva

Figura 5.5: Processo de convolução entre a entrada de forma matricial (quadro amarelo) e o kernel (quadro azul) do neurônio da camada oculta (ponto azul escuro)

\subsubsection{2}

\section{Camada de Amostragem (Pooling Layer)}

O objetivo desta camada é diminuir o número de parâmetros na camada seguinte, para isso, são identificadas as zonas com características predominantes da entrada. Os métodos de amostragem mais usados são a média (averagepooling) e o valor máximo (max-pooling). Esse processo pode ser observado na Figura 5.6. 

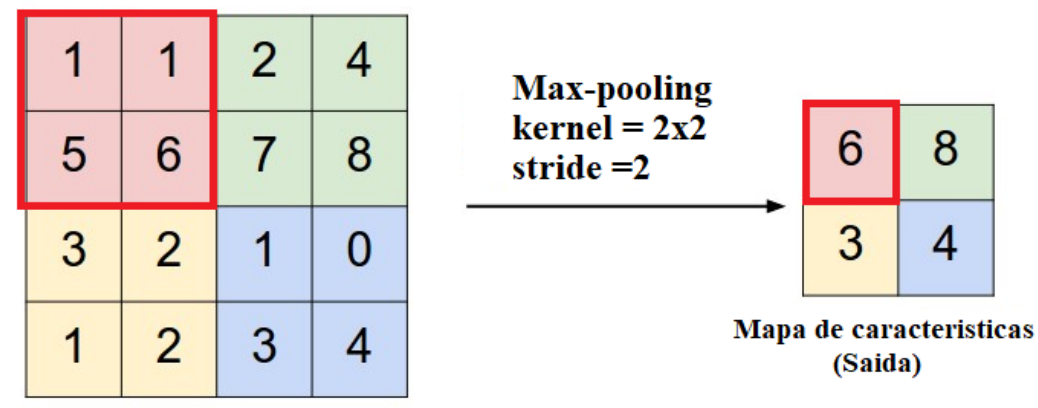

Mapa de caracteristicas (entrada)

Figura 5.6: Exemplo de amostragem usando uma camada tipo Max-pooling, onde é usado um kernel de tamanho 2x2 (quadrado vermelho) para encontrar os valores máximos presentes nas sub-matrizes da entrada (arreglos de $2 \times 2$ cor rouxo, verde, amarelo e azul).

\subsubsection{3}

\section{Fully Connected Layer}

É a última camada da arquitetura convolucional e está composta por um número de neurônios igual ao número de classes a classificar. As FC conectam seus neurônios a todas as saídas da camada anterior, como no caso da MLP tradicional apresentada na Figura 5.2.

\section{2 .2}

\section{Batch Normalization (BN)}

É uma técnica que permite mitigar a variação da distribuição de entrada das redes profundas, causada pelo repetitivo ajuste dos pesos nas camadas anteriores, especialmente para camadas com funções de ativação que se saturam com alguns valores de entrada. Para corrigir este problema normaliza os valores nas entradas da camada, subtraindo-se sua média e dividendo-se pelo seu desvio padrão (estimados com base no minibatch atual), resultando num minibatch com média zero e variância unitária. Em seguida, como a escolha da variância da unidade é uma escolha arbritária, aplica-se um coeficiente de escala $(\gamma)$ e um deslocamento $(\beta)$ por coordenadas. Consequentemente, as magnitudes de ativação para as camadas intermediárias não podem divergir durante o treinamento porque o BN centra ativamente e redimensiona-as de volta para uma determinada média e tamanho (via $\mu$ e $\sigma$ ). A transformação das funções de ativação, numa camada $x$ realiza-se de acordo com a Equação 5-5. Aqui, $\hat{\mu}$ é a média da amostra do minibatch e $\hat{\sigma}$ é o desvio padrão da amostra do minibatch, $\gamma$ o coeficiente de escala, beta o coeficiente de deslocamento e $\odot$ 
denota o produto matricial $[60,69]$.

$$
B N(x)=\gamma \odot \frac{X-\hat{\mu}}{\hat{\sigma}}+\beta
$$

\section{2 .3}

\section{Dropout}

É um método para contornar o overfitting ${ }^{1}$ usado para forçar a rede a distribuir a representação aprendida por todos os neurônios. O dropout desativa uma fração predefinida aleatória das unidades em uma camada. Esses neurônios eliminados são aleatórios (são diferentes para cada cálculo), o que resulta forçando a rede a aprender uma representação que funcionará até mesmo após de ser usado. Esse processo é geralmente nomeado como o treinamento de várias redes, aumentando assim a generalização. Ao usar a rede como um classificador no momento do teste o método dropout é ignorado e toda a rede é usada [71].

\section{2 .4}

\section{Redes Neurais Recorrentes (RNN)}

As RNN -pelas siglas em inglês Recurrent Neural Networks- são um tipo de rede neural projetada para processar dados sequenciais, dado que calculam recursivamente novos estados aplicando funções de transferência a estados e entradas anteriores. As funções de transferência típicas são compostas por uma transformação afim seguida por uma função não linear, que são escolhidas dependendo da natureza do problema específico em questão. Por outro lado, assim como em uma rede MLP simples, as camadas de uma RNN dividem-se em camada de entrada, camadas ocultas e camada de saída [60].

Dada uma sequência de entrada, para cada passo de tempo $t$ o componente $X[t]$ da entrada serial $x$ é processado pela camada de entrada e é adicionado um bias $b_{i}$ que passa a ser multiplicado pela matriz de pesos $W_{i}^{h}$. Da mesma forma, ao estado interno da rede $h[t-1]$, que tem os intervalos de tempo anteriores ao estado atual $t$, é adicionado o bias $b_{h}$ e é multiplicado com a matriz de pesos das conexões recorrentes $W_{h}^{h}$. A entrada atual transformada e o estado passado da rede, são então combinados e processados pelos neurônios nas camadas ocultas, que aplicam uma transformação não linear. As equações de diferença para a atualização do estado interno $h[t]$ e a saída da rede $y[t]$ em uma etapa de tempo t são definidos pelas Equações 5-6 e 5-7 [72].:

\footnotetext{
${ }^{1} \mathrm{~A}$ rede considera válidos só os dados idênticos aos apresentados durante o processo de treinamento [70]
} 


$$
\begin{gathered}
h[t]=f\left(W_{i}^{h}\left(X[t]+b_{i}\right)+W_{h}^{h}\left(h[t-1]+b_{h}\right)\right) \\
y[t]=g\left(W_{h}^{\circ}\left(h[t]+b_{o}\right)\right)
\end{gathered}
$$

Onde, $h[t]$ é o estado interno na etapa do tempo $t$ que transporta o conteúdo da memória da rede, é normalmente inicializado com um vetor de zeros e depende de entradas anteriores e estados de rede. O $f$ é a função de ativação dos neurônios (geralmente tangente hiperbólica ou a função sigmoide). A saída da rede $y[t]$ é calculada é usando uma transformação dada pelo $g$, geralmente linear, na matriz dos pesos de saída $W_{h}^{\circ}$ é aplicada a soma do estado atual $h[t]$ e o vetor de polarização $b_{o}$. Todas as matrizes de peso e vieses podem ser treinados por meio do gradiente descendente. No caso que seja especificado de outra forma, são omitidos os termos de polarização assumindo $x=[x ; 1], h=[h ; 1], y=[y ; 1]$ e aumentando $W_{i}^{h}, W_{h}^{h}, W_{h}^{\circ}$ com uma coluna adicional $[60,72]$.

\subsection{5}

\section{Redes Long Short-Term Memory(LSTM)}

São redes capazes de modelar dependências de tempo de longo e curto prazo. Essas redes possuem uma célula de memória $C(t)$, regulada por quatro portas compostas por diferentes funções não lineares como se ilustra na Figura $5.7[72,73]$.

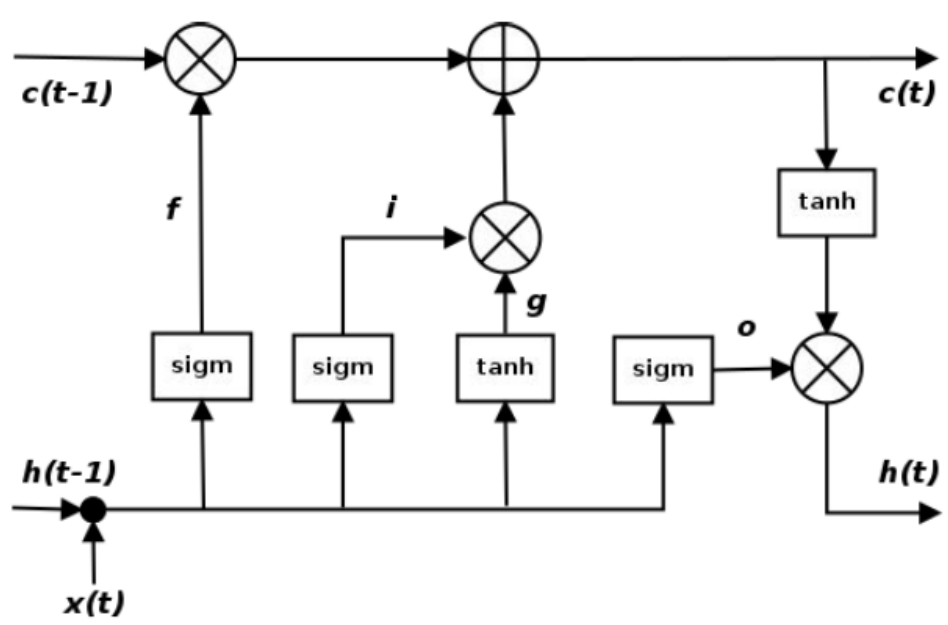

Figura 5.7: Esquema geral de uma Rede LSTM.

Na primeira porta da rede LSTM (Figura 5.8), o passo de tempo $t$ da sequência de entrada $x(t)$ e os estados ocultos da etapa de tempo anterior $h(t-1)$ decidem quais informações devem ser esquecidas na célula de memória $C(t-1)$, na qual a saída $f(t)$ é calculada a partir da Equação 5-8. 


$$
f(t)=\sigma\left(W_{f} x(t)+U_{f} h(t-1)\right)
$$

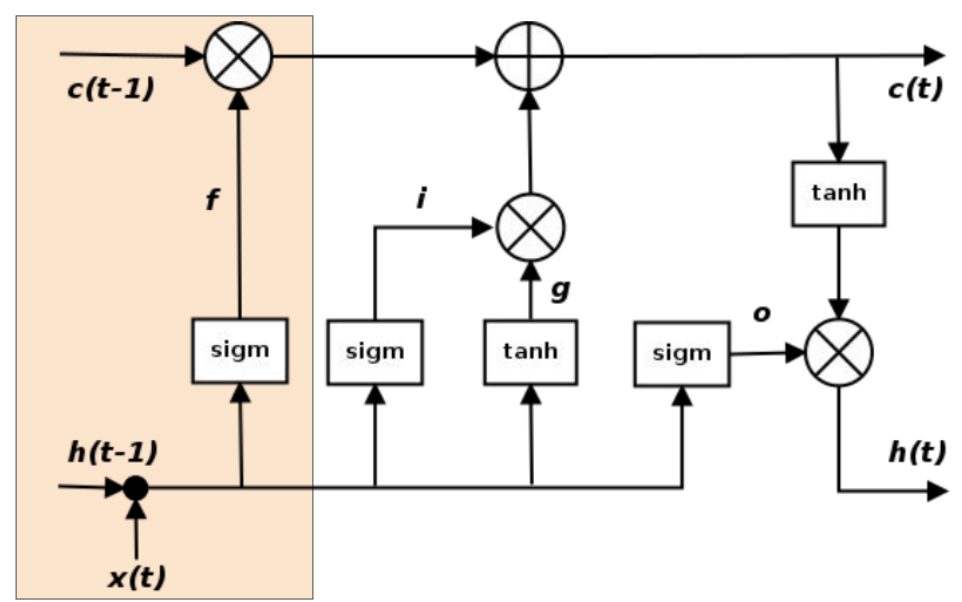

Figura 5.8: Primeira porta da rede LSTM destacada em cor rosa.

Já a segunda porta está dividida em duas: (i) uma camada de entrada que decide quais unidades de células devem ser atualizadas com novas informações, calculando um valor entre 0 e 1 para cada componente da célula de memória $C(t)$ usando a Equação 5-9 (Figura 5.9) e (ii) uma camada de atualização, na qual, um conjunto de novos valores é criado para a célula de memória usando $x(t)$ e $h(t-1)$ como entradas. O estado da memória candidata $\tilde{C}(t)$ é calculado a partir da Equação 5-10.

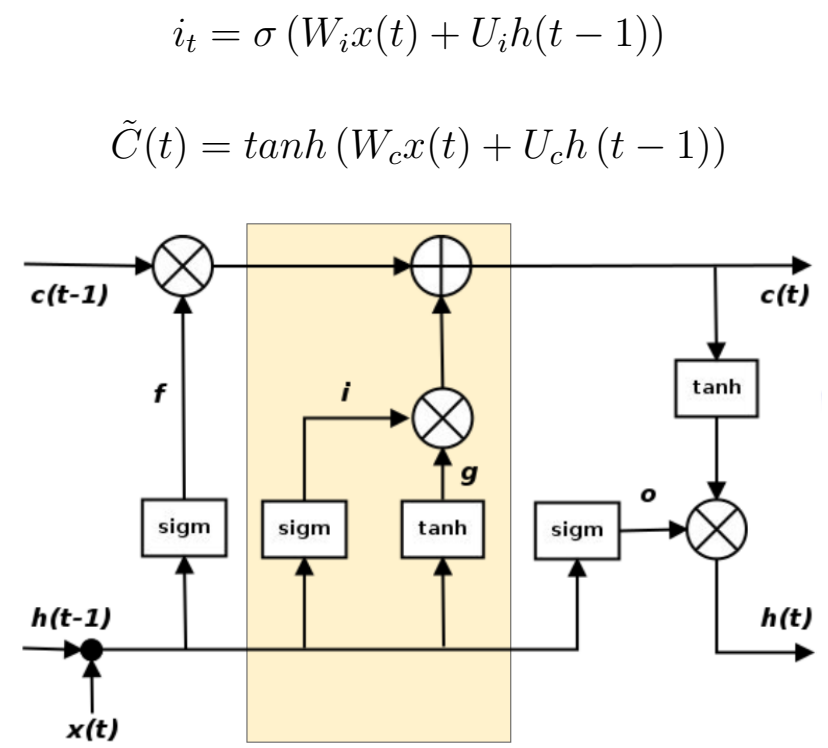

Figura 5.9: Segunda porta de uma rede LSTM destacada em cor laranja claro

$\mathrm{Na}$ terceira porta (Figura 5.10), o novo estado de memória $C(t)$ é atualizado de acordo á Equação 5-11. 


$$
C(t)=f_{t} * C(t-1)+i_{t} * \tilde{C}(t)
$$

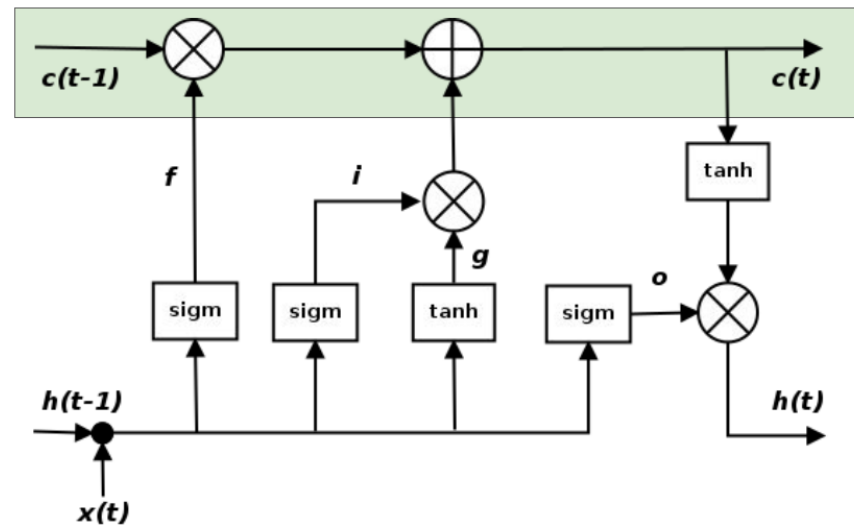

Figura 5.10: Terceira porta de uma rede LSTM destacada em verde

Na porta quatro (Figura 5.11), é decidida a saída da rede, para isso, $x(t)$ e $h(t-1)$ são passados por uma porta de saída, que emite um valor entre 0 e 1 para cada componente no vetor de estado da célula $C(t)$, calculado de acordo com a Equação 5-12. Finalmente o estado oculto atualizado $h(t)$ é calculado a partir da célula de memória $C(t)$ usando a Equação 5-13.

$$
\begin{gathered}
O_{t}=\sigma\left(W_{o} x(t)+U_{o} h(t-1)\right) \\
h(t)=O_{t} * \tanh (C(t))
\end{gathered}
$$

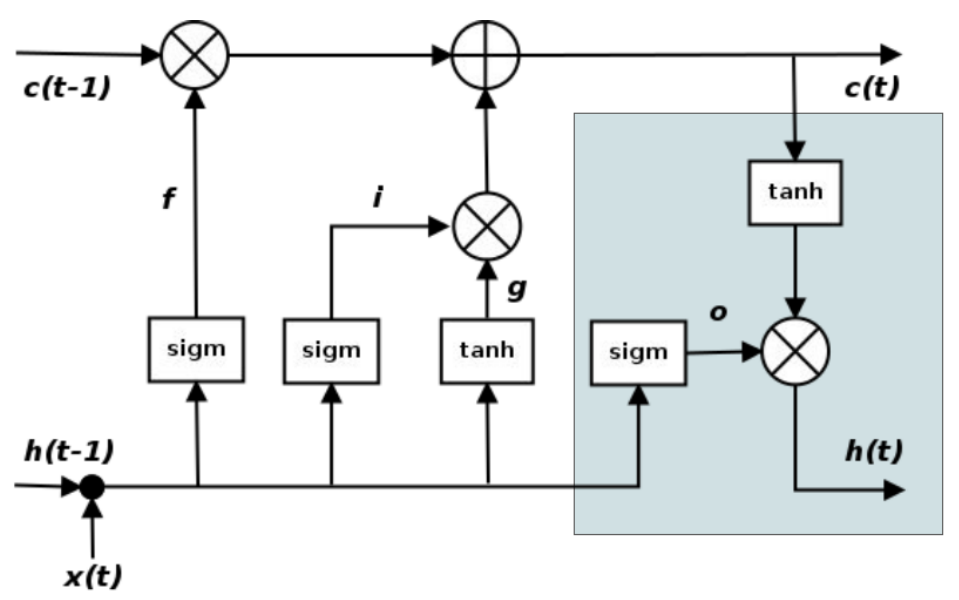

Figura 5.11: Porta de saída de uma rede LSTM destacada em azul 


\subsection{6}

\section{Class Weight}

É um dos métodos mais simples para lidar com o desequilíbrio de classes, consiste em fornecer um peso para cada classe, forçando o classificador a ter mais ênfase nas classes minoritárias, em consequência serão aprendidas igualmente todas as classes. Na Equação 5-14 se expressa a forma geral para calcular o peso de uma classe, nesta $S$ é o número total de exemplos de classe de todo o conjunto de dados, $q_{i}$ é o número de exemplos da classe $i$ e $C$ o número de classes [74].

$$
w_{i}=\frac{1}{q_{i}} \frac{S}{C}=\frac{S}{q_{i} C}
$$

\subsection{7}

\section{Focal Loss (FL)}

De acordo com [75] o FL é considerado um dos melhores métodos para aprimorar modelos de redes neurais, devido a que auxilia na previsão de dados desbalanceados dando pesos maiores para os dados difíceis de classificar, em consequência diminuí o impacto das previsões mais fáceis de classificar. A função de perda é uma forma matemática de dizer a que distância uma suposição está do valor real de um ponto de dados. Em termos matemáticos, o FL tem um fator de escala adicionado à função de perda de entropia cruzada (CE) descrita pela Equação 5-15:

$$
C E(p, y)=\left\{\begin{array}{cc}
-\log (\mathrm{p}) & , y=1 \\
-\log (1-\mathrm{p}) & , \text { outros }
\end{array}\right.
$$

Da qual $y \in\{-1,+1\}$ que especifica a classe verdadeira e $p \in[0,1]$, é a probabilidade estimada do modelo para a classe com rotulo $y=1$ (Equação 516):

$$
p_{t}=\left\{\begin{array}{cc}
p & , y=1 \\
1-p & , \text { outros }
\end{array}\right.
$$

A partir das Equações 5-15 e 5-16 a perda CE é reescrita resultando na Equação 5-17:

$$
C E(p, y)=C E\left(p_{t}\right)=-\log \left(p_{t}\right)
$$

$\mathrm{O}$ fator de modulação $\left(1-p_{i}\right)^{\gamma}$ é adicionado à perda de $\mathrm{CE}$, com um parâmetro de foco ajustável $\gamma \geq 0$, assim na Equação 5-18 é descrita a função matemática do Focal Loss.

$$
F L\left(p_{t}\right)=-\left(-1-p_{t}\right)^{\gamma} \log \left(p_{t}\right)
$$

Destacam-se duas propriedades da perda focal: (i) Quando um exemplo é classificado incorretamente e $p_{t}$ é pequeno, o fator de modulação é próximo 
a 1 e a perda não é afetada. Como $p t \rightarrow 1$, o fator vai para 0 e a perda para exemplos bem classificados é reduzida. (ii) O parâmetro de foco $\gamma$ ajusta suavemente a taxa na qual exemplos fáceis são reduzidos. Quando $\gamma=0, \mathrm{FL}$ é equivalente a $\mathrm{CE}$, e conforme $\gamma$ aumenta o efeito do fator de modulação também aumenta. Na prática, é mais usada uma variante $\alpha$ balanceada da perda focal descrita na Equação 5-19.

$$
F L\left(p_{t}\right)=-\alpha_{t}(1-p t) \gamma \log \left(p_{t}\right)
$$




\section{6}

\section{Materiais e Métodos}

Este capitulo subdivide-se em duas secções: (i) Materiais e (ii) Métodos, nas quais são descritos os equipamentos utilizado e as fases consideradas para o desenvolvimento desta pesquisa de mestrado.

\section{1}

\section{Materiais}

Os materiais usados nesta pesquisa estão divididos em: (i) Equipamento/Software e (ii) Base de dados, expostos a seguir. O local utilizado foi a sala de estudos do Departamento de Pós-Graduação em Engenharia Elétrica (DEE) da PUC-Rio.

\subsection{1 \\ Equipamento/software}

Para o desenvolvimento desta pesquisa foi usado o software de código aberto Spyder IDE e a plataforma Google Colab, que permitem a programação cientifica no python nas versões 3.6 e 3.7 (Figura 6.1c).

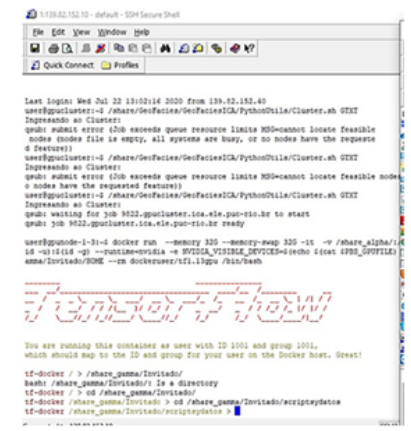

(a)

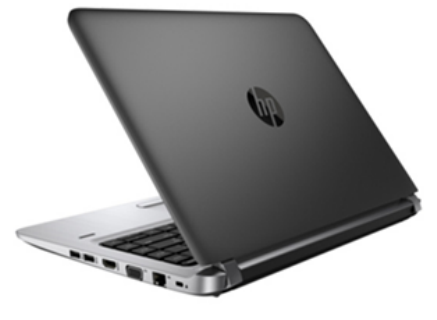

(b)

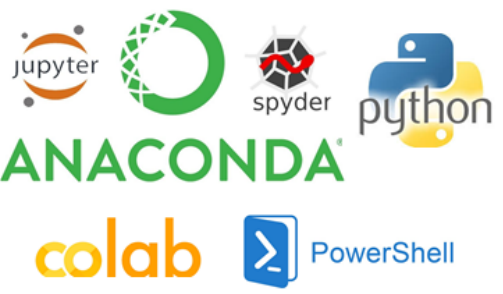

(c)

Figura 6.1: Equipamento e software usado para o desenvolvimento da pesquisa: (a) interface gráfica SSH Power Shell Client usada para conexão ao nodo GPU da máquina remota e (b) Laptop usado para conexão remota e atividades relacionadas ao desenvolvimento de algoritmos

Dados a complexidade e o custo computacional dos sistemas implementados, também foram usados dois equipamentos de computação: o primeiro, foi 
um Laptop Hp 440 Intel(R) Core(TM) i7-4702MQ CPU 2.20 GHz com 8 GB de RAM de uso pessoal apresentado na Figura 6.1b, e o segundo, foi uma máquina remota propriedade do Laboratório de Inteligência Artificial (ICA/PUC Rio), que possui uma GPU GeForce GTX 1080 Ti com 8 GB de RAM, cujo acesso foi feito usando o software SSH Secure Shell Client apresentada na Figura 6.1a.

\subsection{2}

\section{Base de Dados}

O conjunto de dados usado foi The PhysioNet Computing in Cardiology Challenge 2018 [25], cujos dados foram fornecidos pelo Laboratório de Neurofisiologia Clinica Computacional do Hospital Geral de Massachusetts(MGH/CCNL) e pelo Laboratório de Animação de Dados Clínicos (CDAC). Possui os registros polissonográficos (PSG) de 1.985 indivíduos que foram monitorados em um laboratório de sono do MGH durante uma noite. A base de dados está particionada em dois grupos: (i) 994 registros para treinamento balanceado e (ii) 989 registros para Test (cujas classes não são de domínio publico). Cada um dos registros polissonográficos possui um total de 13 sinais fisiológicos referentes a medição da atividade cerebral, muscular, cardíaca e respiratória. Estes sinais são listados na Tabela 6.1.

Tabela 6.1: Sinais contidas em cada um dos registros polissonográficos da base de dados

\begin{tabular}{ccc}
\hline Canal & Sinal $[\mu V]$ & Definição \\
\hline 0 & F3-M2 & EEG atividade frontal \\
1 & F4-M1 & EEG atividade frontal \\
2 & C3-M2 & EEG atividade central \\
3 & C4-M1 & EEG atividade central \\
4 & $01-\mathrm{M} 2$ & EEG atividade posterior \\
5 & $02-\mathrm{M} 1$ & EEG atividade posterior \\
6 & E1-M2 & EOG do olho esquerdo \\
7 & Chin1-Chin2 & EMG de queixo \\
8 & ABD & EMG do movimento abdominal \\
9 & Chest & EMG do movimento torácico \\
10 & Fluxo de Ar & Medida do fluxo do ar respiratório \\
11 & SaO2 ${ }^{*}$ & Saturação de Oxigênio \\
12 & ECG ${ }^{* *}$ & Atividade cardíaca \\
\hline
\end{tabular}

* Medido em \%

** Medido em $\mathrm{mV}$

Na Figura 6.2, é apresentado um exemplo de segmento dos sinais contidos em um dos registro PSG da base de dados, na área vermelha estão os sinais EEG (i.e. canais 0-5, citados na Tabela 6.1), a área amarela corresponde ao sinal EOG (i.e. Canal 6, citado na Tabela 6.1), a área verde corresponde aos sinais de EMG de queixo, peito e abdome (i.e. canais 7-9, citado na Tabela 6.1) e a área celeste corresponde aos sinais de fluxo do ar, SaO2 e ECG. 


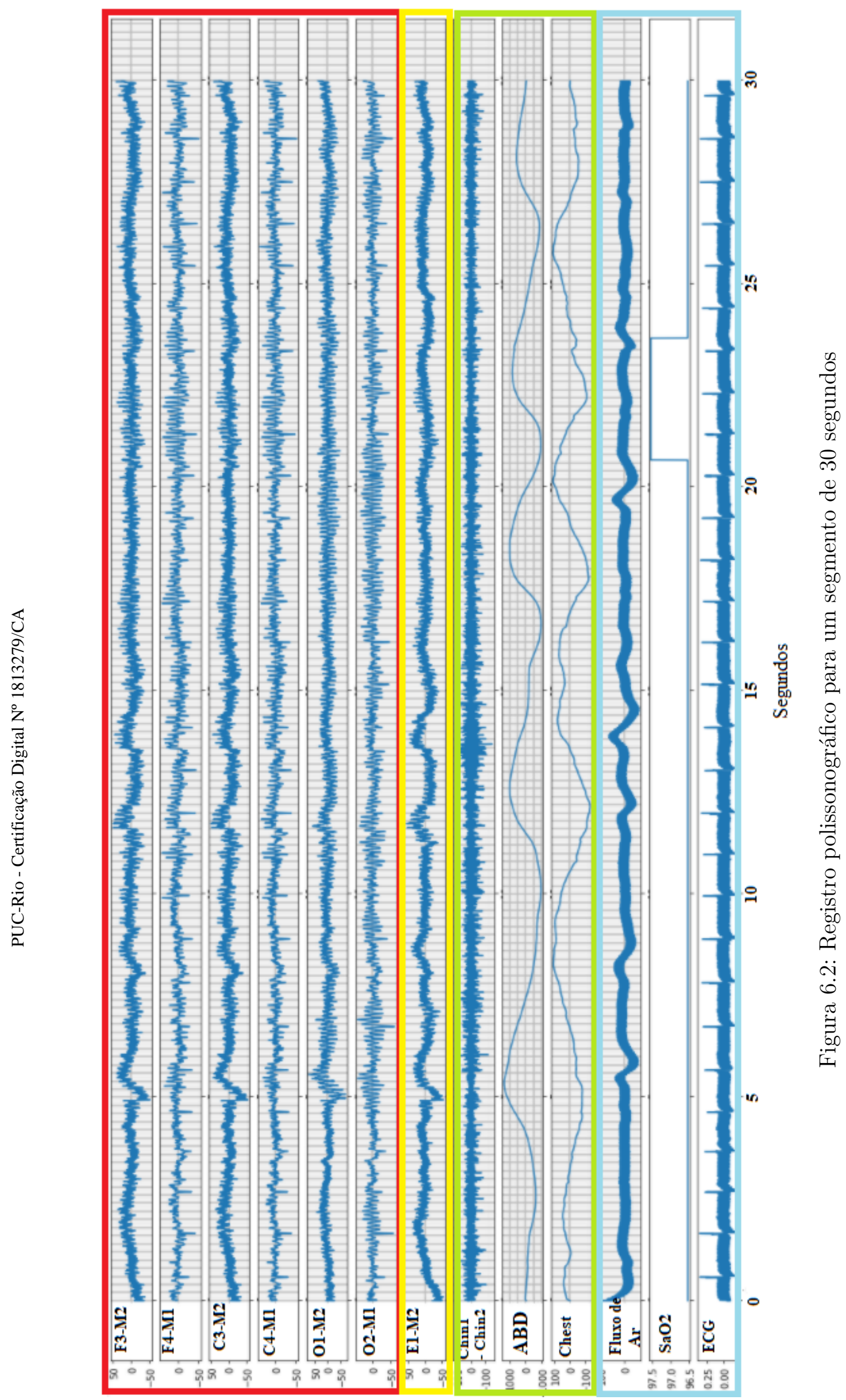


Os PSGs foram divididos em intervalos de 30 segundos, cada intervalo possui diferentes tipos de observações (anotações) feitas pelos tecnólogos certificados de sono do MGH associadas ás seguintes categorias: (i) estágios de sono, (ii) Despertares relacionados a eventos respiratórios e (iii) despertares relacionados a distúrbios de movimento como o bruxismo e o síndrome de pernas inquietas. No caso dos estágios do sono são considerados seis estágios: vigília, estágio NREM1, estágio NREM2, estágio NREM3, Sono REM e indefinido. Já para as excitações, estas foram classificadas de acordo a seu tipo nas categorias: excitações espontâneas, RERA, bruxismos, hipoventilações, hipo-apneias, apneias (centrais, obstrutivas e mistas), vocalizações, roncos, movimentos periódicos das pernas (PLM), respiração periódica de Cheyne-Stokes ou obstruções parciais das vias aéreas. Na Figura 6.3 é apresentada a distribuição de exemplos para cada uma das classes mencionadas anteriormente. Destaca-se que as observações alvo para esta pesquisa, correspondentes aos segmentos com eventos RERA, eventos relacionados à apneia/hipopneia e Normal estão em um arquivo separado das observações mencionadas anteriormente e são descritas por extenso na secção 6.2.1.

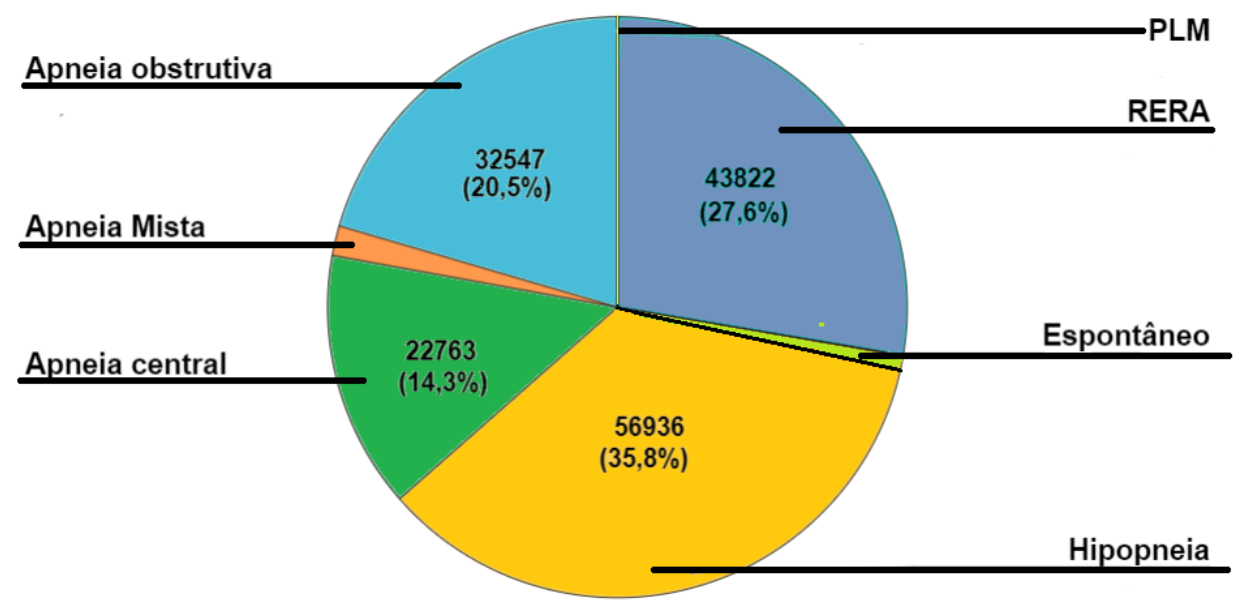

Figura 6.3: Quantidade de exemplos para cada um dos distúrbios de sono presentes na base de dados

\section{2}

\section{Métodos}

Nesta secção são descritos os métodos de análise de dados, os sistemas e as métricas usadas para avaliar o desempenho dos sistemas propostos. Na Figura 6.4 é ilustrada a metodologia aplicada para o desenvolvimento desta pesquisa, que esta dividida em três fases: (i) o estudo da base de dados, sua 
organização, incluindo uma análise exploratória e a compreensão das informações contidas nos registros para seu posterior análise; (ii) o preprocessamento dos dados, a extração de características e a avaliação dos sistemas de classificação propostos, e (iii) a validação dos resultados, assim como seu posterior análise. Cada uma das fases é descrita por extenso nas seções seguintes.

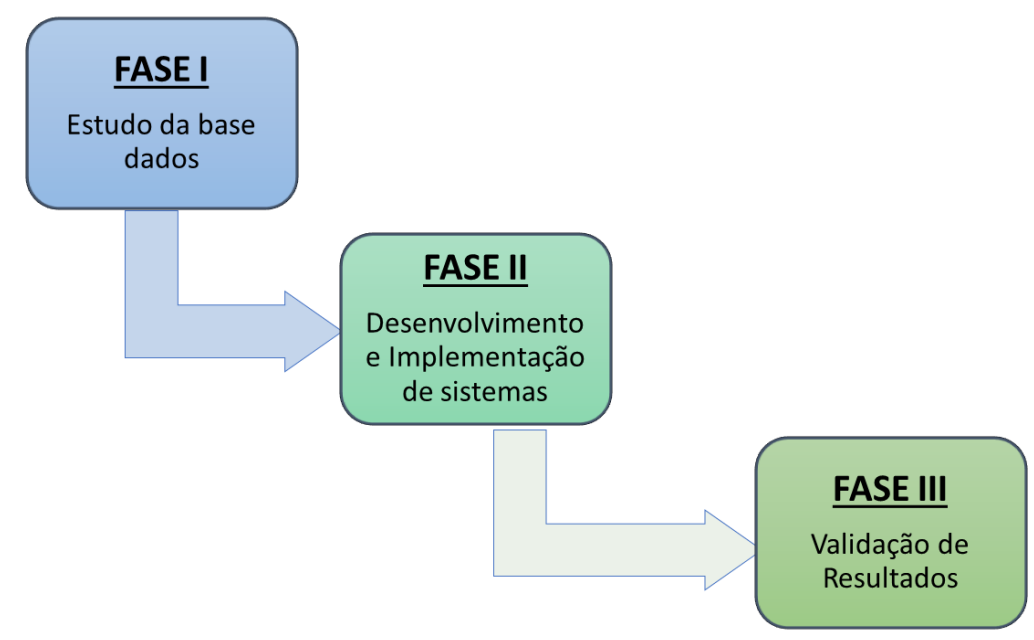

Figura 6.4: Fases da Metodologia

\subsection{1}

\section{FASE I: Estudo da base de dados}

Devido ao fato de que nesta pesquisa são propostos sistemas de aprendizado supervisionado, são considerados unicamente os registros do conjunto de treinamento descrito previamente na seção 6.1.2. Para esta pesquisa os dados foram divididos em três subconjuntos: (a)Treino, (b) Teste e (c) validação, com tamanhos equivalentes a $70 \%, 20 \%$ e $10 \%$, respectivamente. Seguidamente, de cada um dos registros PSG foram extraídos os sinais de eletroencefalografia (EEG) junto com os rótulos de classe divididos em: Normal, Evento RERA e Eventos associados à apneia/hipopneia.

\subsubsection{1}

\section{Normal}

Esta classe designa a ausência de excitações como pode-se observar na Figura 6.5, na qual é apresentado um exemplo da classe normal para uma época de 30 segundos dos 6 canais EEG, nela observa-se que nenhum dos sinais apresenta mudanças abruptas ao longo da época e cada um dos sinais EEG presenta padrões de onda normais. 


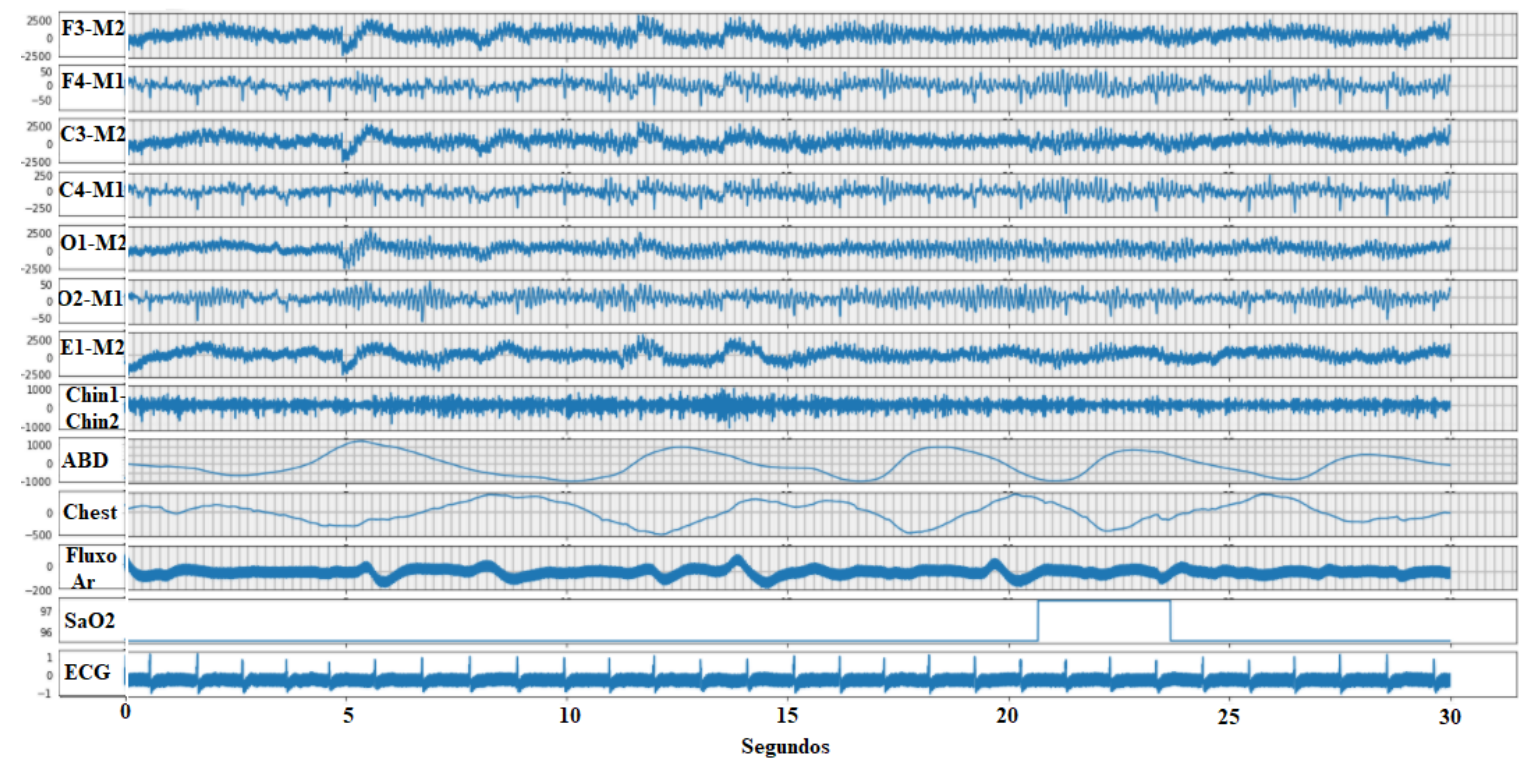

Figura 6.5: Exemplo de um segmento de Polissonografia da classe Normal

\subsubsection{2}

\section{Evento RERA}

Esta classe designa épocas com despertares causados por esforço respiratório (Respiratory Effort-Related Arousal-RERA). Na Figura 6.6 é apresentado um exemplo para uma época de 30 segundos na qual é possível observar algumas mudanças no comportamento dos sinais entre os 15 e 30 segundos que são características dos eventos RERA.

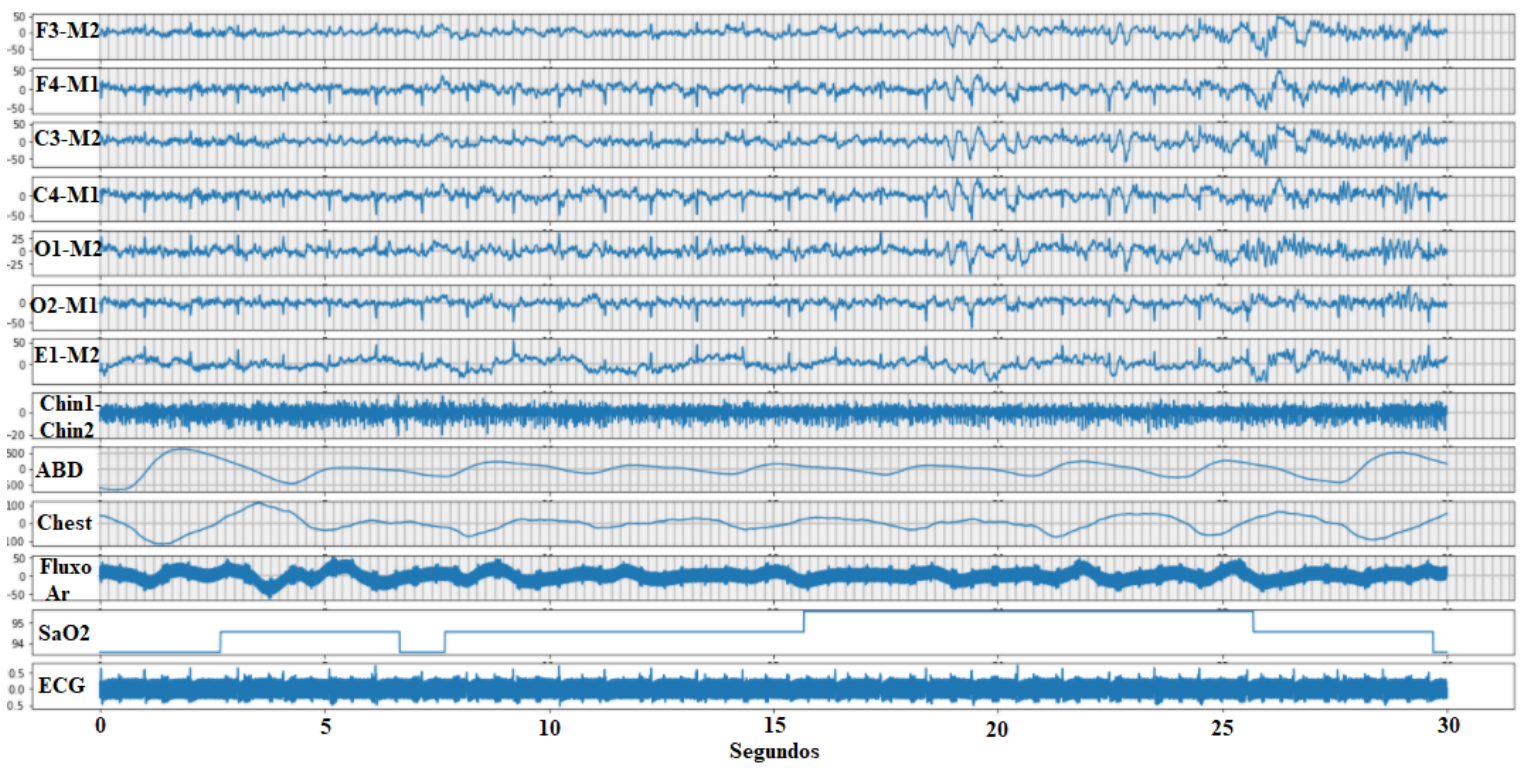

Figura 6.6: Exemplo de um segmento de Polissonografia de um Evento RERA 


\subsubsection{3}

\section{Eventos associados à apneia/hipopneia}

Esta classe designa regiões com eventos respiratórios associados à apneia/hipopneia, na Figura 6.7 é apresentado um exemplo desta classe para uma época de 30 segundos dos 6 canais EEG, na qual, se observa que para os canais F3-M2, C3-M2, C4-M1 e 01-M2 entre os 10 e 20 segundos existem alterações abruptas nas formas de onda desses sinais.

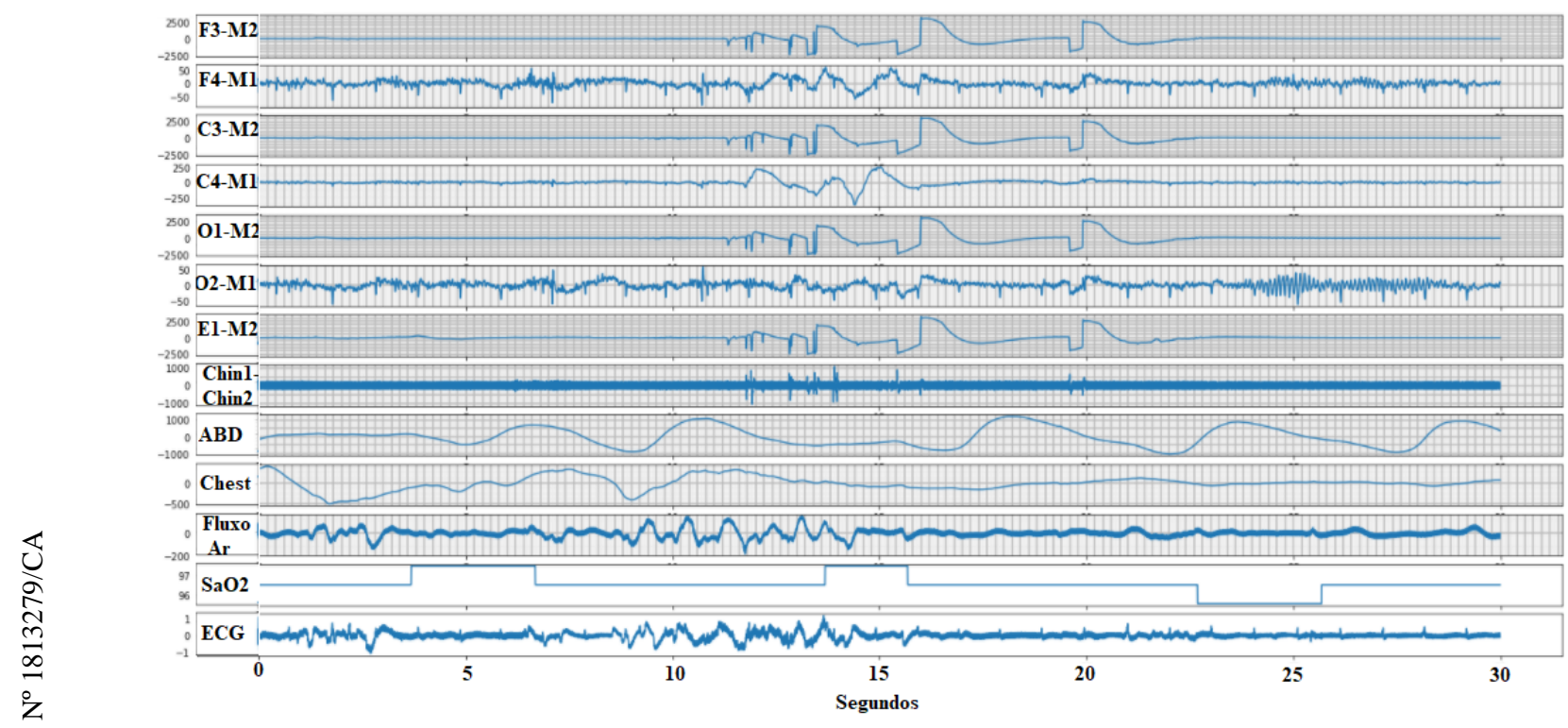

Figura 6.7: Exemplo de um segmento de Polissonografia associado a um evento de apneia/hipopneia 


\section{2 .2}

\section{FASE II: Desenvolvimento e Implementação de sistemas}

Nesta fase foram apresentados cinco sistemas baseados no uso de técnicas de aprendizado de máquina e na extração de características no domínio do tempo e da frequência: O primeiro sistema está baseado no uso de metodologias convencionalmente empregadas nas tarefas de classificação de sinais EEG e os restantes, no uso de redes neurais convolucionais (CNN) e redes LSTM. Os sistemas de Deep Learning estão inspirados em modelos propostos em $[29,76,77]$ e foram avaliadas duas técnicas para lidar com dados desbalanceados: (i) Class Weight e (ii) focal loss mencionados na seção 5.2.6 e seção 5.2.7 respectivamente.

\subsubsection{1}

\section{Notação dos dados}

Os sinais eletroencefalográficos (EEG_raw) para cada um dos indivíduos estão representados como uma matriz de tamanho $\left[N_{i}, 6\right]$ e os rótulos de classe em uma sequência $y_{i}$ de tamanho $N_{i}$, onde $N_{i}$ é o número de amostras no sinais de cada individuo (comprimento dos sinais). Devido a que cada um dos sistemas requer um tamanho de entrada especifico as dimensões dos registros foram modificadas de acordo ao sistema. Para o sistema 1, a sequência de rótulos de classe $y_{i}$ foi segmentada em épocas de 30 segundos, que resulto em uma nova sequência de rótulos de classe $Y_{i}$ com tamanho $n_{i}$, onde $n_{i}$ é calculada a partir da Equação 6-1.

$$
n_{i}=\frac{N_{i}}{F_{s} * w}=\frac{N_{i}}{(200)(30)}
$$

Onde, $F_{s}$ é a frequência de amostragem e $w$ o tamanho da janela em segundos (30 segundos), Seguidamente para cada um dos seis sinais EEG presentes em EEG_raw foram calculadas as potências médias para as bandas de frequência EEG (Delta, alfa, Beta, Teta e Gamma) para cada uma das $n_{i}$ épocas, resultando assim em uma matriz de tamanho $\left[n_{i}, 30\right]$. Na Tabela 6.2 é apresentado o resumo das notações empregadas para o sistema 1.

Tabela 6.2: Notação dos dados para o Sistema 1

\begin{tabular}{ccc}
\hline Nome & Definição & Dimensão \\
\hline$y_{i}$ & Sequência rótulos de classe & $N_{i}$ \\
$Y_{i}$ & Rótulos de classe por epoca & $n_{i}$ \\
EEG_raw & Series temporais EEG & $N_{i} \times \mathbf{6}$ \\
X_EEG & Matriz de PMB * & $n_{i} \times \mathbf{3 0}$ \\
\hline
\end{tabular}

\footnotetext{
* Potências Médias para as bandas de frequência delta, teta, alfa, gamma e beta de EEG_raw
} 
No caso dos sistemas 2, 3, 4 e 5, á matriz de entrada (EEG_raw) foi adicionado um eixo gerando uma matriz de dimensões $\left[1, N_{i}, 6\right]$, Após a nova matriz de entrada foi segmentada em épocas de 30 segundos, resultando em uma matriz de sinais com tamanho $\left[1, n_{i}, 6\right]$, no entanto para, a sequência de rótulos de classe $y_{i}$ foi codificada em formato One Hot Encoding resultando em uma matriz de tamanho $\left[y_{i}, 3\right]$. Finalmente, os dados e os rótulos de classe usados são compactados em lotes $(B a t c h)$ de $\left[B s, 1,\left(w F_{s}\right), 6\right]$ para os sinais EEG e de $[B s, 3]$ para os rótulos de classe, onde $B_{s}$ é o tamanho do subconjunto de dados de entrada para as redes em cada passo durante o treinamento. Ressaltando que o número de passos refere-se ao número total de etapas (lotes de amostras) antes de declarar que uma época terminou e iniciar a próxima época, geralmente é calculado a partir da relação $N_{i} \backslash B_{s}$, Na Tabela 6.3 é apresentado o resumo das notações empregadas para esses sistemas.

Tabela 6.3: Notação dos dados para os sistemas 2, 3, 4 e 5

\begin{tabular}{ccc}
\hline Nome & Definição & Dimensão \\
\hline$y_{i}$ & Sequência rótulos classe ${ }^{* *}$ & $N_{i} \times \mathbf{3}$ \\
EEG_raw & Series temporais EEG & $\mathbf{1} N_{i} \times \mathbf{6}$ \\
EEG_Batch & Lote series temporais EEG & $B s^{*}, \mathbf{1},\left(\mathbf{w} F_{s}\right), \mathbf{6}$ \\
Y_Batch & Lote rótulos de classe ${ }^{* *}$ & $B s^{*} \times \mathbf{3}$ \\
\hline
\end{tabular}

\footnotetext{
* Bs: Tamanho lote

** Formato One Hot Encoding
}

\subsubsection{2}

\section{Sistema 1}

Neste sistema aplica-se uma metodologia convencionalmente empregada para extração de características e análise de EEG descrita em trabalhos como [23, 78, 79]. Também de acordo com outros trabalhos da literatura [80-85], foram elegidos como métodos classificadores três técnicas amplamente usadas para tarefas de classificação em sinais EEG: (i) K-Nearest Neighbor, (ii) Naive Bayes e (iii) Random Forest. Para cada uma destas técnicas, foram estabelecidos testes que permitem a avaliação do impacto da modificação de diversos parâmetros, explicados na seção 7.1 e foi explorada uma classificação binária usando como classes eventos RERA e Sem eventos, a fim de explorar os dados e replicar os trabalhos citados anteriormente. Na Figura 6.8 é apresentado o diagrama de fluxo implementado para o desenvolvimento deste sistema e descritos por extenso a seguir: 


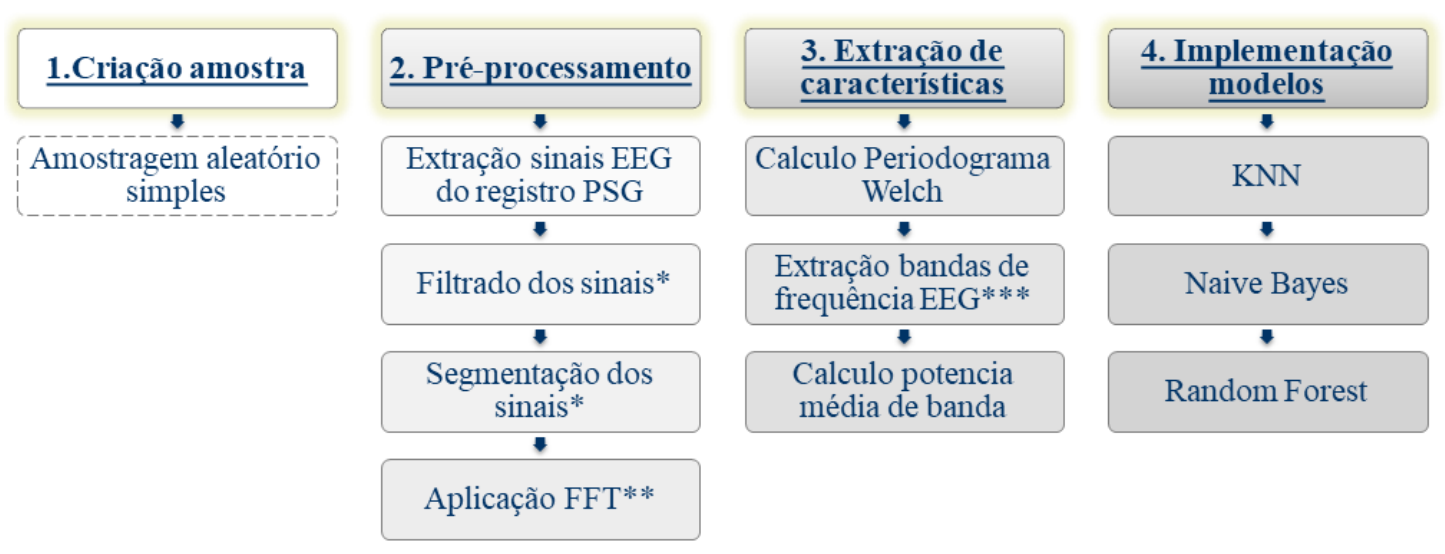

* The AASM Manual for the Scoring of Sleep and Associated Events rules, terminology and technical specifications.

$* *$ Fourier Fast Transform

*** Bandas de frequência alfa, delta, gama, beta, teta

Figura 6.8: Diagrama de fluxo dos passos para o desenvolvimento e implementação do sistema 1

1. Criação amostra: foi criada uma amostra aleatória representativa do conjunto de dados de tamanho $n$, onde $n$ foi calculado usando a Equação 6-2 [86] devido às limitações computacionais para o processamento do conjunto de dados completo.

$$
n=\frac{N p q K^{2}}{\left(e^{2}(N-1)\right)+p q K^{2}}
$$

Na expressão anterior, $n$ é o tamanho da amostra, $N$ é o tamanho da população, $K$ é valor de $\mathrm{Z}$ crítico ou nível de confiança desejado, e é o nível de precisão absoluta ${ }^{1}, p$ é proporção aproximada do fenômeno em estudo na população de referência e $q$ é a proporção da população de referência que não tem o fenômeno de estudo $(1-p)$. Para assegurar a representatividade foi escolhido um intervalo de confiança de 95\%, uma margem de erro do 5\%, o tamanho da população é de 994 indivíduos e $p$ e $q$ têm valores de 0,5 . O resultado desse cálculo é apresentado na Equação 6-3, resultando, assim, num tamanho da amostra calculado de 278 registros.

$$
n=\frac{(994)(0.5)(0.5)\left(0.95^{2}\right)}{\left.\left(0.05^{2}\right)(994-1)\right)+(0.5)(0.5)\left(0.95^{2}\right)}=278
$$

\footnotetext{
${ }^{1}$ Refere-se à amplitude do intervalo de confiança desejado na determinação do valor médio da variável de estudo [86]
} 
2. Pré-processamento: De cada registro polissonográfico (PSG) foram extraídos os sinais correspondentes às derivações eletroencefalográfica: F3-M2, F4-M1, C3-M2, C4-M1, 01-M2 e O2-M1 (canais do 0 até 5 da Tabela 6.1), representados na Figura 6.9. Depois, cada sinal foi filtrado, usando um filtro FIR passa banda na faixa de frequência de 0,1 a $45 \mathrm{~Hz}$ e segmentado em épocas de 30 segundos, seguindo as recomendações da AASM [12]. Em seguida cada época foi transformada para o domínio da frequência aplicando a Fast Fourier Transform (FFT).

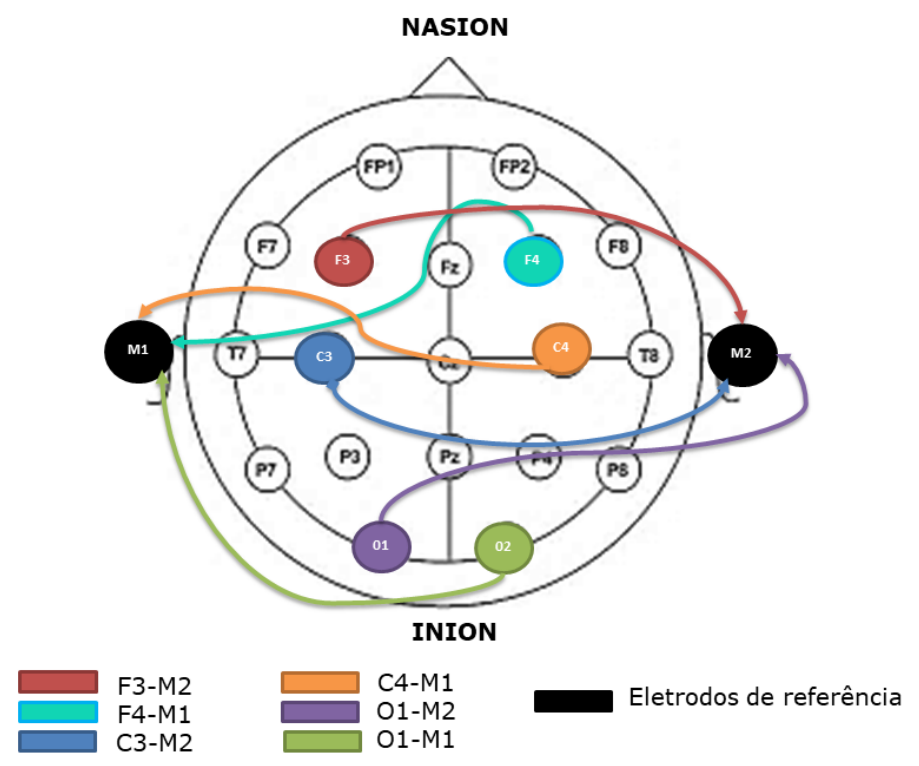

Figura 6.9: Derivações EEG contidas nos registros PSG da base de dados

3. Extração de Características: Para este passo primeiro foi calculada a densidade espectral de potência (PSD) usando o método do periodograma de Welch. Para o cálculo do periodograma foi usada uma janela de 4 segundos dado que o uso deste método permite reduzir drasticamente a variação temporal do sinal EEG em comparação com o periodograma clássico [78,87].

Logo após do cálculo do periodograma de Welch para cada segmento (Figura 6.10a), são extraídas as frequências de interesse correspondentes às bandas delta, teta, alfa, beta e gama. Em seguida calcula-se a potencia média de cada banda EEG [87]. A potência média de banda (average bandpower), é uma métrica relevante na análise de sinais EEG, consiste em calcular o resumo da contribuição de cada banda de frequência (delta, alfa, beta, teta e gama), isto é, á área sob a curva de cada banda do periodograma. Um exemplo é a região azul da Figura 6.10b, para 
(a)

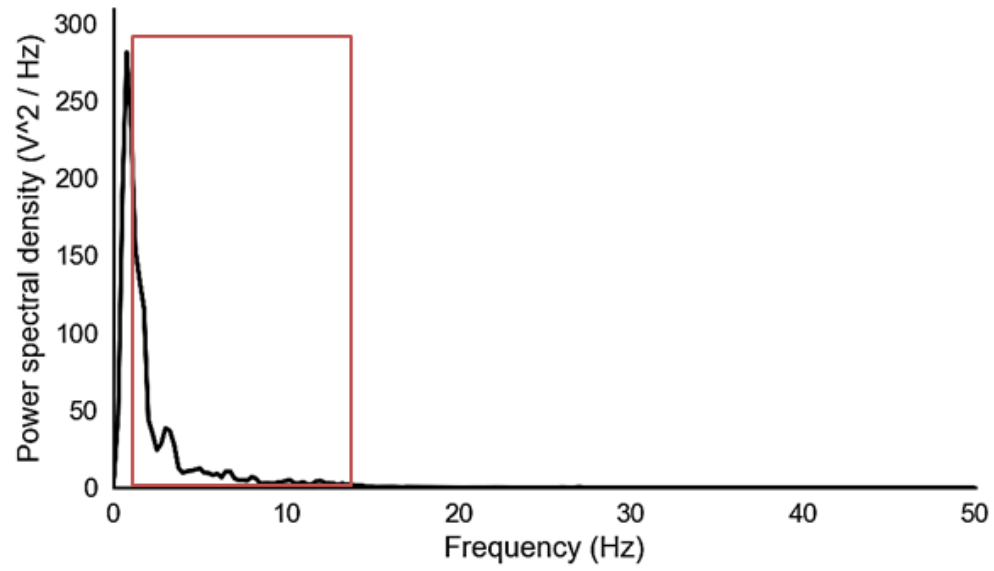

(b)

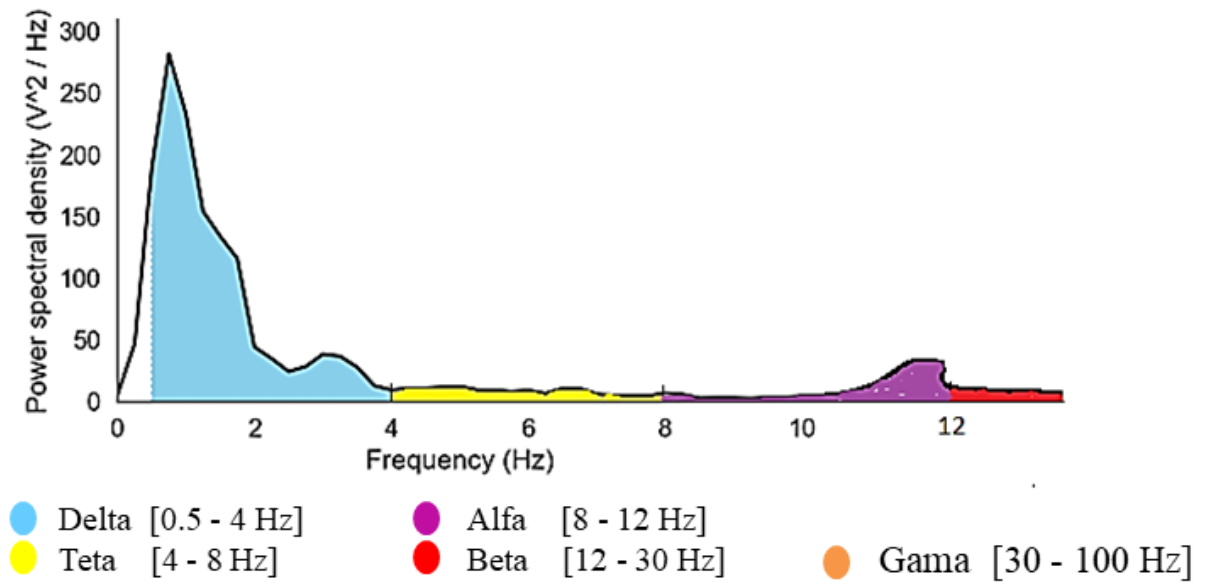

Figura 6.10: Periodograma de Welch: (a) Gráfico do periodograma de Welch, no qual o eixo $\mathrm{x}$ apresenta os bins de frequência contidas no segmento de sinal e o eixo y, a densidade de potência espectral (Power Spectral Density (PSD) usualmente medida em $\mu V^{2} / H z$ para dados EEG.(b) Periodograma de Welch dividido em suas bandas de frequência delta, teta, alfa, beta e gama,

aproximar essa área usa-se a regra composta de Simpson apresentada nas Equações 6-4 - 6-7 [88, 89],

$$
\begin{gathered}
\tau_{2}(h)=\frac{h}{6}\left(f(a)+4 \sum_{k=1}^{N}\left(f\left(x_{k-\frac{1}{2}}\right)+2 \sum_{k=1}^{N-1}\left(f\left(x_{k}+f(b)\right)\right.\right.\right. \\
\tau_{2}(h)=\approx \int_{a}^{b} f(x) d x \\
x_{j}=a+j h, j \geq 0 \\
h=\frac{(b-a)}{N}
\end{gathered}
$$

Finalmente as potências médias de cada banda de frequência EEG e as classes correspondentes foram organizados em uma matriz de tamanho 
$\left[n_{i}, 31\right]$, sendo $n_{i}$ o número de épocas de 30 segundos no registro polissonográfico, como se ilustra na Figura 6.11, conforme o descrito na seção 6.2.2.1

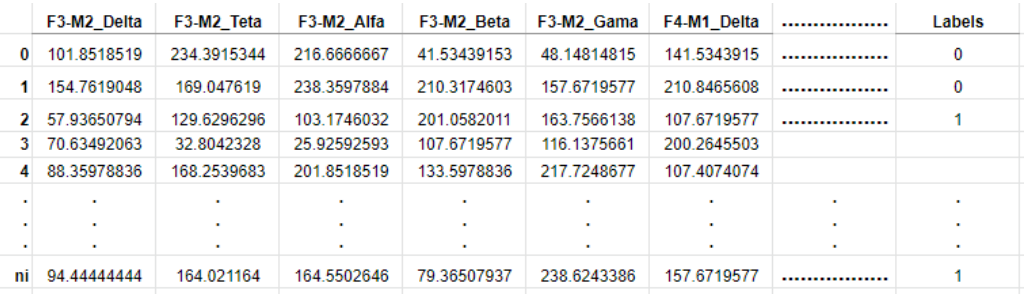

Figura 6.11: Matriz de dados polissonográficos para um individuo.

4. Implementação modelos: Uma vez foram completados os passo anteriores a matriz com as potências médias de banda e os rótulos de classe são usados para treinar os modelos de classificação: (i) K-Nearest Neighbor, (ii) Naive Bayes e (iii) Random Forest.

\subsubsection{3}

\section{Sistema 2: CNN1}

Este sistema é composto por uma arquitetura de rede, formada por três blocos convolucionais (camadas convolucionais e de amostragem Max-pooling), como é ilustrado na Figura 6.12a. Esta arquitetura é inspirada no modelo convolucional proposto em [76], que foi usado para extrair características do sinais EEG para a classificação de estágios de sono. A arquitetura proposta usa como funções de ativação não linear a função ReLu para os blocos convolutivos, e a função sigmoide para a camada de classificação. Além disso, foi inclusa uma camada BatchNormalization ao final da arquitetura, seguido de uma camada ReLU, dado que seu uso permite reduzir a mudança de covariança, permitindo que cada camada da rede aprenda de uma forma mais independente das outras, além de suavizar a função objetivo e melhorar o desempenho da rede [69].

\subsubsection{4}

\section{Sistema 3: RCNN1}

Este sistema é uma variação do sistema 2, no qual os blocos convolutivos do início da rede são seguidos por quatro redes Long Short-Term Memory (LSTM) empilhadas, o que resulta em um modelo híbrido. A ideia deste modelo, é extrair as características do sinal e manter a relação temporal dos dados EEG alongo prazo.

Na figura 6.12b é ilustrada a arquitetura de rede do sistema 3, nesta, primeiro uma rede CNN processa as épocas de 30 segundos dos dados EEG (ja- 
(a)

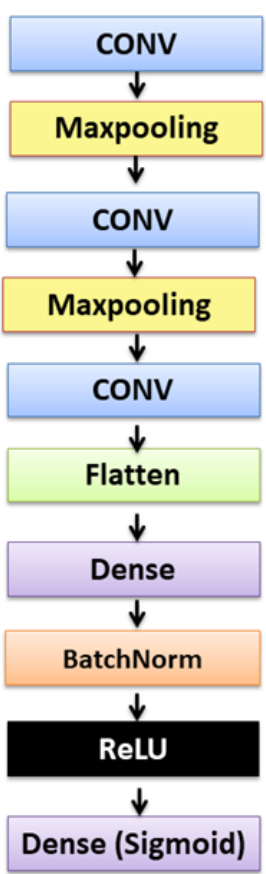

(b)

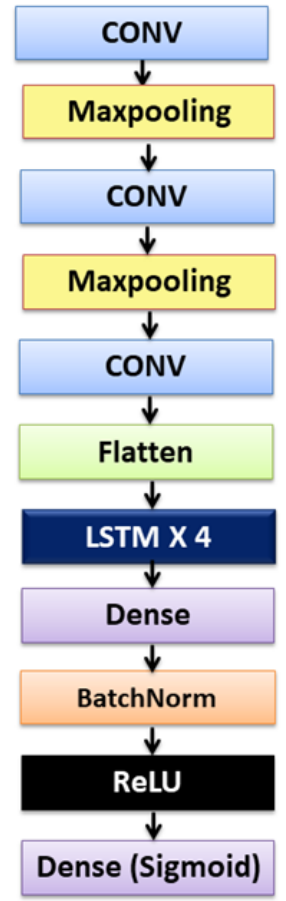

Camada Convolutiva

Camada Maxpooling

Ativação ReLU

BatchNormalization

Rede Recorrente LSTM

Figura 6.12: Arquiteturas usadas para o (a) Sistema 2 e (b) Sistema 3.

nelas de dados sem sobreposição), gerando um mapa de características que representa sequência de entrada. O mapa de características resultante dos blocos convolucionais consecutivos torna-se a entrada das redes LSTM empilhadas, as quais aprendem a dependência temporal e escolhem a informação relevante para a classificação (seção 5.2.5), após a sequência gerada pelas redes LSTM, passa a uma rede Fully Connected (FC), seguida de uma camada BatchNormalization, uma função ReLu e uma função Sigmoid para gerar a predição do evento respiratório como na arquitetura do sistema 2.

\subsubsection{5}

\section{Sistema 4: CNN2}

Este sistema é uma variação do sistema 2, no qual é proposta a adicão de Blocos convolucionais CBR. O bloco CBR está composto por uma camada convolucional, seguida de uma camada BatchNormalization (BN), uma função de ativação ReLU e uma camada de amostragem Max-pooling, como ilustrado na Figura 6.13a. Quando a convolução tem vários canais de saída, precisa-se usar BN para cada uma das saídas desses canais, uma vez que cada canal tem sua própria escala e parâmetros de deslocamento (ambos escalares). Supondose, $m$ Batches e que, para cada canal, a saída da convolução tenha altura $p$ 
(a)

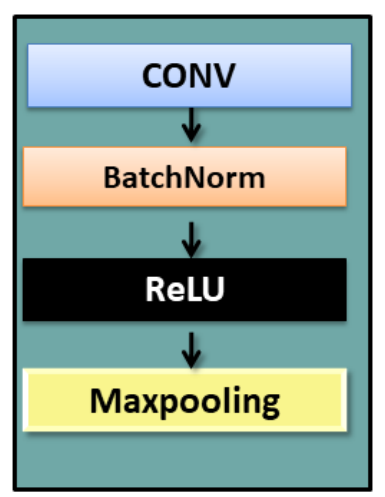

Camada Convolutiva

BatchNormalization (b)

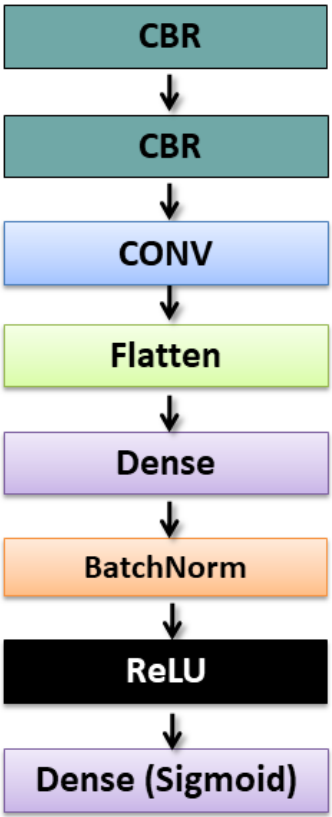

Camada Maxpooling

Rede Recorrente LSTM (c)

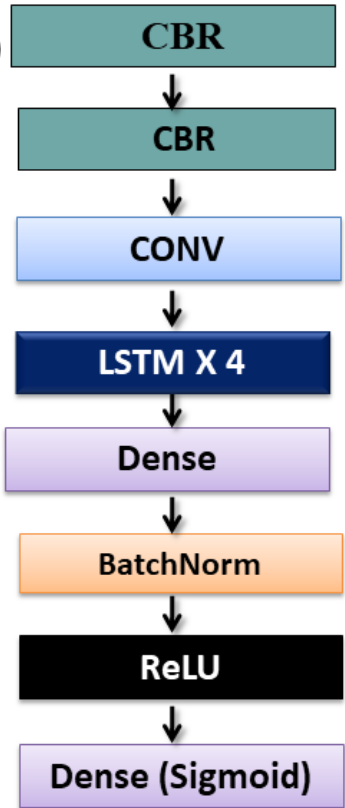

Ativação ReLU

Figura 6.13: (a) Bloco CBR e arquiteturas usadas para o (b) Sistema 4 e (c) Sistema 5.

e largura q. Para camadas convolucionais, realiza-se a normalização sobre os mxpxq elementos por canal de saída simultaneamente. Assim, são coletados todos os valores das localizações espaciais ao calcular a média e a variância e, consequentemente (dentro de um determinado canal), aplica-se a mesma média e variância para normalizar os valores em cada localização espacial [60,69].

A arquitetura usada neste sistema é composta por dois blocos CBR, seguidos de uma camada convolucional, uma camada totalmente conectada, uma camada BatchNormalization, uma função ReLu e uma função sigmoid para gerar a predição dos eventos respiratórios, como é ilustrado na Figura 6.13b.

\subsubsection{6}

\section{Sistema 5: RCNN2}

Este sistema é uma variação do sistema 4, no qual, seguido dos blocos CBR e a camada convolucional, são adicionadas quatro redes LSTM empilhadas encargadas de manter a relação temporal das características espacias extraídas nos Blocos CBR e a camada convolucional imediatamente anterior. A arquitetura usada neste sistema é ilustrada na Figura 6.13c. 


\subsection{3}

\section{FASE III: Validação dos resultados}

Nesta fase foram realizados diferentes testes com todos os sistemas, visando encontrar a melhor combinação de parâmetros em cada um deles. Para a análise da capacidade de discriminação e generalização frente a novos dados, foram avaliados os conjuntos de validação e de teste e calculadas as métricas descritas a seguir.

\subsubsection{1}

\section{Matriz de confusão}

É uma métrica que permite resumir o desempenho de um algoritmo de classificação, consiste em um matriz quadrada na qual as linhas e colunas listam o número de instâncias como proporções entre a classe real e a classe prevista. Por exemplo, na Figura 6.14 ilustra-se uma matriz de confusão, supondo que para um rótulo $P$ é a classe 1 e um rótulo $N$ é a classe 2 , ou de todas as outras classes que não são da classe 1. Nesta matriz têm-se as seguintes métricas $[60,65]$ :

- Verdadeiros Positivos (True Positives (TP)): É o número de predições positivas que foram preditas corretamente pelo classificador.

- Verdadeiros Negativos (True Negatives (TN)): É o número de predições negativas que foram preditas corretamente pelo classificador.

- Falsos Positivos (Falses Positives (FP)): É o número de predições que foram classificados incorretamente para a classe positiva sendo da classe negativa.

- Falsos Negativos(Falses Negative (FN)): É o número de predições que foram classificados incorretamente para a classe negativa sendo da classe positiva.

\subsubsection{2}

\section{Área sob a Curva de característica de operação do receptor (AUROC)}

Refere-se à probabilidade de que um classificador classifique um rótulo de classe corretamente. No caso clínico, informa a probabilidade de que um paciente escolhido aleatoriamente terá uma pontuação de risco previsto mais alto do que um paciente selecionado aleatoriamente que não experimentou um evento. Em outras palavras é uma métrica que informa a capacidade de discriminação de exemplos positivos dos negativos. É calculada como a área sob a curva ROC, aquela que expressa a compensação entre a taxa de 


\section{Classes Previstas}

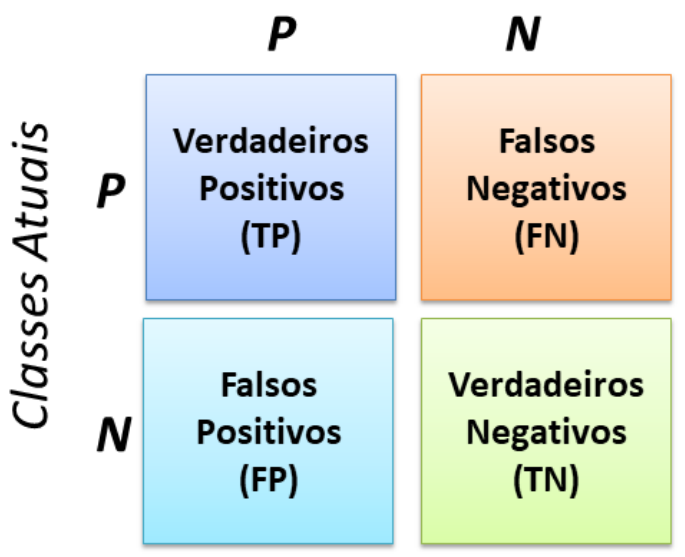

Figura 6.14: Matriz de confusão

verdadeiros positivos (TP) e a taxa de falsos positivos (FP) em diferentes limites de decisão [90,91].

\subsubsection{3}

\section{Precision}

Refere-se a qual fração das previsões da classe positiva foi realmente positiva. Para o calculo desta métrica é usada a Equação 6-8 [90].

$$
\text { Precision }=\frac{T P}{T P+F P}
$$

\subsubsection{4}

Recall

Refere-se a qual fração de todas as amostras positivas, foi corretamente prevista como positiva pelo classificador. Também é conhecido como taxa de positivo verdadeiro (True Positive Rate (TPR)), sensitividade, probabilidade de detecção e é calculada a partir da Equação 6-9 [90].

$$
\text { Recall }=\frac{T P}{T P+F N}
$$

\subsubsection{5}

\section{Área sob a curva de Recall de Precisão (AUPRC)}

Refere-se a um único número que resume as informações na curva de recuperação de precisão (PR). É calculada como área sob a curva PR, que é aquela que expressa a compensação entre precision e recall em diferentes limites de decisão [91, 92]. 


\subsubsection{6}

Acuracy

Refere-se á fração do total de amostras que foram classificadas corretamente pelo classificador. Para o cálculo desta métrica é usada a Equação 6$10[65,90]$.

$$
\text { Accuracy }=\frac{T P+T N}{T P+T N+F P+F N}
$$

\subsubsection{7}

\section{Especificidade}

Num teste é a proporção de indivíduos com teste negativo na população em estudo e que não possuem a doença descrito na Equação 6-11 [65].

$$
\text { Especificidade }=\frac{T N}{T N+F P}
$$




\section{7 \\ Resultados: apresentação, análise e discussão}

Este capítulo apresenta e descreve os resultados obtidos nas fases de desenvolvimento e implementação dos sistemas propostos e a validação de resultados, para a identificação de despertares relacionados a eventos RERA e apneia/hipopneia em registros PSG baseando-se apenas nos dados de EEG.

\section{1}

\section{Resultados Sistema 1}

Como foi mencionado na seção 6.2.2.2, este sistema foi criado a fim de explorar a classificação dos eventos RERA, devido à complexidade que requer sua detecção, aplicando uma metodologia convencionalmente empregada para extração de características e análise de EEG, descrita em trabalhos como $[23,78,79]$. Destaca-se que para este sistema foi calculada AUROC e AUPRC, objetivando a comparação com os resultados relatados na literatura. $\mathrm{Na}$ Tabela 7.1 são apresentados os resultados obtidos usando como classificador o algoritmo Random Forest. Nesta tabela apresenta-se o número de estimadores usados (\# estimadores), o número mínimo de amostras necessárias para dividir um nó interno (min_split), o número de amostras necessárias para estar em um nó folha (minleaf), a função para medir a qualidade de uma divisão (Criterion) e as métricas de avaliação usadas: AUROC e AUPRC.

Na Tabela 7.2 são apresentados os resultados obtidos usando como classificador o algoritmo Naive Bayes. Nessa tabela são apresentados os valores testados de var_smoothing, que é um valor adicionado á variância da distribuição para estabilidade do cálculo e os valores de AUROC e AUPRC obtidos para o conjunto de teste.

Já na Tabela 7.3 são apresentados os resultados obtidos usando como classificador o algoritmo de K-Nearest Neighbor (KNN), na coluna \# Vizinhos são apresentados os valores de vizinhos testados para todos os registros, e na última linha, o intervalo usado para um teste feito com uma pesquisa de grade (Grid Search), a qual permitiu obter o melhor número de vizinhos para cada registro de forma independente dos outros

Os melhores resultados foram com o uso das técnicas de Naive Bayes (AUROC: 0,509785 e AUPRC: 0,118652) e KNN (AUROC: 0,502323 e AU- 
Tabela 7.1: Resultados obtidos pelo Sistema 1 usando Random Forest.

\begin{tabular}{cccccc}
\hline \# Estimadores & minsplit & minleaf & Criterion & AUROC & AUPRC \\
\hline $\mathbf{1 0}$ & $\mathbf{4}$ & $\mathbf{1}$ & Entropy & $\mathbf{0 . 3 7 0 8 8 6}$ & $\mathbf{0 . 0 8 1 5 5 2}$ \\
60 & 1 & 2 & Gini & 0.362969 & 0.079979 \\
70 & 2 & 1 & Gini & 0.362969 & 0.079979 \\
70 & 35 & 1 & Gini & 0.363981 & 0.080221 \\
80 & 2 & 1 & Gini & 0.349788 & 0.110375 \\
90 & 2 & 1 & Gini & 0.363753 & 0.080185 \\
$\mathbf{1 0 0}$ & $\mathbf{2}$ & $\mathbf{1}$ & Gini & $\mathbf{0 . 4 5 1 8 6 5}$ & $\mathbf{0 . 1 8 9 7 6 9}$ \\
100 & 2 & 1 & Entropy & 0.363743 & 0.080241 \\
100 & 4 & 2 & Entropy & 0.36203 & 0.080295 \\
100 & 25 & 1 & Gini & 0.364568 & 0.080892 \\
100 & 2 & 1 & Gini & 0.348059 & 0.10989 \\
200 & 2 & 1 & Gini & 0.36548 & 0.080185 \\
\hline
\end{tabular}

Tabela 7.2: Resultados obtidos pelo Sistema 1 usando Naive Bayes

\begin{tabular}{ccc}
\hline \# Var_smoothing & AUROC & AUPRC \\
\hline $1^{-10}$ & $\mathbf{0 . 5 0 8 7 5 5}$ & $\mathbf{0 . 1 1 2 8 6 6}$ \\
$1^{-9}$ & 0.4823695 & 0.1869320 \\
$1^{-8}$ & 0.504403 & 0.112166 \\
$1^{-7}$ & 0.444969 & 0.122504 \\
$1^{-6}$ & 0.502848 & 0.118012 \\
$1^{-5}$ & 0.481748 & 0.128980 \\
$1^{-4}$ & 0.498511 & 0.113556 \\
$1^{-3}$ & 0.501098 & 0.115239 \\
$1^{-2}$ & $\mathbf{0 . 5 0 9 7 8 5}$ & $\mathbf{0 . 1 1 8 6 5 2}$ \\
$1^{-1}$ & 0.504255 & 0.113608 \\
1 & 0.464879 & 0.101860 \\
\hline
\end{tabular}

Tabela 7.3: Resultados obtidos pelo Sistema 1 usando KNN

\begin{tabular}{ccc}
\hline \# Vizinhos & AUROC & AUPRC \\
\hline 1 & 0.419967 & 0.084958 \\
$\mathbf{2}$ & $\mathbf{0 . 5 0 2 3 2 3}$ & $\mathbf{0 . 2 0 2 8 9 6}$ \\
3 & 0.430727 & 0.087811 \\
4 & 0.436949 & 0.089030 \\
5 & 0.441791 & 0.090064 \\
6 & 0.443476 & 0.096557 \\
7 & 0.443719 & 0.090585 \\
8 & 0.444493 & 0.090938 \\
9 & 0.445658 & 0.091071 \\
$\mathbf{1 0}$ & $\mathbf{0 . 4 4 6 1 4 4}$ & $\mathbf{0 . 0 9 1 2 4 5}$ \\
11 & 0.409184 & 0.122711 \\
{$[1-50]^{*}$} & 0.4081965 & 0.0766005 \\
\hline
\end{tabular}

* Teste usando KNN e uma pesquisa de grade nesse intervalo de vizinhos.

PRC: 0,202896). Dada a complexidade na detecção dos eventos RERA, os resultados são relativamente baixos, porém, estudos como [24] também apresentaram resultados baixos (próximos dos obtidos nesta dissertação), usando a 
mesma base de dados (Physionet Challenge 2018). Considerando os resultados obtidos neste sistema 1, foi a avaliada a possibilidade de empregar técnicas mais robustas e eficientes baseadas em Deep Learning (sistemas 2, 3, 4 e 5). 


\section{2}

\section{Resultados Sistema 2}

Para este sistema foram feitos testes com diferentes números de camadas convolutivas, número de neurônios e tamanhos de kernel. As melhores combinações desses hiperparâmetros são apresentadas na Tabela 7.4. Para esta arquitetura de rede foram usadas camadas convolutivas 2D (conv2d), o que permitiu operar os sinais em duas dimensões para extrair a maior quantidade de características possíveis. Já para cada uma das camadas de amostragem (Max-pooling), foram usados kernels de tamanho $(1,2)$, como otimizador foi usado Adam e as funções de perda foram alternadas entre focal loss e binary crossentropy. O número de neurônios na camada FC encontra-se na coluna \# D, e os tamanhos de lote usados, na coluna BS. Finalmente, a coluna TBD expressa a técnica de balanceamento de dados usadas: i) class weigth (cw) e ii) focal loss (fl). Para cada uma das configurações de rede apresentadas na Tabela 7.4, foram calculadas as métricas citadas na seção 6.2.3.

Tabela 7.4: Configurações de Hiperparâmetros para o Sistema 2.

\begin{tabular}{ccccccc}
\hline$\#$ & CNN* & Neurônios & Kernels & \#D & $B S$ & TBD \\
\hline 1 & 4 & $32,64,128,256$ & $3,3,3,3$ & 128 & 128 & - \\
2 & 4 & $32,64,128,256$ & $3,3,3,3$ & 128 & 256 & - \\
3 & 4 & $32,64,128,256$ & $3,3,3,3$ & 128 & 128 & $\mathrm{fl}$ \\
4 & 4 & $16,32,64,128$ & $3,3,3,3$ & 64 & 128 & $\mathrm{fl}$ \\
5 & 4 & $32,64,128,256$ & $3,3,3,3$ & 128 & 128 & $\mathrm{cw}$ \\
6 & 4 & $16,32,64,128$ & $3,3,3,3$ & 64 & 28 & $\mathrm{w}$ \\
7 & 3 & $16,32,64$ & $7,5,3$ & 64 & 128 & $\mathrm{fl}$ \\
8 & 4 & $32,64,128,256$ & $11,7,5,3$ & 128 & 128 & $\mathrm{fl}$ \\
9 & 4 & $16,32,64,128$ & $11,7,5,3$ & 64 & 128 & $\mathrm{cw}$ \\
10 & 4 & $32,64,128,256$ & $7,5,3,3$ & 28 & 28 & $\mathrm{fl}$ \\
\hline
\end{tabular}

* CNN:Numero camadas CNN; \# D:Neurônios camada Dense; BS:Tamanho Batch; TBD: Técnica de balanceamento de dados

Tabela 7.5: Resultados obtidos avaliando o Sistema 2.

\begin{tabular}{|c|c|c|c|c|c|c|c|c|c|}
\hline \multirow[b]{2}{*}{ \# } & \multicolumn{3}{|c|}{ Accuracy } & \multirow[t]{2}{*}{ AUROC* } & \multirow[t]{2}{*}{ AUPRC* } & \multirow[t]{2}{*}{ Normal* } & \multirow[t]{2}{*}{ RERA* } & \multirow[t]{2}{*}{ ApHip* } & \multirow[t]{2}{*}{ EBC** } \\
\hline & Treino & Val & Test & & & & & & \\
\hline 1 & 0,9537 & 0,7573 & 0,8430 & 0,8940 & 0,8165 & $118505(95,53 \%)$ & $8139(65,57 \%)$ & $28089(60,26 \%)$ & 154733 \\
\hline 2 & 0,9269 & 0,7955 & 0,8378 & 0,8849 & 0,8048 & $116525(93,94 \%)$ & $3366(27,12 \%)$ & $33888(72,70 \%)$ & 153779 \\
\hline 3 & 0,8010 & 0,7488 & 0,7684 & 0,8823 & 0,7838 & $11373(91,72 \%)$ & $6210(50,03 \%)$ & $21060(45,18 \%)$ & 141043 \\
\hline 4 & 0,7704 & 0,7459 & 0,7530 & 0,8618 & 0,7287 & $118421(95,47 \%)$ & $2780(22,40 \%)$ & $17005(36,48 \%)$ & 138.206 \\
\hline 5 & 0,8959 & 0,7800 & 0,8177 & 0,8676 & 0,7904 & $123559(99,61 \%)$ & $4134(33,31 \%)$ & $22391(48,04 \%)$ & 150.084 \\
\hline 6 & 0,8643 & 0,8148 & 0,8404 & 0,8885 & 0,8141 & $116327(93,78 \%)$ & $8689(70,00 \%)$ & $29250(62,75 \%)$ & 154266 \\
\hline 7 & 0,8162 & 0,7146 & 0,7824 & 0,8855 & 0,7803 & $108742(87,66 \%)$ & $5407(43,56 \%)$ & $29471(63,22 \%)$ & 143620 \\
\hline 8 & 0,7842 & 0,7032 & 0,7659 & 0,8703 & 0,7516 & $108178(87,21 \%)$ & $2005(16,16 \%)$ & $30396(65,21 \%)$ & 140579 \\
\hline 9 & 0,8721 & 0,8186 & 0,7558 & 0,8931 & 0,8199 & $108059(87,11 \%)$ & $2279(18,36 \%)$ & $28387(60,90 \%)$ & 138725 \\
\hline \multirow[t]{2}{*}{10} & 0,8266 & 0,7261 & 0,8170 & 0,8926 & 0,7862 & $109113(87,96 \%)$ & $5776(46,53 \%)$ & $35074(75,25 \%)$ & 149963 \\
\hline & & & & & TEC $* *$ & $124045(100 \%)$ & $12413(100 \%)$ & $46613(100 \%)$ & 183552 \\
\hline
\end{tabular}

* Calculados para o conjunto de Teste

** ApHip:apneia/hipopneia; TEC:Total Exemplos por Classe; EBC: Total Exemplos Bem Classificados 
Na Tabela 7.5 são apresentados os resultados obtidos para o cálculo de Accuracy para todos os subconjuntos de Treino, validação e Teste, os valores de AUROC e AUPRC para o conjunto de Teste, e a quantidade de exemplos bem classificados para cada uma das classes (Normal, Evento RERA e apneia/hipopneia). Na Figura 7.1a, é apresentada a comparação dos valores de Accuracy obtidos para cada configuração do sistema 2 avaliando o conjunto de teste. Uma vez que os resultados das configurações foram próximos, procedeuse a realizar uma ampliação na faixa 80 a $85 \%$, apresentada na Figura 7.1b. Nesta figura é possível diferenciar nitidamente os melhores resultados (i.e. configurações 1, 2, 5, 6 e 10) em termos de Accuracy.
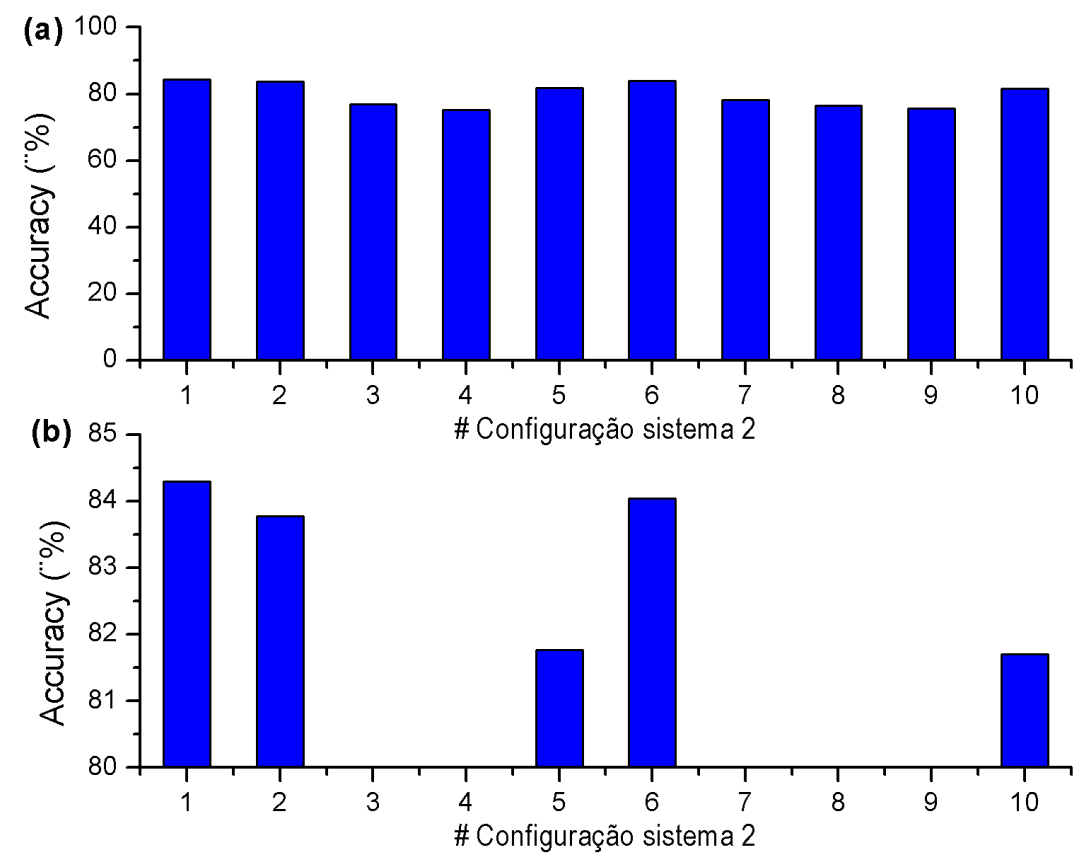

Figura 7.1: Valores de Accuracy obtidos para o Sistema 2: (a) Comparação da Accuracy alcançada por cada configuração de hiperparâmetros e (b) Zoom dos melhores resultados de Accuracy obtidos para o sistema.

Na Figura 7.2a, é apresentada a comparação dos valores de AUROC obtidos para cada configuração do sistema 2 avaliando o conjunto de teste. Como os resultados das configurações foram próximo, procedeu-se a realizar uma ampliação na faixa 0,85 a 0,90, apresentada na Figura 7.2b. Nesta figura é possível diferenciar nitidamente os melhores resultados (i.e. configurações 1, 2, 6, 9 e 10) em termos de AUROC. Já na Figura 7.3a, é apresentada a comparação dos valores de AUPRC obtidos para cada configuração do sistema 2 avaliando o conjunto de teste. Já que os resultados das configurações foram próximos procedeu-se a realizar uma ampliação na faixa 0,75 a 0,85, 
apresentada na Figura 7.3b. Nesta figura é possível diferenciar nitidamente os melhores resultados (i.e. configurações 1, 2, 6 e 9)em termos de AUPRC.

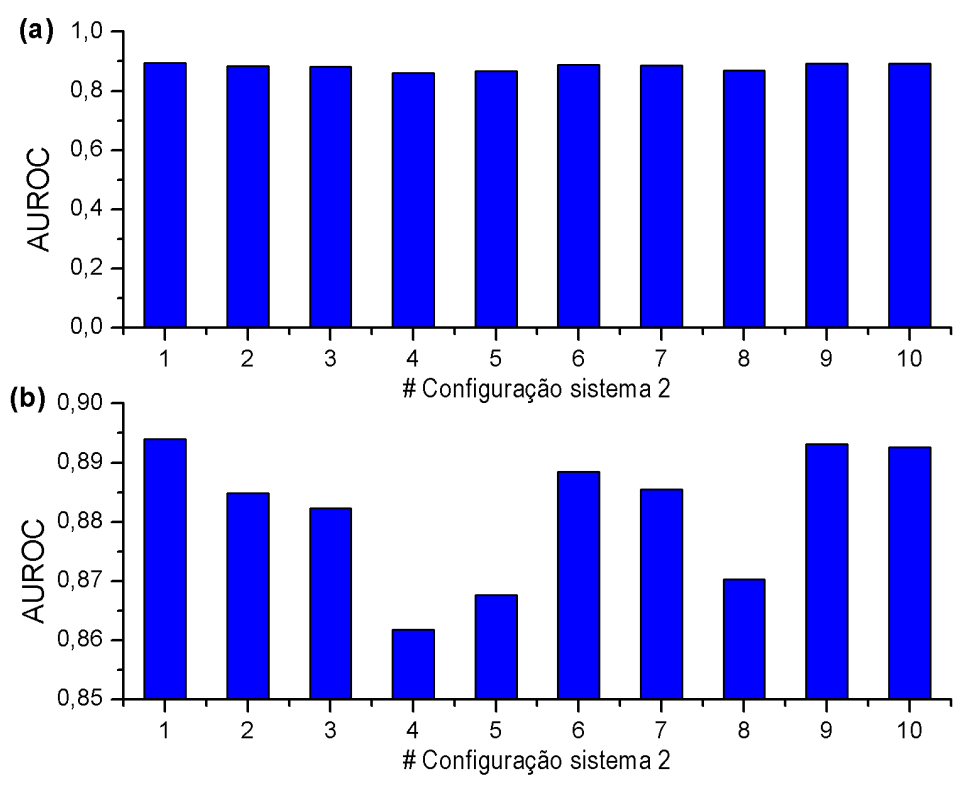

Figura 7.2: Valores de AUROC obtidos para o Sistema 2: (a) Comparação da AUROC alcançada por cada configuração de hiperparâmetros e (b) Zoom dos melhores resultados de AUROC obtidos para o sistema.
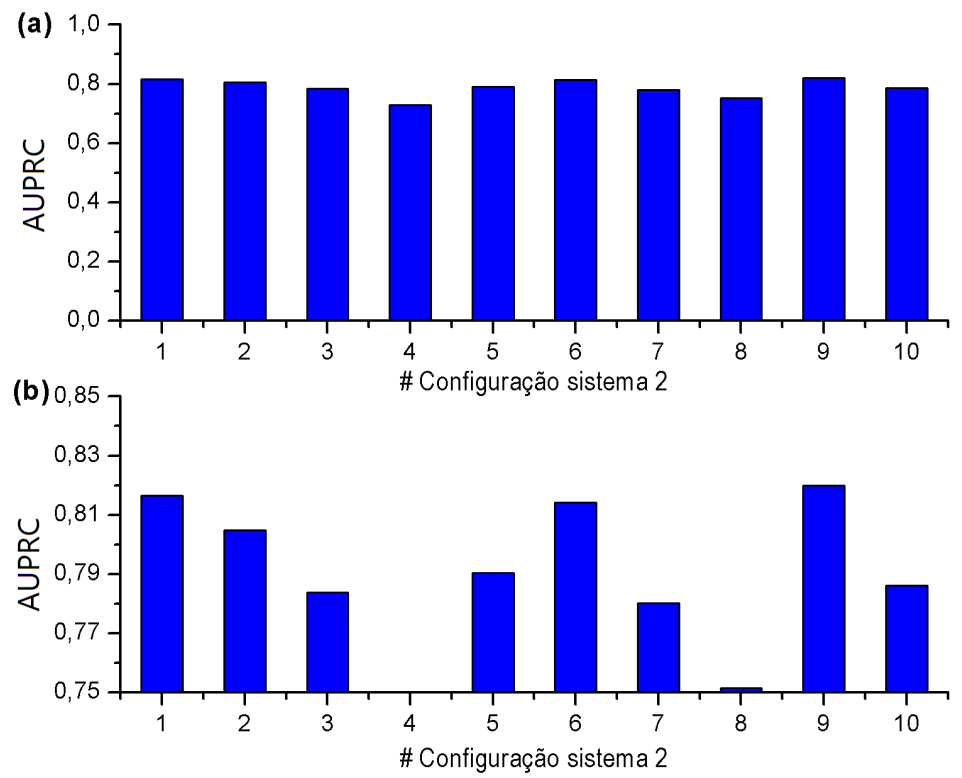

Figura 7.3: Valores de AUPRC obtidos para o Sistema 2: (a) Comparação da AUPRC alcançada por cada configuração de hiperparâmetros e (b) Zoom dos melhores resultados de AUPRC obtidos para o sistema. 


\section{3}

\section{Resultados Sistema 3}

Para este sistema foram feitos testes com diferentes número de camadas convolutivas, tamanhos de kernel e número de neurônios. As melhores combinações desses hiperparâmetros são apresentadas na Tabela 7.6. Foram usadas camadas convolutivas 1D ( conv1d), que são usadas para a extração de características em series temporais ou dados sequenciais, para cada uma das camadas de amostragem (Max-pooling), foram usados kernels de tamanho (2), como otimizador foi usado Adam e as funções de perda foram alternadas entre focal loss e binary crossentropy. O número de neurônios na camada FC e nas redes LSTM relaciona-se na coluna \# D e U respetivamente. Os tamanhos de lote (Batch size) usados na coluna BS, finalmente, a coluna TBD expressa a técnica de balanceamento de dados usadas: i) class weigth (cw) e ii) focal loss (fl).

Tabela 7.6: Configurações de Hiperparâmetros para o Sistema 3.

\begin{tabular}{ccccccccc}
\hline \# & CNN & Neurônios & kernels & LSTM & $U$ & $\# D$ & $B S$ & TBD \\
\hline 1 & 3 & $32,64,128$ & $3,3,3$ & 4 & $100,100,100,100$ & 64 & 256 & - \\
2 & 3 & $32,64,128$ & $3,3,3$ & 4 & $100,100,100,100$ & 64 & 128 & $\mathrm{fl}$ \\
3 & 3 & $32,64,128$ & $7,5,3$ & 4 & $100,100,100,100$ & 64 & 256 & $\mathrm{fl}$ \\
4 & 3 & $32,64,128$ & $7,5,3$ & 4 & $100,100,100,100$ & 64 & 256 & $\mathrm{fl}$ \\
5 & 3 & $32,64,128$ & $3,3,3$ & 3 & $100,100,100,100$ & 64 & 128 & $\mathrm{cw}$ \\
6 & 3 & $32,64,128$ & $3,3,3$ & 2 & 128,128 & 128 & 256 & $\mathrm{cw}$ \\
7 & 3 & $32,64,128$ & $7,5,3$ & 2 & 128,128 & 128 & 128 & $\mathrm{cw}$ \\
8 & 3 & $32,64,128$ & $11,7,5$ & 2 & 128,128 & 128 & 256 & $\mathrm{cw}$ \\
9 & 9 & $16,32,64$ & $3,3,3,3$ & 4 & $100,100,100,100$ & 64 & 128 & - \\
\hline
\end{tabular}

* CNN:Numero camadas CNN; \# D:Neurônios camada Dense; LSTM:Numero redes LSTM; U:Neurônios redes LSTM; BS:Tamanho Batch; TBD:Técnica de balanceamento de dados; fl:Focal loss; cw:class weight

Tabela 7.7: Resultados obtidos avaliando o Sistema 3.

\begin{tabular}{|c|c|c|c|c|c|c|c|c|c|}
\hline \multirow[t]{2}{*}{ \# } & \multicolumn{3}{|c|}{ Accuracy } & \multirow[t]{2}{*}{ AUROC* } & \multirow[t]{2}{*}{ AUPRC* } & \multirow[t]{2}{*}{ Normal* } & \multirow[t]{2}{*}{ RERA* } & \multirow[t]{2}{*}{ ApHip* } & \multirow[t]{2}{*}{$\mathrm{EBC}^{* *}$} \\
\hline & Treino & Val & Test & & & & & & \\
\hline 1 & 0,7273 & 0,2183 & 0,6647 & 0,7468 & 0,5056 & $89448(72,11 \%)$ & $2409(19,41 \%)$ & $30154(64,69 \%)$ & 122011 \\
\hline 2 & 0,7024 & 0,4109 & 0,7129 & 0,7798 & 0,5568 & $101020(81,44 \%)$ & $4445(35,81 \%)$ & $25386(54,46 \%)$ & 130851 \\
\hline 3 & 0,7514 & 0,7014 & 0,7119 & 0,5806 & 0,3731 & $90140(72,67 \%)$ & $4057(32,68 \%)$ & $36480(78,26 \%)$ & 130677 \\
\hline 4 & 0,7493 & 0,2958 & 0,5702 & 0,6139 & 0,363 & $82720(66,69 \%)$ & $3867(31,16 \%)$ & $18074(38,77 \%)$ & 104661 \\
\hline 5 & 0,8413 & 0,6479 & 0,7777 & 0,869 & 0,7653 & $117820(94,98 \%)$ & $2077(16,73 \%)$ & $22860(49,04 \%)$ & 142757 \\
\hline 6 & 0,832 & 0,7659 & 0,7134 & 0,8493 & 0,7157 & $91354(73,65 \%)$ & $4159(33,51 \%)$ & $35434(76,02 \%)$ & 130947 \\
\hline 7 & 0,849 & 0,6149 & 0,7900 & 0,877 & 0,7894 & $105052(84,69 \%)$ & $8872(71,47 \%)$ & $31075(66,67 \%)$ & 144999 \\
\hline 8 & 0,8472 & 0,7905 & 0,7651 & 0,8684 & 0,7864 & $123012(99,17 \%)$ & $7165(57,73 \%)$ & $10260(22,01 \%)$ & 140437 \\
\hline \multirow[t]{2}{*}{9} & 0,7905 & 0,7281 & 0,7116 & 0,7568 & 0,6007 & $114433(92,25 \%)$ & $3165(25,50 \%)$ & $13021(27,93 \%)$ & 130619 \\
\hline & & & & & $T E C^{* *}$ & $124045(100 \%)$ & $12413(100 \%)$ & $46613(100 \%)$ & 183552 \\
\hline
\end{tabular}

* Calculados para o conjunto de Teste

** ApHip: apneia/hipopneia;TEC: Total Exemplos por Classe; EBC: Total Exemplos Bem Classificados

Para cada uma das configurações de rede apresentadas na Tabela 7.6, foram calculadas as métricas citadas na seção 6.2.3. Na Tabela 7.7 são apresentados os resultados obtidos para o cálculo de Accuracy de todos os subconjuntos de Treino, validação e Teste; também, os valores de AUROC e AUPRC para o conjunto de Teste; e a quantidade de exemplos bem classificados para 
as classes Normal, Evento RERA e apneia/hipopneia. Finalmente, na coluna EBC é apresentado o total de exemplos que foram bem classificados.

Na Figura 7.4a, é apresentada a comparação dos valores de Accuracy obtidos para cada configuração do sistema 3 avaliando o conjunto de teste. Uma vez que os resultados das configurações foram próximos, procedeu-se a realizar uma ampliação na faixa 70 a $80 \%$, apresentada na Figura 7.4b. Nesta figura é possível diferenciar nitidamente os melhores resultados (i.e. configurações 5, 7 e 8) em termos de Accuracy.
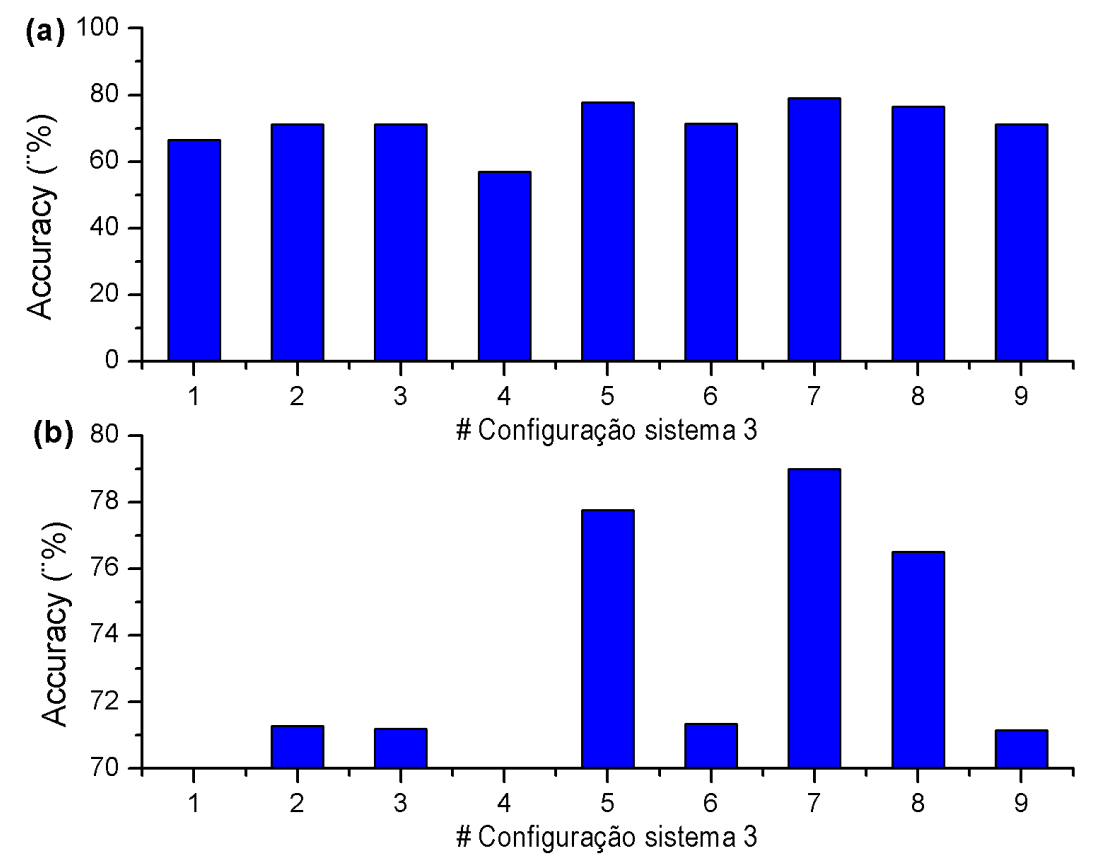

Figura 7.4: Valores de Accuracy obtidos para o Sistema 3: (a) Comparação da Accuracy alcançada por cada configuração de hiperparâmetros e (b) Zoom dos melhores resultados de Accuracy obtidos para o sistema.

Na Figura 7.5a, é apresentada a comparação dos valores de AUROC obtidos para cada configuração do sistema 3 avaliando o conjunto de teste. Como os resultados das configurações foram próximos procedeu-se a realizar uma ampliação na faixa 0,80 a 0,90 , apresentada na Figura 7.5b. Nesta figura é possível diferenciar nitidamente os melhores resultados (i.e. configurações 5,7 e 8) em termos de AUROC. Já na Figura 7.6a, é apresentada a comparação dos valores de AUPRC obtidos para cada configuração do sistema 3 avaliando o conjunto de teste. Devido a que os resultados das configurações foram próximos, procedeu-se a realizar uma ampliação na faixa 0,70 a 0,80, apresentada na Figura 7.6b. Nesta figura é possível diferenciar nitidamente os melhores resultados (i.e. configurações 5, 7 e 8) em termos de AUPRC. 

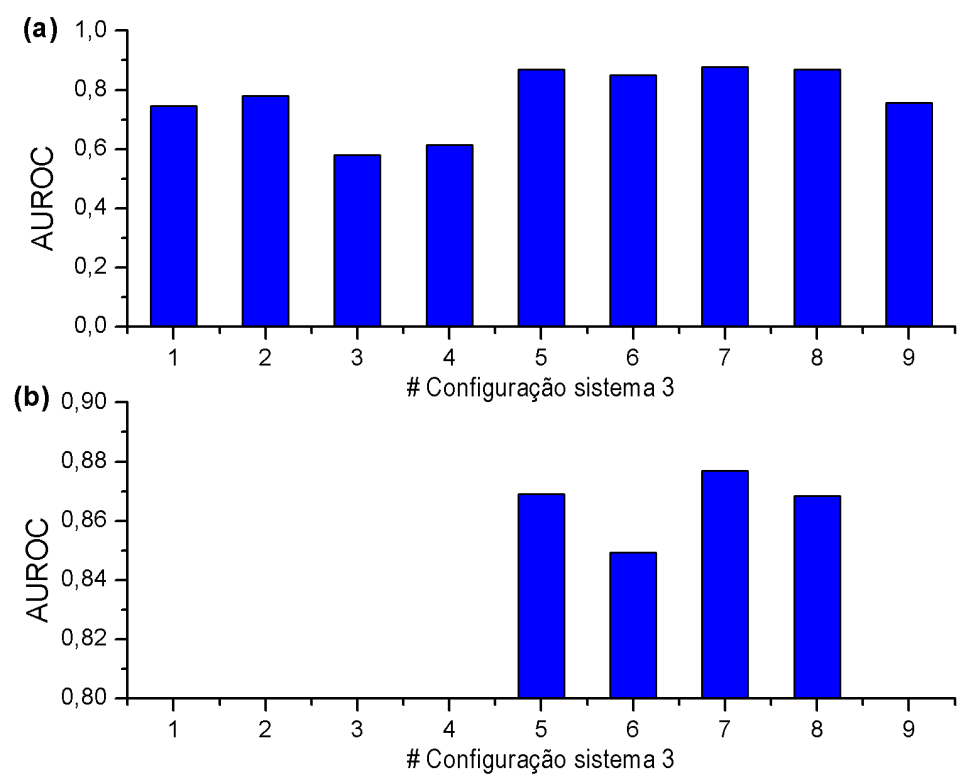

Figura 7.5: Valores de AUROC obtidos para o Sistema 3: (a) Comparação da AUROC alcançada por cada configuração de hiperparâmetros e (b) Zoom dos melhores resultados de AUROC obtidos para o sistema
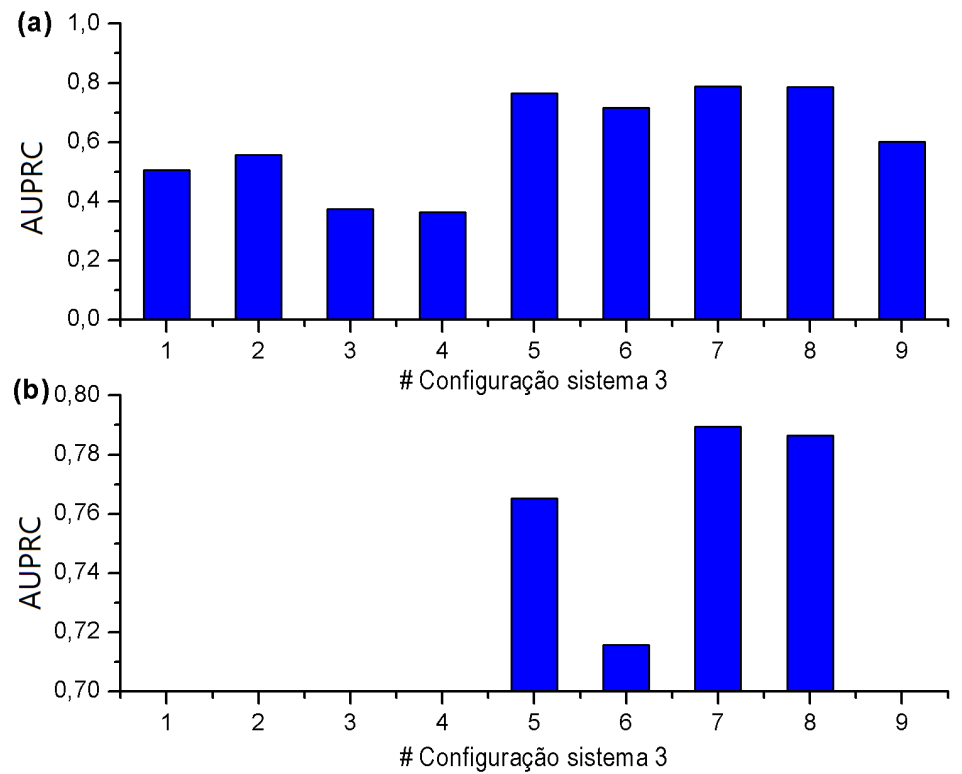

Figura 7.6: Valores de AUPRC obtidos para o Sistema 3: (a) Comparação da AUPRC alcançada por cada configuração de hiperparâmetros e (b) Zoom dos melhores resultados de AUPRC obtidos para o sistema 


\section{4}

\section{Resultados Sistema 4}

Para este sistema foram feitos testes com diferentes números de camadas convolutivas, número de neurônios e tamanhos de kernel. As melhores combinações desses hiperparâmetros são apresentadas na Tabela 7.8. Para esta arquitetura de rede foram usadas camadas convolutivas 2D (conv2d), o que permitiu operar os sinais em duas dimensões para extrair a maior quantidade de características possíveis. Já para cada uma das camadas de amostragem (Max-pooling) foram usados kernels de tamanho $(1,2)$, como otimizador foi usado Adam e as funções de perda foram alternadas entre focal loss e binary crossentropy. O número de neurônios na camada FC é mostrado na coluna \# D. Os tamanhos de lote (Batch size) usados na coluna BS, finalmente, a coluna TBD expressa a técnica de balanceamento de dados usadas: i) class weigth (cw) e ii) focal loss (fl).Para cada uma das configurações de rede apresentadas na Tabela 7.8 foram calculadas as métricas citadas na Seção 6.2.3.

Tabela 7.8: Configurações de Hiperparâmetros para o Sistema 4

\begin{tabular}{ccccccc}
\hline$\#$ & CNN & Neurônios & Kernels & \#D & $B S$ & TBD \\
\hline 1 & 4 & $32,64,128,256$ & $3,3,3,3$ & 128 & 128 & - \\
2 & 4 & $32,64,128,256$ & $3,3,3,3$ & 128 & 128 & $\mathrm{fl}$ \\
3 & 4 & $32,64,128,256$ & $3,3,3,3$ & 128 & 128 & $\mathrm{wc}$ \\
4 & 4 & $32,64,128,256$ & $11,7,5,3$ & 128 & 128 & - \\
5 & 4 & $16,32,64,128$ & $3,3,3,3$ & 128 & 128 & - \\
6 & 4 & $16,32,64,128$ & $3,3,3,3$ & 128 & 128 & $\mathrm{fl}$ \\
7 & 4 & $16,32,64,128$ & $3,3,3,3$ & 64 & 128 & $\mathrm{cw}$ \\
8 & 4 & $16,32,64,128$ & $7,5,3,3$ & 128 & 256 & $\mathrm{cw}$ \\
9 & 4 & $16,64,128,128$ & $11,7,5,3$ & 128 & 256 & $\mathrm{cw}$ \\
10 & 4 & $16,64,128,128$ & $11,7,5,3$ & 128 & 128 & $\mathrm{cw}$ \\
\hline
\end{tabular}

* CNN:Numero camadas CNN; \# D:Neurônios camada Dense; BS:Tamanho Batch; TBD: Técnica de balanceamento de dados

Tabela 7.9: Resultados obtidos avaliando o Sistema 4.

\begin{tabular}{|c|c|c|c|c|c|c|c|c|c|}
\hline \multirow[t]{2}{*}{$\#$} & \multicolumn{3}{|c|}{ Accuracy } & \multirow[t]{2}{*}{ AUROC* } & \multirow[t]{2}{*}{ AUPRC* } & \multirow[t]{2}{*}{ Normal* } & \multirow[t]{2}{*}{ RERA* } & \multirow[t]{2}{*}{ ApHip* } & \multirow[t]{2}{*}{ EBC** } \\
\hline & Treino & Val & Test & & & & & & \\
\hline 1 & 0,8797 & 0,7901 & 0,7365 & 0,8779 & 0,7943 & $103739(83,63 \%)$ & $1593(12,83 \%)$ & $29854(64,05 \%)$ & 135186 \\
\hline 2 & 0,8003 & 0,7389 & 0,7715 & 0,8852 & 07862 & $116525(93,94 \%)$ & $285(2,30 \%)$ & $24800(53,20 \%)$ & 141610 \\
\hline 3 & 0,9235 & 0,7749 & 0,7596 & 0,8878 & 0,8079 & $112573(90,75 \%)$ & $1201(9,68 \%)$ & $25652(55,03 \%)$ & 139426 \\
\hline 4 & 0,7756 & 0,7462 & 0,7656 & 0,8861 & 0,8023 & $116481(93,90 \%)$ & $1946(15,68 \%)$ & $22100(47,41 \%)$ & 140527 \\
\hline 5 & 0,7903 & 0,7181 & 0,6869 & 0,8385 & 0,7597 & $122089(98,42 \%)$ & $1474(11,87 \%)$ & $2519(5,40 \%)$ & 126082 \\
\hline 6 & 0,7844 & 0,766 & 0,7628 & 0,8732 & 0,7417 & $114827(92,57 \%)$ & $1508(12,15 \%)$ & $23678(50,80 \%)$ & 140013 \\
\hline 7 & 0,9011 & 0,8011 & 0,7522 & 0,8666 & 0,7706 & $106742(86,05 \%)$ & $1576(12,69 \%)$ & $29750(63,82 \%)$ & 138068 \\
\hline 8 & 0,9602 & 0,7949 & 0,7567 & 0,8865 & 0,7997 & $106178(85,60 \%)$ & $998(8,04 \%)$ & $31718(63,82 \%)$ & 138894 \\
\hline 9 & 0,6287 & 0,6407 & 0,7472 & 0,8546 & 0,7627 & $108059(87,11 \%)$ & $644(5,19 \%)$ & $28447(61,03 \%)$ & 137150 \\
\hline \multirow[t]{2}{*}{10} & 0,6561 & 0,654 & 0,7395 & 0,8663 & 0,7843 & $107113(86,35 \%)$ & $3871(31,18 \%)$ & $24753(53,10 \%)$ & 135737 \\
\hline & & & & & TEC $* *$ & $124045(100 \%)$ & $12413(100 \%)$ & $46613(100 \%)$ & 183552 \\
\hline
\end{tabular}

* Calculados para o conjunto de Teste

** Ap/Hip:apneia/hipopneia;TEC: Total Exemplos por Classe; EBC: Total Exemplos Bem Classificados 
Na Tabela 7.9 são apresentados os resultados obtidos para o cálculo de Accuracy de todos os subconjuntos de Treino, validação e Test; também, os valores de AUROC e AUPRC para o conjunto de Teste, e a quantidade de exemplos bem classificados para as classes Normal, Evento RERA e apneia/hipopneia. Finalmente, na coluna EBC é apresentada o total de exemplos que foram bem classificados. Na Figura 7.7a, é apresentada a comparação dos valores de Accuracy obtidos para cada configuração do sistema 4 avaliando o conjunto de teste. Uma vez que os resultados das configurações foram próximos procedeu-se a realizar uma ampliação na faixa 70 a $80 \%$, apresentada na Figura 7.7b. Nesta figura é possível diferenciar nitidamente os melhores resultados (i.e. configurações 2, 4 e 6) em termos de Accuracy.
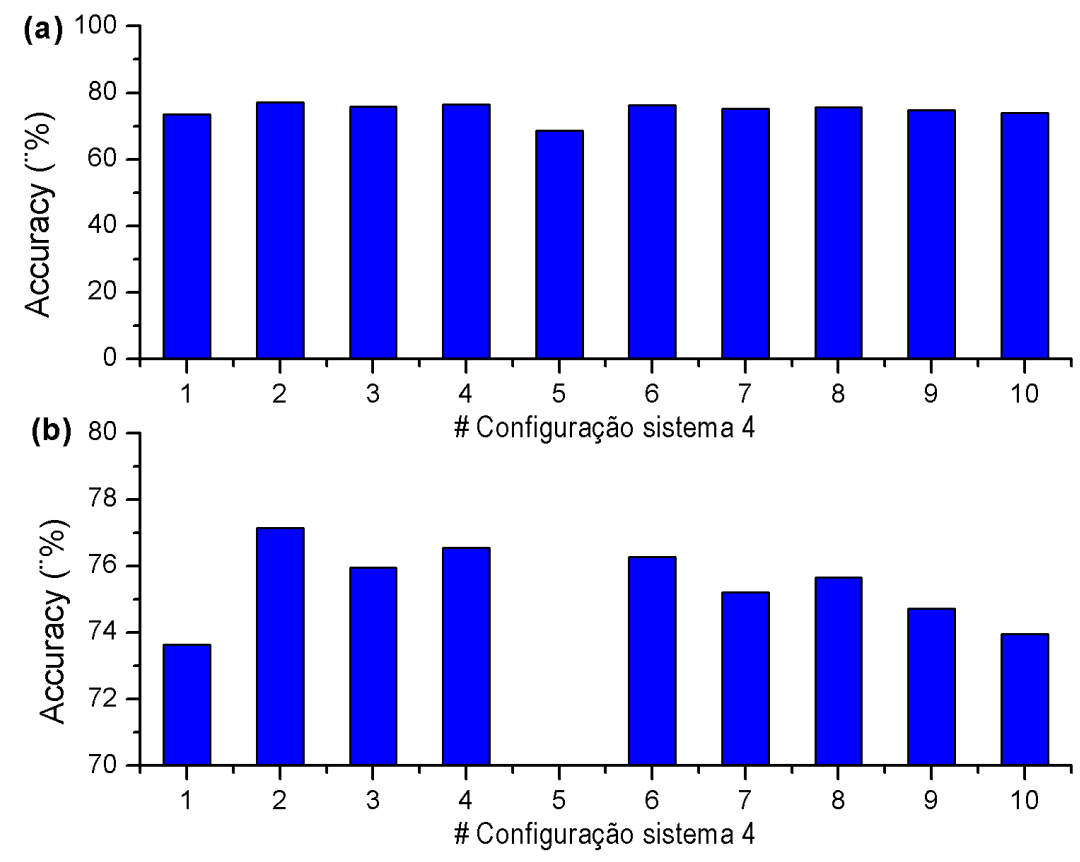

Figura 7.7: Valores de Accuracy obtidos para o Sistema 4: (a) Comparação da Accuracy alcançada por cada configuração de hiperparâmetros e (b) Zoom dos melhores resultados de Accuracy obtidos para o sistema

Na Figura 7.8a, é apresentada a comparação dos valores de AUROC obtidos para cada configuração do sistema 4 avaliando o conjunto de teste. Como os resultados das configurações foram próximos, procedeu-se a realizar uma ampliação na faixa 0,85 a 0,95, apresentada na Figura 7.8b. Nesta figura é possível diferenciar nitidamente os melhores resultados (i.e. configurações 2, 3, 4 e 8) em termos de AUROC. Já na Figura 7.9a, é apresentada a comparação dos valores de AUPRC obtidos para cada configuração do sistema 4 avaliando o conjunto de teste. Já que os resultados das configurações foram próximo, 
procedeu-se a realizar uma ampliação na faixa 0,72 a 0,82 , apresentada na Figura 7.9b. Nesta figura é possível diferenciar nitidamente os melhores resultados (i.e. configurações 1, 3, 4 e 8) em termos de AUPRC.

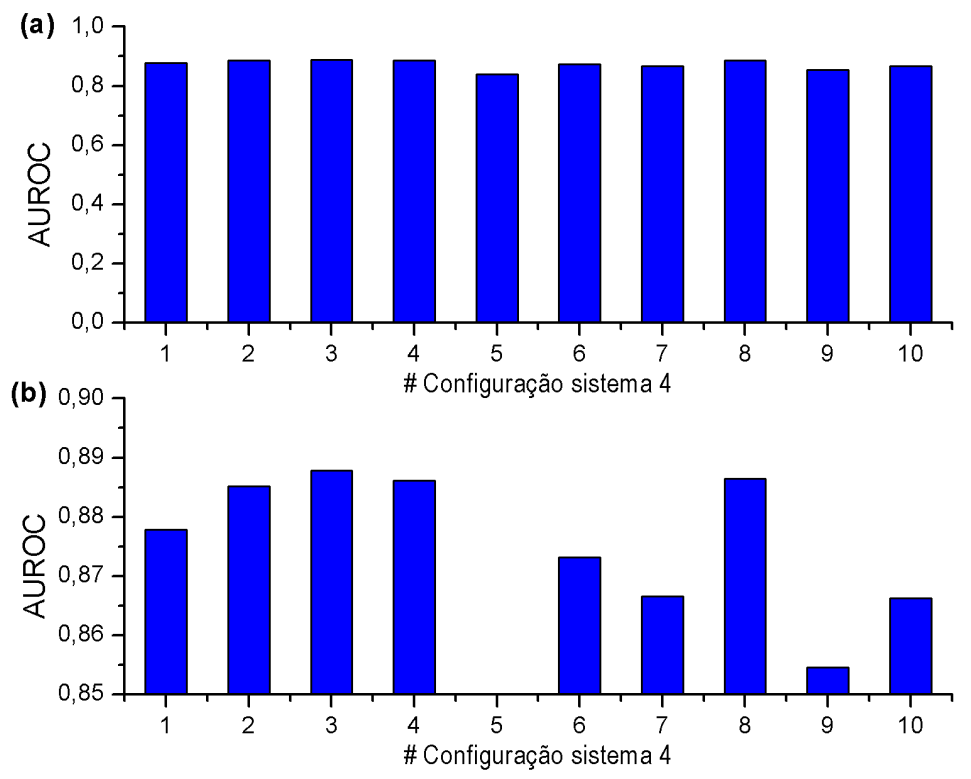

Figura 7.8: Valores de AUROC obtidos para o Sistema 4: (a) Comparação da AUROC alcançada por cada configuração de hiperparâmetros e (b) Zoom dos melhores resultados de AUROC obtidos para o sistema
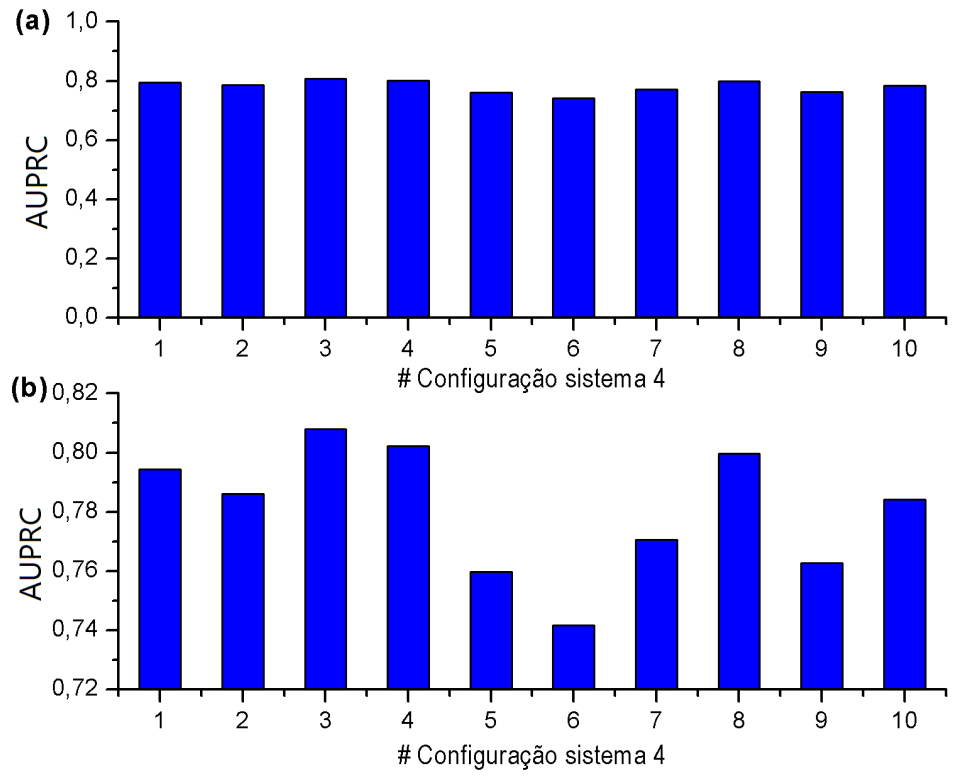

Figura 7.9: Valores de AUPRC obtidos para o Sistema 4: (a) Comparação da AUPRC alcançada por cada configuração de hiperparâmetros e (b) Zoom dos melhores resultados de AUPRC obtidos para o sistema 


\section{5}

\section{Resultados Sistema 5}

Para este sistema foram feitos testes com diferentes número de camadas convolutivas, tamanhos de kernel e número de neurônios. As melhores combinações desses hiperparâmetros são apresentados na Tabela 7.10. Foram usadas camadas convolutivas conv1d que são usadas para a extração de características em series temporais ou dados sequenciais, para cada uma das camadas de amostragem (Max-pooling) foram usados kernels de tamanho (2), como otimizador foi usado Adam e as funções de perda foram alternadas entre focal loss e binary crossentropy. O número de neurônios na camada FC e nas redes LSTM relaciona-se na coluna \# D e U respetivamente. Os tamanhos de lote (Batch size) usados na coluna BS, finalmente, a coluna TBD expressa a técnica de balanceamento de dados usadas: i) class weigth (cw) e ii) focal loss (fl).

Tabela 7.10: Configurações de Hiperparâmetros para o Sistema 5.

\begin{tabular}{ccccccccc}
\hline$\#$ & CNN & Neurônios & kernels & LSTM & $U$ & $\# D$ & $B S$ & TBD \\
\hline 1 & 3 & $32,64,128$ & $3,3,3$ & 4 & $100,100,100,100$ & 64 & 128 & - \\
2 & 3 & $32,64,128$ & $11,7,5$ & 2 & 216,128 & 128 & 256 & $\mathrm{cw}$ \\
$3^{* *}$ & 3 & $32,64,128$ & $11,7,5$ & 2 & 216,128 & 128 & 256 & $\mathrm{fl}$ \\
$4^{* *}$ & 3 & $32,64,128$ & $11,7,5$ & 2 & 216,128 & 128 & 128 & - \\
5 & 3 & $16,32,64$ & $3,3,3$ & 2 & 100,100 & 64 & 128 & $\mathrm{fl}$ \\
6 & 3 & $32,64,128$ & $3,3,3$ & 2 & 216,128 & 64 & 256 & $\mathrm{cw}$ \\
\hline
\end{tabular}

* CNN:Numero camadas CNN; \# D:Neurônios camada Dense; LSTM:Numero redes LSTM; U:Neurônios redes LSTM; BS:Tamanho Batch; TBD:Técnica de balanceamento de dados; fl: Focal loss; cw: class weight ** Camada Dropout 0,5

Tabela 7.11: Resultados obtidos avaliando o Sistema 5.

\begin{tabular}{|c|c|c|c|c|c|c|c|c|c|}
\hline \multirow[t]{2}{*}{ \# } & \multicolumn{3}{|c|}{ Accuracy } & \multirow[t]{2}{*}{ AUROC* } & \multirow[t]{2}{*}{ AUPRC* } & \multirow[t]{2}{*}{ Normal* } & \multirow[t]{2}{*}{ RERA* } & \multirow[t]{2}{*}{ ApHip* } & \multirow[t]{2}{*}{$\mathrm{EBC}^{* *}$} \\
\hline & Treino & Val & Test & & & & & & \\
\hline 1 & 0,8553 & 0,5200 & 0,8121 & 0,8788 & 0,8028 & $112196(90,45 \%)$ & $3404(27,43 \%)$ & $33456(71,77 \%)$ & 149056 \\
\hline 2 & 0,8516 & 0,8243 & 0,8061 & 0,8749 & 0,7911 & $120424(97,08 \%)$ & $2588(20,85 \%)$ & $24955(53,54 \%)$ & 147967 \\
\hline 3 & 0,7692 & 0,6792 & 0,8233 & 0,8812 & 0,7974 & $117272(94,54 \%)$ & $2814(22,67 \%)$ & $31033(66,58 \%)$ & 151119 \\
\hline 4 & 0,8533 & 0,8342 & 0,8214 & 0,8915 & 0,8097 & $114912(92,64 \%)$ & $6661(53,66 \%)$ & $29196(62,63 \%)$ & 150769 \\
\hline 5 & 0,7851 & 0,8030 & 0,7162 & 0,8087 & 0,6236 & $110047(88,72 \%)$ & $1162(9,36 \%)$ & $20259(43,46 \%)$ & 131468 \\
\hline 6 & 0,8464 & 0,8062 & 0,8163 & 0,8823 & 0,8055 & $114891(92,62 \%)$ & $2161(17,41 \%)$ & $32783(70,33 \%)$ & 149835 \\
\hline \multirow[t]{2}{*}{7} & 0,7905 & 0,7281 & 0,6473 & 0,7913 & 0,6062 & $82834(66,78 \%)$ & $2725(21,95 \%)$ & $32262(71,36 \%)$ & 118821 \\
\hline & & & & & TEC** & $124045(100 \%)$ & $12413(100 \%)$ & $46613(100 \%)$ & 183552 \\
\hline
\end{tabular}

* Calculados para o conjunto de Teste

** Ap/Hip:apneia/hipopneia;TEC: Total Exemplos por Classe; EBC: Total Exemplos Bem Classificados

Para cada uma das configurações de rede apresentadas na Tabela 7.10 foram calculadas as métricas citadas na seção 6.2.3. Na Tabela 7.11 são apresentados os resultados obtidos para o cálculo de Accuracy de todos os subconjuntos de Treino, validação e Test; Também os valores de AUROC e AUPRC para o conjunto de Teste, e a quantidade de exemplos bem classificados as clas- 
ses Normal,Evento RERA e apneia/hipopneia. Finalmente, na coluna EBC é apresentando o total de exemplos que foram bem classificados.

Na Figura 7.10a, é apresentada a comparação dos valores de Accuracy obtidos para cada configuração do sistema 5 avaliando o conjunto de teste. Devido a que os resultados das configurações foram próximos procedeu-se a realizar uma ampliação na faixa 72 a 82 \%, apresentada na Figura 7.10b. Nesta figura é possível diferenciar nitidamente os melhores resultados (i.e. configurações 1, 3, 4 e 6) em termos de Accuracy.
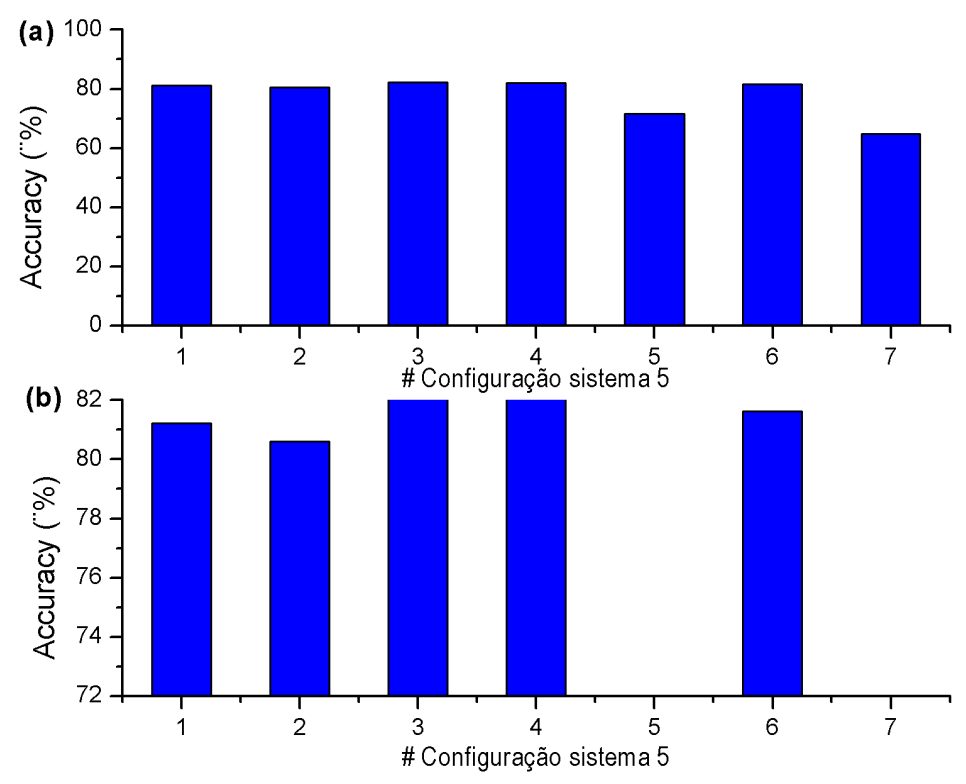

Figura 7.10: Valores de Accuracy obtidos para o Sistema 5: (a) Comparação da Accuracy alcançada por cada configuração de hiperparâmetros e (b) Zoom dos melhores resultados de Accuracyobtidos para o sistema

Na Figura 7.11a, é apresentada a comparação dos valores de AUROC obtidos para cada configuração do sistema 5 avaliando o conjunto de teste. Como os resultados das configurações foram próximo, procedeu-se a realizar uma ampliação na faixa 0,85 a 0,95, apresentada na Figura 7.11b. é apresentado uma ampliação da Figura 7.11a, entre os limites 0,85 a 0,95. Nesta figura é possível diferenciar nitidamente os melhores resultados (i.e. configurações 1, 3, 4 e 6) em termos de AUROC. Já na Figura 7.12a, é apresentada a comparação dos valores de AUPRC obtidos para cada configuração do sistema 5 avaliando o conjunto de teste. Uma vez que os resultados das configurações foram próximo, procedeu-se a realizar uma ampliação na faixa 0,75 a 0,85, apresentada na Figura 7.12b. Nesta figura é possível diferenciar nitidamente os melhores resultados (i.e. configurações 1, 3, 4 e 6) em termos de AUPRC. 

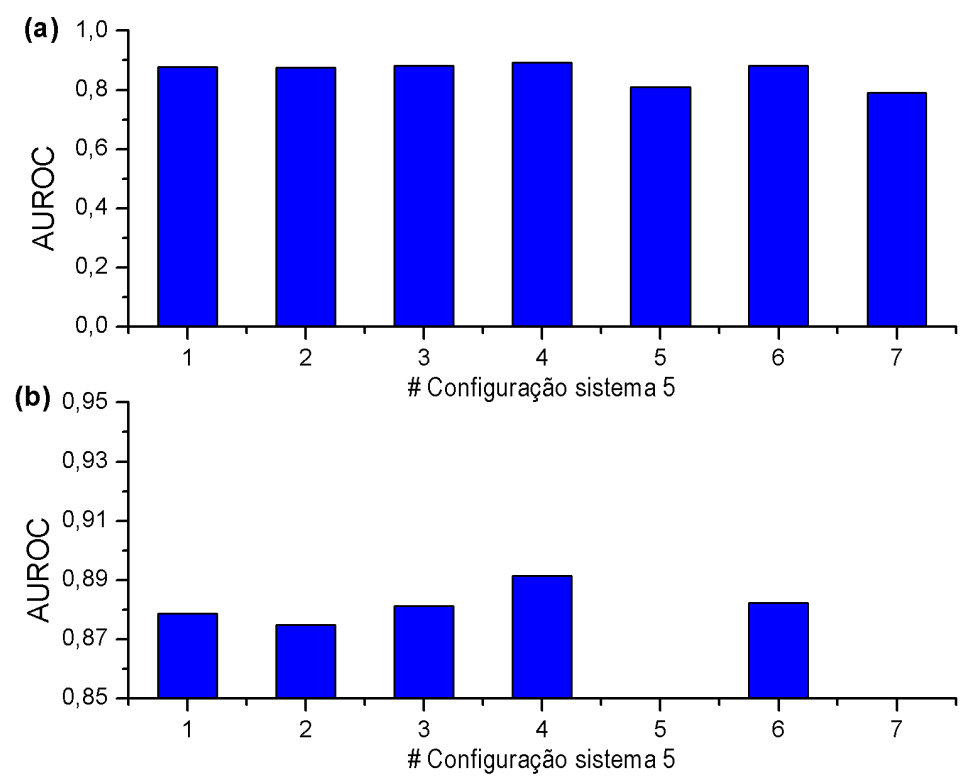

Figura 7.11: Valores de AUROC obtidos para o Sistema 5: (a) Comparação da AUROC alcançada por cada configuração de hiperparâmetros e (b) Zoom dos melhores resultados de AUROC obtidos para o sistema
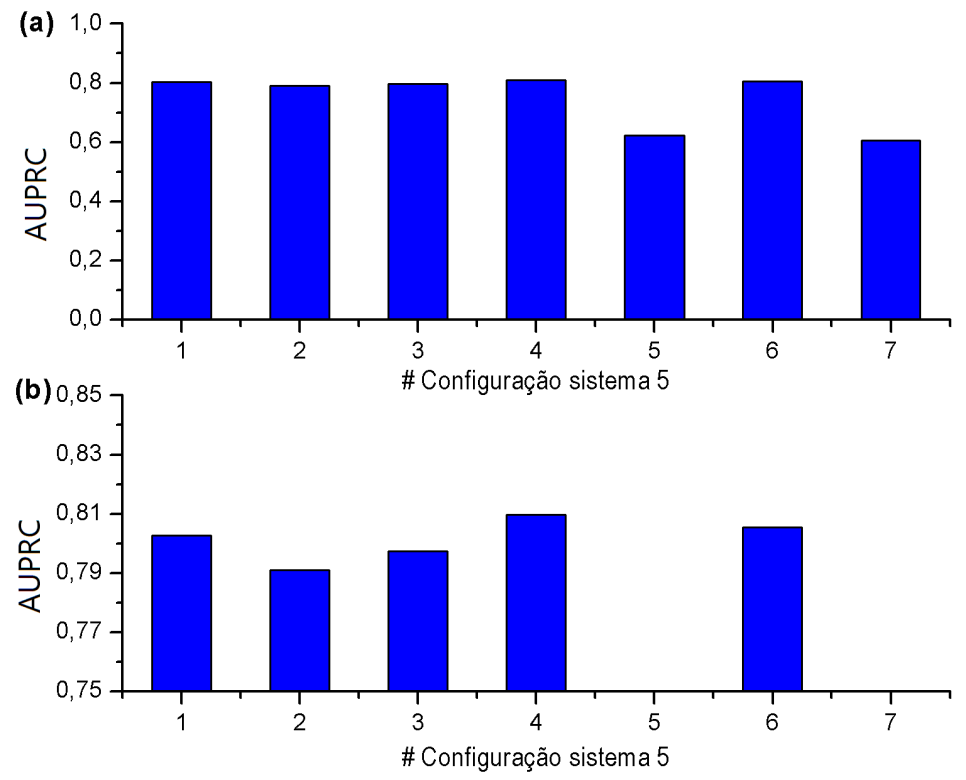

Figura 7.12: Valores de AUPRC obtidos para o Sistema 5: (a) Comparação da AUPRC alcançada por cada configuração de hiperparâmetros e (b) Zoom dos melhores resultados de AUPRC obtidos para o sistema 


\section{6}

\section{Discussão dos resultados}

Esta seção apresenta a discussão dos resultados obtidos durante as fases de desenho e implementação dos sistemas de identificação automática de despertares por eventos respiratórios propostos e de validação dos resultados.

Em relação aos resultados obtidos para os sistemas propostos nesta pesquisa (sistemas 2, 3, 4 e 5), a Tabela 7.12 resume os melhores resultados, segundo as métricas Accuracy Test, AUROC, AUPRC e quantidade de exemplos RERA bem classificados, obtidos para cada um dos sistemas propostos (i.e. sistemas 2, 3, 4 e 5). Destaca-se que os exemplos de RERA apresentaram maior dificuldade para classificação para todos os sistemas. Em termos de $A c$ curacy Test, AUPRC, AUROC e eventos RERA bem classificados. O melhores classificadores são o sistema 2 (configuração 7), seguido do sistema 5 (configuração 4), assinalados em cor cinza. Já na Tabela 7.13 são apresentadas as configurações dos melhores resultados.

Tabela 7.12: Resumo dos melhores resultados obtidos para os sistemas 2, 3, 4 e 5

\begin{tabular}{|c|c|c|c|c|c|c|c|c|c|c|}
\hline \multirow[t]{2}{*}{ Sistema } & \multirow[t]{2}{*}{ \# } & \multicolumn{3}{|c|}{ Accuracy } & \multirow[t]{2}{*}{ AUROC } & \multirow[t]{2}{*}{$A U P R C$} & \multirow[t]{2}{*}{ Normal* } & \multirow[t]{2}{*}{$R E R A^{*}$} & \multirow[t]{2}{*}{ ApHip* } & \multirow[t]{2}{*}{$\# \boldsymbol{E B C}$} \\
\hline & & Treino & Val & Test & & & & & & \\
\hline 2 & 1 & 0,9537 & 0,7573 & 0,8430 & 0,8940 & 0,8165 & $118505(95,53 \%)$ & $8139(65,57 \%)$ & $28089(60,29 \%)$ & 154.733 \\
\hline 2 & 3 & 0,8010 & 0,7488 & 0,7684 & 0,8823 & 0,7838 & $113773(91,72 \%)$ & $6210(50,03 \%)$ & $21060(45,18 \%)$ & 141.043 \\
\hline 2 & 6 & 0,8643 & 0,8148 & 0,8404 & 0,8885 & 0,8141 & $116327(93,78 \%)$ & $8689(70,00 \%)$ & $29250(62,75 \%)$ & 154266 \\
\hline 2 & 10 & 0,8266 & 0,7261 & 0,8170 & 0,8926 & 0,7862 & $109113(87,96 \%)$ & $5776(46,53 \%)$ & $35074(75,25 \%)$ & 149963 \\
\hline 3 & 2 & 0,7024 & 0,4109 & 0,7129 & 0,7798 & 0,5568 & $101020(81,44 \%)$ & $4445(35,81 \%)$ & $25386(54,46 \%)$ & 130851 \\
\hline 3 & 6 & 0,8320 & 0,7659 & 0,7134 & 0,8493 & 0,7157 & $91354(73,65 \%)$ & $4159(33,51 \%)$ & $35434(76,02 \%)$ & 130947 \\
\hline 3 & 7 & 0,8490 & 0,6149 & 0,7900 & 0,8770 & 0,7894 & $105052(84,69 \%)$ & $8872(71,47 \%)$ & $31075(66,67 \%)$ & 144999 \\
\hline 3 & 8 & 0,8472 & 0,7905 & 0,7651 & 0,8684 & 0,7864 & $123012(99,17 \%)$ & $7165(57,73 \%)$ & $10260(22,01 \%)$ & 140437 \\
\hline 4 & 1 & 0,8797 & 0,7901 & 0,7365 & 0,8779 & 0,7943 & $103739(83,63 \%)$ & $1593(12,83 \%)$ & $29854(64,05 \%)$ & 135186 \\
\hline 4 & 4 & 0,7756 & 0,7462 & 0,7656 & 0,8861 & 0,8023 & $116481(93,90 \%)$ & $1946(15,68 \%)$ & $22100(47,41 \%)$ & 140527 \\
\hline 4 & 7 & 0,9011 & 0,8011 & 0,7522 & 0,8666 & 0,7706 & $106742(86,05 \%)$ & $1576(12,69 \%)$ & $29750(63,82 \%)$ & 138068 \\
\hline 4 & 10 & 0,6561 & 0,654 & 0,7395 & 0,8663 & 0,7843 & $107113(86,35 \%)$ & $3871(31,18 \%)$ & $24753(53,10 \%)$ & 135737 \\
\hline 5 & 1 & 0,8553 & 0,5200 & 0,8121 & 0,8788 & 0,8028 & $112196(90,45 \%)$ & $3404(27,43 \%)$ & $33456(71,77 \%)$ & 149056 \\
\hline 5 & 3 & 0,7692 & 0,6792 & 0,8233 & 0,8812 & 0,7974 & $117272(94,54 \%)$ & $2814(22,67 \%)$ & $31033(66,58 \%)$ & 151119 \\
\hline 5 & 4 & 0,8533 & 0,8342 & 0,8214 & 0,8915 & 0,8097 & $114912(92,64 \%)$ & $6661(53,66 \%)$ & $29196(62,63 \%)$ & 150769 \\
\hline \multirow[t]{2}{*}{5} & 7 & 0,8464 & 0,8062 & 0,8163 & 0,8823 & 0,8055 & $114891(92,62 \%)$ & $2161(17,41 \%)$ & $32783(70,33 \%)$ & 149835 \\
\hline & & & & & & TEC** & $124045(100 \%)$ & $12413(100 \%)$ & $46613(100 \%)$ & 183552 \\
\hline
\end{tabular}

Tabela 7.13: Resumo das melhores configurações para os sistemas 2, 3, 4 e 5.

\begin{tabular}{cccccccccc}
\hline Sistema & $\#$ & $\boldsymbol{C N N}^{*}$ & $\boldsymbol{N e \boldsymbol { u }}$ & $\boldsymbol{T K}$ & $\boldsymbol{L S T M}$ & $\boldsymbol{U}$ & \# $\boldsymbol{D}$ & $\boldsymbol{B} \boldsymbol{S}$ & $\boldsymbol{T} \boldsymbol{B} \boldsymbol{D}$ \\
\hline 2 & 6 & 4 & $16,32,64,128$ & $3,3,3,3$ & - & - & 64 & 128 & $\mathrm{cw}$ \\
3 & 7 & 3 & $32,64,128$ & $7,5,3$ & 2 & 128,128 & 128 & 128 & $\mathrm{cw}$ \\
4 & 10 & 4 & $16,64,128,128$ & $11,7,5,3$ & - & - & 128 & 128 & $\mathrm{cw}$ \\
5 & $4^{* *}$ & 3 & $32,64,128$ & $11,7,5$ & 2 & 216,128 & 128 & 128 & - \\
\hline
\end{tabular}

* CNN:Numero camadas CNN; \# D:Neurônios camada Dense; LSTM:Numero redes LSTM; U:Neurônios redes LSTM; BS:Tamanho Batch; TBD:Técnica de balanceamento de dados; fl: Focal loss; cw: class weight

A Tabela 7.14 apresenta uma comparação entre os resultados reportados na literatura relacionados a identificação de despertares relacionados a eventos RERA e/ou a apnea/hipopneia e os resultados obtidos nesta pesquisa. 
Tabela 7.14: Comparação trabalhos da Literatura com os sistemas propostos

\begin{tabular}{|c|c|c|c|}
\hline Trabalho & Sinais usados & Técnica/Abordagem usada & Desempenho alcançado \\
\hline $\begin{array}{c}{[23]} \\
(2015)\end{array}$ & $\begin{array}{l}\text { EEG } \\
\text { EMG } \\
\text { Fluxo de ar }\end{array}$ & $\begin{array}{l}\text { Welch Periodogram } \\
\text { RMS } \\
\text { K-Nearest Neighbor(KNN) } \\
\text { Cross-Validation Leave-one-out } \\
\mathbf{9} \text { Registros PSG }\end{array}$ & $\begin{array}{l}\text { Objetivo: Detectar RERA, } \\
\text { Movement Arousal (MA) } \\
\text { e Spontaneus Arousal (SA). } \\
\text { Accuracy: } 0,9300\end{array}$ \\
\hline $\begin{array}{c}{[24]} \\
(2018)\end{array}$ & $\begin{array}{l}\text { EEG } \\
\text { EOG, EKG } \\
\text { SaO2, Fluxo de Ar }\end{array}$ & $\begin{array}{l}\text { Minimum Redundancy } \\
\text { Maximum Relevance (mRMR) } \\
\text { Multiple Unbiased } \\
\text { Random Forest } \\
\text { Cross-validation } \\
\text { 994 Registros PSG [25] }\end{array}$ & $\begin{array}{l}\text { Objetivo: Detectar eventos RERA } \\
\text { AUPRC: } 0,2900\end{array}$ \\
\hline $\begin{array}{c}{[93]} \\
(2018)\end{array}$ & $\begin{array}{l}\text { EEG } \\
\text { EMG queixo } \\
\text { SaO2 }\end{array}$ & $\begin{array}{l}\text { PSD } \\
\text { LDA } \\
\text { Logistic Regression (LR) } \\
\text { Single Hidden Layer (SHLN) } \\
\text { 994 Registros PSG [25] }\end{array}$ & $\begin{array}{l}\text { Objetivo: Detectar eventos RERA } \\
\text { AUROC(LR): } 0,7760 \\
\text { AUPRC(LR): } 0,1720 \\
\text { AUROC(SHLN): } 0,7790 \\
\text { AUPRC(SHLN): } 0,173\end{array}$ \\
\hline $\begin{array}{c}{[30]} \\
(2018)\end{array}$ & $\begin{array}{l}\text { EEG } \\
\text { EMG queixo } \\
\text { EMG perna } \\
\text { SaO2 } \\
\text { Fluxo transdutor } \\
\text { de pressão (PTAF) }\end{array}$ & $\begin{array}{l}\text { RCNN } \\
\text { Espectogramas } \\
\text { 15804 Registros PSG }\end{array}$ & $\begin{array}{l}\text { Objetivo: Detecção de } \\
\text { estágios de sono, } \\
\text { eventos respiratórios } \\
\text { (apneia obstrutiva, apneia central, } \\
\text { apneia mista e hipopnea) } \\
\text { e movimento dos membros. } \\
\text { Accuracy: } 0,8820\end{array}$ \\
\hline $\begin{array}{c}{[31]} \\
(2018)\end{array}$ & $\begin{array}{l}\text { EEG, EOG } \\
\text { EMG } \\
\text { SaO2, Fluxo de ar }\end{array}$ & $\begin{array}{l}\text { Redes Neurais Profundas } \\
\text { 994 Registros PSG [25] }\end{array}$ & $\begin{array}{l}\text { Objetivo: Detectar eventos RERA } \\
\text { AUROC: } 0,4000 \\
\text { AUPRC: } 0,4500\end{array}$ \\
\hline $\begin{array}{c}{[94]} \\
(2019)\end{array}$ & $\begin{array}{l}\text { EEG, EMG } \\
\text { EOG,EKG } \\
\text { SaO2, Fluxo de ar }\end{array}$ & $\begin{array}{l}\text { Trend Statistics Network (TSN) } \\
\text { Ch. invariant EEGNet (CHEN) } \\
\text { Ch. FusiNet } \\
\text { Objective Function } \\
\text { 994 Registros PSG [25] }\end{array}$ & $\begin{array}{l}\text { Objetivo: Detectar eventos RERA } \\
\text { AUPRC: } 0,5000\end{array}$ \\
\hline $\begin{array}{c}{[95]} \\
(2019)\end{array}$ & $\begin{array}{l}\text { EEG, EMG } \\
\text { Fluxo de ar, SaO2 } \\
\text { EKG, EOG }\end{array}$ & $\begin{array}{l}\text { CNN } \\
\text { RNN } \\
\text { Google Cloud ML } \\
\text { 994 Registros PSG [25] }\end{array}$ & $\begin{array}{l}\text { Objetivo: Detectar eventos RERA } \\
\text { AUROC: } 0,9160 \\
\text { AUPRC: } 0,5730\end{array}$ \\
\hline $\begin{array}{c}{[33]} \\
(2019)\end{array}$ & $\begin{array}{l}\text { EEG, EOG } \\
\text { ECG } \\
\text { EMG queixo } \\
\text { EMG Abdominal } \\
\text { EMG peito } \\
\text { Fluxo de Ar } \\
\text { SaO2 } \\
\text { Cross-Channel }\end{array}$ & $\begin{array}{l}\text { Bi-LSTM apiladas } \\
\text { 994 Registros PSG [25] }\end{array}$ & $\begin{array}{l}\text { Objetivo: Detectar eventos RERA } \\
\text { AUROC: } 0,9000 \\
\text { AUPRC: } 0,5000\end{array}$ \\
\hline $\begin{array}{c}{[29]} \\
(2019)\end{array}$ & $\begin{array}{l}\text { EEG, EOG } \\
\text { EMG, SaO2 } \\
\text { Fluxo de ar }\end{array}$ & $\begin{array}{l}\text { DCU+ Bi-LSTM } \\
\text { 994 Registros PSG [25] }\end{array}$ & $\begin{array}{l}\text { Objetivo: Detectar eventos RERA, } \\
\text { apneia (central, mista e obstrutiva) } \\
\text { e hipopneia } \\
\text { AUROC: } 0,5050 \\
\text { AUPRC: } 0,9220\end{array}$ \\
\hline Presente Trabalho & EEG & $\begin{array}{l}\text { Sistema } 2 \text { (s2) } \\
\text { Sistema } 5 \text { (s5) } \\
\text { 994 Registros PSG [25] }\end{array}$ & $\begin{array}{l}\text { AUROC(s2): } 0,8885 \\
\text { AUPRC(s2): } 0,8141 \\
\text { AUROC(s5): } 0,8214 \\
\text { AUPRC(s5): } 0,8915\end{array}$ \\
\hline
\end{tabular}

Na Tabela 7.14 verifica-se que todos os estudos descritos na literatura incorporaram, além dos sinais de EEG, vários outros parâmetros do PSG, e em todos utilizaram-se sinais fisiológicos diretamente associados a fenômenos respiratórios, como $\mathrm{SaO} 2$ e fluxo de ar. A maioria dos trabalhos empregaram a mesma base de dados do presente trabalho [25], à exceção de [23] e [30]

Na Figura 7.13 é apresentada uma comparação dos resultados de $A c$ curacy do sistema 2, selecionado por ter apresentado o melhor resultado na 
presente pesquisa, com os obtidos pelos únicos estudos que reportaram este parâmetro de desempenho [23], [30]. Estes trabalhos também foram os únicos que não empregaram a mesma base de dados utilizada na dissertação e, assim como todos os outros na literatura, fez uso de parâmetros respiratórios do PSG para realização da classificação.

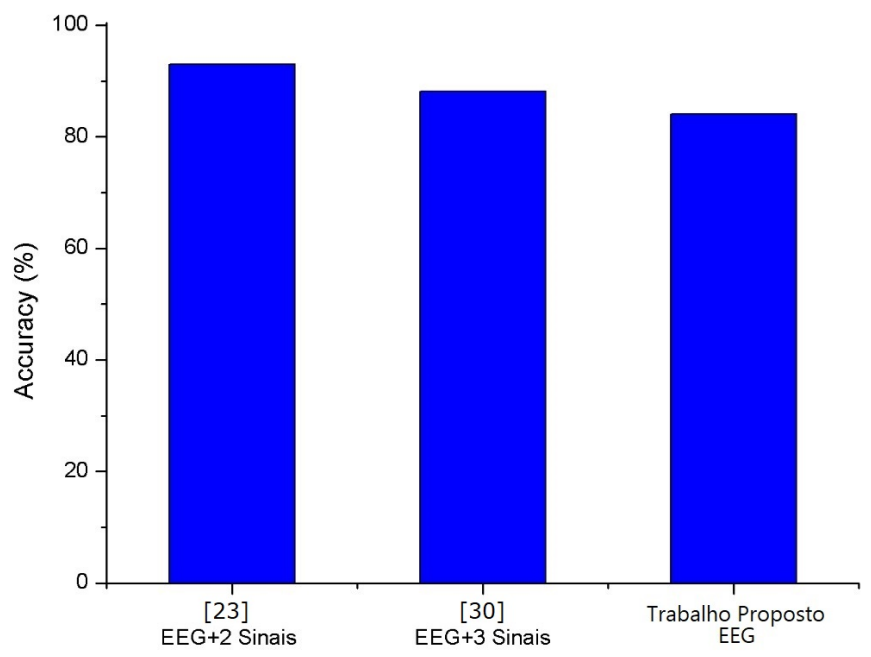

Figura 7.13: Comparação entre o presente trabalho e os trabalhos da literatura em função da Accuracy

Na Figura 7.13 evidencia-se que os resultados obtidos para Accuracy estão próximos dos valores reportados na literatura [23], [30], com aproximadamente $9 \%$ de diferença. Destaca-se, porém, que os trabalhos da literatura baseiam-se no registro de EEG em conjunto com outros parâmetros do PSG que são mais diretamente associados ao fenômeno respiratório.

Na Figura 7.14a é apresentada a comparação entre [24], [93], [31], [94], [95], [33], [29], que reportam AUROC, com o sistema 2. Observa-se que os resultados do presente trabalho estão próximos aos melhores resultados reportados na literatura especializada, [95] e [33], apresentando uma diferença de aproximadamente $11 \%$. Vale destacar novamente que os resultados obtidos no presente trabalho são baseados apenas em sinais EEG, sem adição de outros sinais fisiológicos, diferentemente dos estudos reportados na literatura.

Na Figura 7.15 é apresentada a comparação dos estudos que reportam AUPRC ( [93], [31], [95], [33], [29]), com o sistema 2 proposto no presente trabalho. Os dois melhores resultados foram obtidos por [29] e pelo sistema 2, com uma diferença de apenas $3 \%$ entre os dois. 


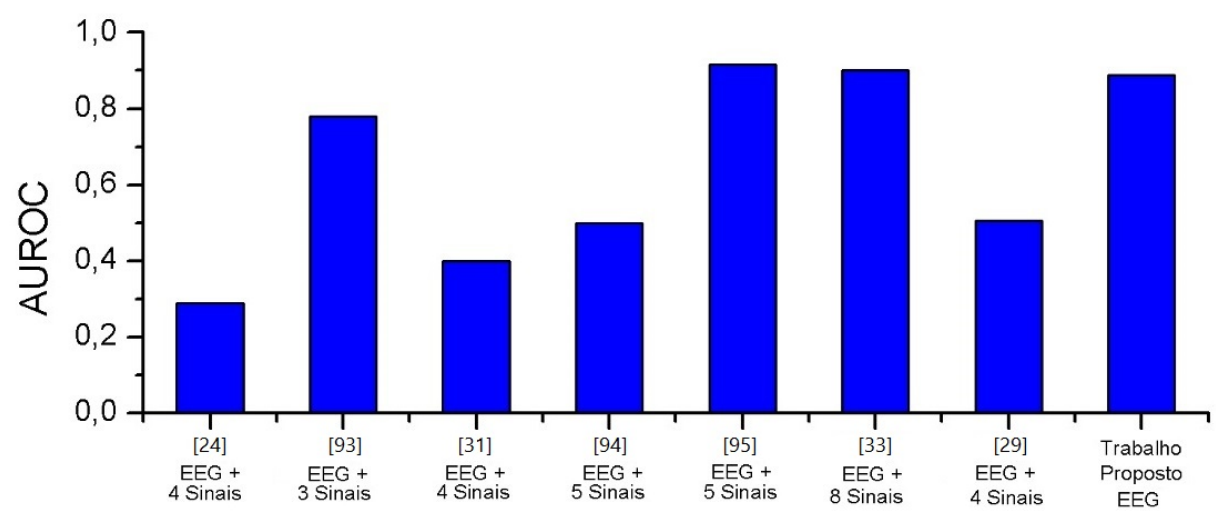

Figura 7.14: Comparação entre o presente trabalho e os trabalhos da literatura em função da AUROC

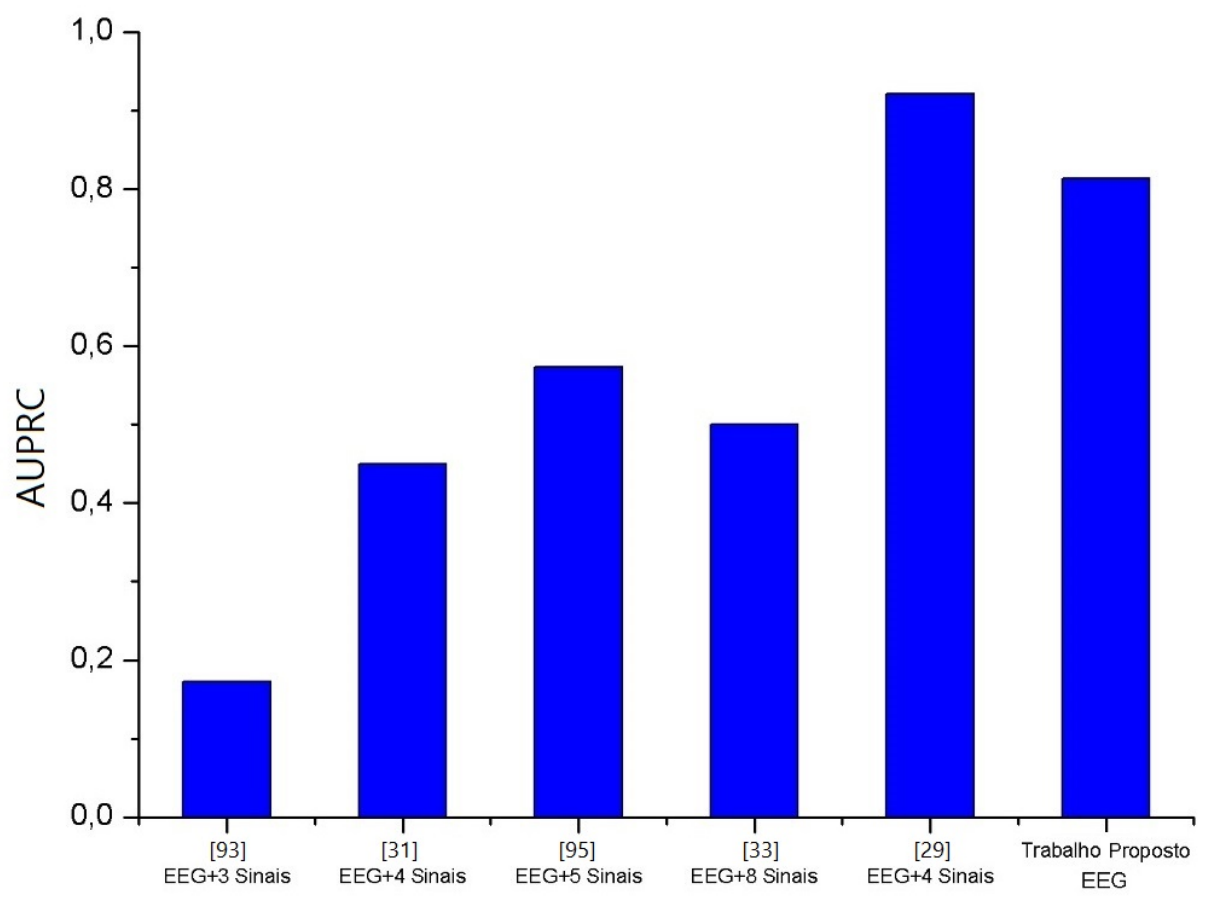

Figura 7.15: Comparação entre o presente trabalho e os trabalhos da literatura em função da AUPRC

Pode-se evidenciar na Figura 7.15 que o Sistema 2, utilizando apenas sinais de EEG, destaca-se entre os dois melhores resultados, os quais apresentaram valores significativamente superiores aos demais estudos ( [93], [31], [95], [33], [29]), ainda que estes últimos tenham empregado múltiplos parâmetros PSG adicionalmente aos registros de EEG.

A Tabela 7.15 apresenta uma comparação de desempenho entre o siste- 
mas 2 e 5 e o resultado descrito em [29], já que este último se utiliza da mesma base de dados e busca identificar o mesmo conjunto de distúrbios (Rera e Apneia/Hipopneia), mas emprega 4 parâmetros de PSG além do EEG.

Tabela 7.15: Comparação entre os desempenhos alcançados pelos sistemas 2 e 5 e os trabalhos da literatura

\begin{tabular}{cccc} 
& & \multicolumn{2}{c}{ Presente Trabalho } \\
\cline { 3 - 4 } & {$[29](2019)$} & Sistema 2 & Sistema 5 \\
\hline Parâmetros usados & EEG + 4 canais PSG & EEG & EEG \\
\hline AUROC & 0,505 & 0,8885 & 0,8214 \\
\hline AUPRC & 0,92 & 0,8141 & 0,8915 \\
\hline
\end{tabular}

Observa-se que, para AUROC, ambos sistemas 2 e 5, desenvolvidos no presente trabalho utilizando apenas sinais de EEG, apresentaram os melhores resultados, significativamente superiores a [29], que utilizou EEG e outros 4 parâmetros PSG, com a mesma base de dados e os mesmo objetivos de classificação. Para a métrica AUPRC, conforme já observado na Figura 7.15, [29] apresenta o melhor resultado, seguido do sistema 2. Na Tabela 7.15 observa-se, porém, que o sistema 5 atinge resultados ainda mais próximos de [29], lembrando que esses são os melhores resultados apresentados para AUPRC, com valores bem acima dos resultados reportados pelos outros estudos ( [93], [31], [95], [33], [29]). 


\section{8 \\ Conclusões}

Atendendo aos objetivos formulados, os resultados experimentais demostram a eficácia e potencialidade de redes neurais de aprendizado profundo para o reconhecimento de padrões, em séries temporais, que permitiram a identificação de despertares relacionados a eventos respiratórios. Os resultados dos sistemas de classificação propostos nesta pesquisa, obtidos utilizando registros de eletroencefalograma, apresentam valores de desempenho similares aos reportados na bibliografia especializada que, por sua vez, empregaram outros parâmetros do registro polissonográfico, dentre os quais aqueles diretamente associados a fenômenos respiratórios. Os resultados diferiram dos melhores desempenhos em apenas $9 \%$ para Accuracy, $11 \%$ para AUPRC e $3 \%$ para AUROC, confirmando sua eficiência, com aprimoramento do tempo de treinamento e da quantidade de hiperparâmetros envolvidos.

Com base nos resultados consolidados pela pesquisa foi possível concluir que os objetivos originalmente formulados foram plenamente atingidos. No que concerne ao primeiro objetivo específico-Implementar técnicas para lidar com o desbalanceamento dos dados e melhorar o desempenho dos sistemas na identificação de eventos Respiratórios- foram implementadas duas técnicas de balanceamento de dados: Class Weight e Focal loss, que permitiram melhorar o desempenho dos sistemas sem alterar sua relações temporais e sem aumentar o custo computacional.

Com relação ao segundo objetivo específico- Desenhar e Implementar diferentes sistemas de classificação para a identificação de despertares relacionados a eventos Respiratórios usando sinais de EEG polissonográficos- foram desenhados e implementados quatro sistemas baseados em redes de aprendizado profundo, mais especificamente em redes CNN e LSTM (i.e. sistemas 2, $3,4,5)$, para a identificação de despertares associados a eventos respiratórios como RERA e relacionados à apneia/hipopneia.

No que concerne ao terceiro objetivo específico-Analisar o desempenho obtido para cada um dos classificadores implementados frente aos modelos apresentados na literatura- Os resultados obtidos foram comparados quanto ao desempenho entre todos os sistemas propostos, considerando as métricas Accuracy, AUROC, AUPRC e matrizes de confusão. Por outro lado, no 
que concerne à comparação entre os sistemas propostos com os descritos na literatura, considerando os valores de AUROC e Accuracy, o desempenho dos sistemas propostos tiveram resultados próximos aos dos dois melhores desempenhos reportados [95] e [33] constituídos por sistemas mais robustos; e em função do AUPRC, o segundo melhor resultado foi obtido pelo presente trabalho.

A conjunção desses objetivos específicos permite concluir que o objetivo central originalmente proposto - i.e. identificação automática de despertares por eventos respiratórios, especificamente por eventos RERA (Respiratory Effort-Related Arousal) e eventos associados a apnea/hipopneia usando sinais polissonográficos de EEG.-foi plenamente alcançado.

Como resultado da contribuição da presente dissertação de mestrado, conclui-se que o uso de redes CNN e LSTM, junto como técnicas como Class Weight e Focal loss, permitiu a identificação dos despertares associados ao esforço respiratório e a eventos associados à apneia/hipopneia, melhorando a capacidade dos sistemas para generalizar novos dados, embora o conjunto de dados esteja desbalanceado. Em relação aos eventos respiratórios, o maior desafio para os sistemas propostos é a discriminação entre os despertares associados a eventos RERA e a classe normal, dado que a maioria desses eventos podem ser percebidos como despertares comuns, associados a mudanças nos estados de sono ou a falsos despertares. Já no caso dos despertares associados a eventos apneicos ou hipopneicos, a discriminação foi mais fácil para os sistemas propostos, em comparação à detecção de eventos RERA. O uso de métricas robustas, como AUROC, AUPRC e matrizes de confusão, permitiu obter uma noção mais real do comportamento dos sistemas na classificação de dados de um conjunto desbalanceado.

Os resultados do presente trabalho apontam para a possibilidade de classificação automática dos registros quanto à ocorrência de despertares ocasionados por distúrbios respiratórios com base apenas em seis canais de EEG, sem emprego de parâmetros respiratórios ou quaisquer outros parâmetros de PSG. Dessa forma, a abordagem proposta, baseada apenas em registros de EEG, pode reduzir a complexidade na avaliação diagnóstica de distúrbios respiratórios do sono e apresenta potencial aplicação para identificação desses distúrbios em avaliações eletroencefalográficas de rotina para identificação de alterações epilépticas em crianças. 


\section{1}

\section{Trabalhos Futuros}

Como desdobramentos naturais desta pesquisa de mestrado, recomendam-se os seguintes trabalhos futuros:

- Criação de sistemas conjuntos ou de aprendizado multi-tarefa (Multi-task Learning), para a classificação tanto de despertares associados a eventos respiratórios RERA, como de despertares associados a eventos apneicos ou hipopneicos, usando redes neurais profundas individuais ajustadas às características própias de cada evento.

- Classificação de apneias centrais, obstrutivas e mistas a partir da modificação dos sistemas propostos.

- Discriminação entre eventos apneicos de eventos hipopneicos, usando sistemas conjuntos o de aprendizado multi-tarefa. 


\section{Referências bibliográficas}

[1] CUENCA, E. M.. Fundamentos de fisiología. Editorial Paraninfo, 2006.

[2] DEVNANI, P. A.; HEGDE, A. U.. Autism and sleep disorders. Journal of pediatric neurosciences, 10(4):304, 2015.

[3] FRENCH, I. T.; MUTHUSAMY, K. A.. A review of sleep and its disorders in patients with parkinson's disease in relation to various brain structures. Frontiers in aging neuroscience, 8:114, 2016.

[4] BATHgATE, CHRISTINA JAYNE E EDINGER, J. D.. Critérios de diagnóstico e avaliação de distúrbios do sono. In: Elsevier, editor, MANUAL DE DISTúRBIOS DO SONO EM CONDIçõES MéDICAS, p. 325.

[5] IMIRIZALDU, J. J. Z.. Neurología. Elsevier Health Sciences, 2018.

[6] THORPY, M.. International classification of sleep disorders. In: SLEEP DISORDERS MEDICINE, p. 475-484. Springer, 2017.

[7] MATHESON, J. K.; SINGH, R. ; PACKARD, A.. Polysomnography and sleep disorders. In: THE CLINICAL NEUROPHYSIOLOGY PRIMER, p. 393-445. Springer, 2007.

[8] HEINZER, R.; VAT, S.; MARQUES-VIDAL, P.; MARTI-SOLER, H.; ANDRIES, D.; TOBBACK, N.; MOOSER, V.; PREISIG, M.; MALHOTRA, A.; WAEBER, G. ; OTHERS. Prevalence of sleep-disordered breathing in the general population: the hypnolaus study. The Lancet Respiratory Medicine, 3(4):310-318, 2015.

[9] MCNICHOLAS, W. T.; HANSSON, D.; SCHIZA, S. ; GROTE, L.. Sleep in chronic respiratory disease: Copd and hypoventilation disorders. European Respiratory Review, 28(153):190064, 2019.

[10] CHOKROVERTY, S.. Sleep Disorders Medicine: Basic Science, Technical Considerations and Clinical Aspects. Springer New York, 2017. 
[11] CHOKROVERTY, S.. Sleep Disorders Medicine E-Book: Basic Science, Technical Considerations, and Clinical Aspects, Expert Consult-Online and Print. Elsevier Health Sciences, 2009.

[12] BERRY, R. B.; BROOKS, R.; GAMALDO, C.; HARDING, S. M.; LLOYD, R. M.; QUAN, S. F.; TROESTER, M. T. ; VAUGHN, B. V.. The AASM Manual for the Scoring of Sleep and Associated Events RULES, TERMINOLOGY AND TECHNICAL SPECIFICATIONS (version 2.4), 2017.

[13] CHOKROVERTY, S.; FERINI-STRAMBI, L.. Oxford textbook of sleep disorders. Oxford University Press, 2017.

[14] PENZEL, T.; HIRSHKOWITZ, M.; HARSH, J.; CHERVIN, R. D.; BUTKOV 5, N.; KRYGER, M.; MALOW, B.; VITIELLO, M. V.; SILBER, M. H.; KUSHIDA, C. A. ; OTHERS. Digital analysis and technical specifications. Journal of clinical sleep medicine, 3(02):109-120, 2007.

[15] LIANG, S.-F.; KUO, C.-E.; HU, Y.-H.; PAN, Y.-H. ; WANG, Y.-H.. Automatic stage scoring of single-channel sleep eeg by using multiscale entropy and autoregressive models. IEEE Transactions on Instrumentation and Measurement, 61(6):1649-1657, 2012.

[16] OleSEN, A. N.; CHRISTENSEN, J. A.; SORENSEN, H. B. ; JENNUM, P. J.. A noise-assisted data analysis method for automatic eogbased sleep stage classification using ensemble learning. In: 2016 38TH ANNUAL INTERNATIONAL CONFERENCE OF THE IEEE ENGINEERING IN MEDICINE AND BIOLOGY SOCIETY (EMBC), p. 3769-3772. IEEE, 2016.

[17] Olesen, A. N.; JenNUM, P.; PEPPARD, P.; MIGNOT, E. ; SORENSEN, H. B.. Deep residual networks for automatic sleep stage classification of raw polysomnographic waveforms. In: 2018 40TH ANNUAL INTERNATIONAL CONFERENCE OF THE IEEE ENGINEERING IN MEDICINE AND BIOLOGY SOCIETY (EMBC), p. 1-4. IEEE, 2018.

[18] MATSIKI, D.; DELIGIANNI, X.; VLACHOGIANNI-DASKALOPOULOU, E. ; HADJILEONTIADIS, L. J.. Wavelet-based analysis of nocturnal snoring in apneic patients undergoing polysomnography. In: 2007 29TH ANNUAL INTERNATIONAL CONFERENCE OF THE IEEE ENGINEERING IN MEDICINE AND BIOLOGY SOCIETY, p. 1912-1915. IEEE, 2007. 
[19] JAMASEBI, R.; REDLINE, S. ; LOPARO, K.. Novel polysomnography derived features as biomarkers for sleep dynamics. In: 2008 30TH ANNUAL INTERNATIONAL CONFERENCE OF THE IEEE ENGINEERING IN MEDICINE AND BIOLOGY SOCIETY, p. 1611-1614. IEEE, 2008.

[20] TORTEROLO, P.; CASTRO-ZABALLA, S.; CAVELLI, M. ; GONZALEZ, J.. Arousal and normal conscious cognition. Arousal in Neurological and Psychiatric Diseases, p. 1, 2019.

[21] DE LOS SANTOS, M.; HIRSHKOWITZ, M.. Scoring of sleep stages, breathing, and arousals. Oxford Textbook of Sleep Disorders, p. 71, 2017.

[22] ÁLVAREZ-ESTÉVEZ, D.; MORET-BONILLO, V.. Identification of electroencephalographic arousals in multichannel sleep recordings. IEEE Transactions on Biomedical Engineering, 58(1):54-63, 2010.

[23] SHAHRBABAKI, S. S.; DISSANAYAKA, C.; PATTI, C. R. ; CVETKOVIC, D.. Automatic detection of sleep arousal events from polysomnographic biosignals. In: 2015 IEEE BIOMEDICAL CIRCUITS AND SYSTEMS CONFERENCE (BIOCAS), p. 1-4. IEEE, 2015.

[24] BHATTACHARJEE, T.; DAS, D.; ALAM, S.; RAO, A.; GHOSH, P. K.; LOHANI, A. R.; BANERJEE, R.; CHOUDHURY, A. D. ; PAL, A.. Sleeptight: Identifying sleep arousals using inter and intra-relation of multimodal signals. In: 2018 COMPUTING IN CARDIOLOGY CONFERENCE (CINC), volumen 45, p. 1-4. IEEE, 2018.

[25] HOSPITALS, M. G.; LABORATORY, C. C. N. ; THE CLINICAL DATA ANIMATION LABORATORY. Physionet/cinc challenge 2018: Training/test sets.

[26] SOFAER, H. R.; HOETING, J. A. ; JARNEVICH, C. S.. The area under the precision-recall curve as a performance metric for rare binary events. Methods in Ecology and Evolution, 10(4):565-577, 2019.

[27] GOODFELlOW, I.; BENGIO, Y. ; COURVILLE, A.. Deep Learning. MIT Press, 2016. http://www.deeplearningbook.org.

[28] LAZIĆ, I. M.; JAKOVLJEVIĆ, N. M.; DESPOTOVIĆ, D. M. ; LONČARTURUKALO, T. G.. Automatic detection of respiratory effort related arousals from polysomnographic recordings. In: 2018 COMPUTING IN CARDIOLOGY CONFERENCE (CINC), volumen 45, p. 1-4. IEEE, 2018. 
[29] POURBABAEE, B.; PATTERSON, M.; PATTERSON, M. ; BENARD, F.. Sleepnet: automated sleep analysis via dense convolutional neural network using physiological time series. Physiological measurement, 40(8):084005, 2019.

[30] BISWAL, S.; SUN, H.; GOPARAJU, B.; WESTOVER, M. B.; SUN, J. ; BIANCHI, M. T.. Expert-level sleep scoring with deep neural networks. Journal of the American Medical Informatics Association, 25(12):1643-1650, 2018.

[31] PATANE, A.; GHIASI, S.; SCILINGO, E. P. ; KWIATKOWSKA, M.. Automated recognition of sleep arousal using multimodal and personalized deep ensembles of neural networks. In: 2018 COMPUTING IN CARDIOLOGY CONFERENCE (CINC), volumen 45, p. 1-4. IEEE, 2018.

[32] ZABIHI, M.; RAD, A. B.; KIRANYAZ, S.; SÄRKKÄ, S. ; GABBOUJ, M.. 1d convolutional neural network models for sleep arousal detection. arXiv preprint arXiv:1903.01552, 2019.

[33] BAHRAMI RAD, A.; ZABIHI, M.; ZHAO, Z.; GABBOUJ, M.; KATSAGGELOS, A. K. ; SÄRKKÄ, S.. Automated polysomnography analysis for detection of non-apneic and non-hypopneic arousals using feature engineering and a bidirectional lstm network. arXiv, p. arXiv-1909, 2019.

[34] VELAYOS, J. L.. Medicina del sueño: enfoque multidisciplinar. Buenos Aires. Editorial medica Panamericana, 2009.

[35] HALES, R. E.; YUDOFSKY, S. C. ; OTHERS. Tratado de psiquiatría clínica. The American Psychiatric Publishing., 2004.

[36] CARLEY, DAVID W, Y. S. S. F.. Physiology of sleep. Espectro de diabetes, 29(1):5-9, 2016.

[37] RÁPIDA, G.. Guía de práctica clínica sobre trastornos del sueño en la infancia y adolescencia en atención primaria. 2011.

[38] GUTIÉRREZ, C. T.; TORRES, F. D. ; PÉREZ, I.. Sueño: carecterísticas generales. patrones fisiológicos y fisiopatológicos en la adolescencia. Ciencias de la salud, 11(3):333-348, 2013.

[39] CAMPOS, M. S.. G. pin arboledas. Pediatríalntegral, p. 358, 2018.

[40] LYDIC, R.; BIEBUYCK, J. F.. Clinical physiology of sleep. Springer, 2013. 
[41] MALHOTRA, R. K.; AVIDAN, A. Y.. Sleep stages and scoring technique. Atlas of Sleep Medicine, p. 77-99, 2013.

[42] LEE-CHIONG JR, T.. Biology of Sleep, An Issue of Sleep Medicine Clinics - E-Book, volumen 7. Elsevier Health Sciences, 2012.

[43] MECARELLI, O.. Clinical Electroencephalography. Springer, 2019.

[44] BARRETT, K. E.; BARMAN, S. M.; BROOKS, H. L. ; YUAN, J. X.-J.. Ganong's review of medical physiology. McGraw-Hill Education, 2019.

[45] CHOKROVERTY, S.; THOMAS, R. J. ; BHATT, M.. Atlas of Sleep Medicine E-Book. Elsevier Health Sciences, 2013.

[46] MUTZ, J.; JAVADI, A.-H.. Exploring the neural correlates of dream phenomenology and altered states of consciousness during sleep. Neuroscience of Consciousness, 2017(1), 052017.

[47] MALIK, V.; SMITH, D. ; LEE-CHIONG, T.. Respiratory physiology during sleep. Sleep Medicine Clinics, 7(3):497-505, 2012.

[48] BADR, M. S.. Essentials of Sleep Medicine: An Approach for Clinical Pulmonology. Springer, 2012.

[49] GELPI, R. J.; BUCHHOLZ, B.. Neurocardiología: Aspectos fisiopatológicos e implicaciones clínicas. Elsevier Health Sciences, 2018.

[50] ARMENGOL, S.; BernAL, C. ; GARCÍA, R.. Polisomnografía, poligrafía, oximetría. requisitos e interpretación de resultados. JG Santos, Manual de diagnóstico y terapéutica en neumología Coordinador José Gregorio Soto Campos, p. 199-210, 2006.

[51] LLOBERES, P.; DURÁN-CANTOLLA, J.; MARTÍNEZ-GARCÍA, M. Á.; MARÍN, J. M.; FERRER, A.; CORRAL, J.; MASA, J. F.; PARRA, O.; ALONSO-ÁlVAREZ, M. L. ; TERÁN-SANTOS, J.. Diagnóstico y tratamiento del síndrome de apneas- hipopneas del sueño. Arch Bronconeumol, 47(3):143-56, 2011.

[52] GÁllego PÉREZ-LARRAYA, J.; TOLEDO, J.; URRESTARAZU, E. ; IRIARTE, J.. Clasificación de los trastornos del sueño. In: ANALES DEL SISTEMA SANITARIO DE NAVARRA, volumen 30, p. 19-36. SciELO Espana, 2007. 
[53] GALEANO, S. A.; BUITRAGO, D. M. V.. Interpretación de la polisomnografía. Revista Acta de otorrinolaringología \& cirugía de cabeza y cuello, 39(3):57-65, 2011.

[54] ALDUENDA, J. L. C.; DEL BOSQUE, F. M. A.; ZÚÑIGA, M. R.; MALDONADO, A. C.; GARCÍA, J. C. V. ; BOUSCOULET, L. T.. Síndrome de apnea obstructiva del sueño en población adulta. Neumología y Cirugía de Tórax, 69(2):103-115, 2010.

[55] KAKKAR, R. K.; HILL, G. K.. Interpretation of the adult polysomnogram. Otolaryngologic Clinics of North America, 40(4):713-743, 2007.

[56] RESPIROCNICS, P.. La guía del sueño para técnicos : Aspectos Prácticos sobre el diagnóstico del sueño.

[57] FRIEDMAN, M.. Apnea del sueño y roncopatía. Elsevier España, 2009.

[58] FACUNDO, N.; CARLOS, N.; HUGO, C.; EDUARDO, B.; JULIO, S. ; ÁVILA, J.. Guías prácticas de diagnóstico y tratamiento del síndrome de apneas e hipopneas obstructivas del sueño. Medicina (Buenos Aires), 73(4), 2013.

[59] KAMATH, U.; LIU, J. ; WHITAKER, J.. Deep learning for nlp and speech recognition, volumen 84. Springer, 2019.

[60] ZHANG, A.; LIPTON, Z. C.; LI, M. ; SMOLA, A. J.. Dive into deep learning. Unpublished Draft. Retrieved, 19:2019, 2019.

[61] GOOdFEllow, I.; BengIO, Y. ; COURVILLE, A.. Deep Learning. MIT Press, 2016. http://www.deeplearningbook.org.

[62] KUBBEN, P.; DUMONTIER, M. ; DEKKER, A.. Fundamentals of clinical data science. Springer Nature, 2019.

[63] ALBON, C.. Machine learning with python cookbook: Practical solutions from preprocessing to deep learning. "O'Reilly Media, Inc.", 2018.

[64] SWAMYNATHAN, M.. Mastering machine learning with python in six steps: A practical implementation guide to predictive data analytics using python. Apress, 2019.

[65] PATTERSON, J.; GIBSON, A.. Deep learning: A practitioner's approach. "O'Reilly Media, Inc.", 2017. 
[66] PÉREZ ARNAL, R. L.. Wordnet y deep learning: Una posible unión. B.S. thesis, Universitat Politècnica de Catalunya, 2018.

[67] ROBLES-CAMARILLO, D.; PARIS, S.; NAKANO-MIYATAKE, M. ; ÁLVARO LUNA-GONZÁLEZ, J.. Comparación de arquitecturas de redes neuronales convolucionales para la clasificación de imágenes de ojos, 092016.

[68] DURÁN SUÁREZ, J.. Redes neuronales convolucionales en r: Reconocimiento de caracteres escritos a mano. 2017.

[69] IOFFE, S.; SZEGEDY, C.. Batch normalization: Accelerating deep network training by reducing internal covariate shift. arXiv preprint arXiv:1502.03167, 2015.

[70] RICE, L.; WONG, E. ; KOLTER, Z.. Overfitting in adversarially robust deep learning. In: III, H. D.; Singh, A., editors, PROCEEDINGS OF THE 37TH INTERNATIONAL CONFERENCE ON MACHINE LEARNING, volumen 119 de Proceedings of Machine Learning Research, p. 8093-8104. PMLR, 13-18 Jul 2020.

[71] HOPE, T.; RESHEFF, Y. S. ; LIEDER, I.. Learning tensorflow: A guide to building deep learning systems. "O'Reilly Media, Inc.", 2017.

[72] BIANCHI, F. M.; MAIORINO, E.; KAMPFFMEYER, M. C.; RIZZI, A. ; JENSSEN, R.. Recurrent neural networks for short-term load forecasting: an overview and comparative analysis. Springer, 2017.

[73] PATTANAYAK, S.; PATTANAYAK ; JOHN, S.. Pro deep learning with tensorflow. Springer, 2017.

[74] DANGETI, P.. Statistics for machine learning. Packt Publishing Ltd, 2017.

[75] LIN, T.-Y.; GOYAL, P.; GIRSHICK, R.; HE, K. ; DOLLÁR, P.. Focal loss for dense object detection. In: PROCEEDINGS OF THE IEEE INTERNATIONAL CONFERENCE ON COMPUTER VISION, p. 29802988, 2017.

[76] BISWAL, S.; KULAS, J.; SUN, H.; GOPARAJU, B.; WESTOVER, M. B.; BIANCHI, M. T. ; SUN, J.. Sleepnet: automated sleep staging system via deep learning. arXiv preprint arXiv:1707.08262, 2017. 
[77] RUFFINI, G.; IBAÑEZ, D.; CASTELLANO, M.; DUBREUIL-VALL, L.; SORIA-FRISCH, A.; POSTUMA, R.; GAGNON, J.-F. ; MONTPLAISIR, J.. Deep learning with eeg spectrograms in rapid eye movement behavior disorder. Frontiers in neurology, 10, 2019.

[78] CHATTERJEE, R.; BANDYOPADHYAY, T.; SANYAL, D. K. ; GUHA, D.. Comparative analysis of feature extraction techniques in motor imagery eeg signal classification. In: PROCEEDINGS OF FIRST INTERNATIONAL CONFERENCE ON SMART SYSTEM, INNOVATIONS AND COMPUTING, p. 73-83. Springer, 2018.

[79] SCHELLENBERGER, S.; SHI, K.; MAI, M.; WIEDEMANN, J. P.; STEIGLEDER, T.; ESKOFIER, B.; WEIGEL, R. ; KÖLPIN, A.. Detecting respiratory effort-related arousals in polysomnographic data using lstm networks. In: 2018 COMPUTING IN CARDIOLOGY CONFERENCE (CINC), volumen 45, p. 1-4. IEEE, 2018.

[80] KUMAR, M. R.; RAO, Y. S.. Epileptic seizures classification in eeg signal based on semantic features and variational mode decomposition. Cluster Computing, 22(6):13521-13531, 2019.

[81] GARDE, P.; THAKARE, A.; BIRADAR, A. ; PAWAR, N.. Performance analysis of machine learning algorithms for classification of electroencephalogram signals for detection of seizures.

[82] LESTARI, F. P.; HAEKAL, M.; EDISON, R. E.; FAUZY, F. R.; KHOTIMAH, S. N. ; HARYANTO, F.. Epileptic seizure detection in eegs by using random tree forest, naïve bayes and knn classification. In: JOURNAL OF PHYSICS: CONFERENCE SERIES, volumen 1505, p. 012055. IOP Publishing, 2020.

[83] EDLA, D. R.; MANGALOREKAR, K.; DHAVALIKAR, G. ; DODIA, S.. Classification of eeg data for human mental state analysis using random forest classifier. Procedia computer science, 132:1523-1532, 2018.

[84] RODRIGUES, J. D. C.; REBOUÇAS FILHO, P. P.; PEIXOTO JR, E.; KUMAR, A. ; DE ALBUQUERQUE, V. H. C.. Classification of eeg signals to detect alcoholism using machine learning techniques. Pattern Recognition Letters, 125:140-149, 2019. 
[85] KAYA, Y.; ERTUĞRUL, Ö. F.. A stable feature extraction method in classification epileptic eeg signals. Australasian physical \& engineering sciences in medicine, 41(3):721-730, 2018.

[86] THOMPSON, S.. Sampling. CourseSmart. Wiley, 2012.

[87] COHEN, M. X.. Analyzing neural time series data: theory and practice. MIT press, 2014.

[88] PLATO, R.. Concise numerical mathematics. Número 57. American Mathematical Soc., 2003.

[89] CHIRANJEEVI, R.; DIXIT, U.. A note on clamped simpson's rule. Global Journal of Pure and Applied Mathematics, 13(9):5275-5285, 2017.

[90] FAWCETT, T.. An introduction to roc analysis. Pattern recognition letters, 27(8):861-874, 2006.

[91] DAVIS, J.; GOADRICH, M.. The relationship between precisionrecall and roc curves. In: PROCEEDINGS OF THE 23RD INTERNATIONAL CONFERENCE ON MACHINE LEARNING, p. 233-240, 2006.

[92] BOYD, K.; ENG, K. H. ; PAGE, C. D.. Area under the precision-recall curve: point estimates and confidence intervals. In: JOINT EUROPEAN CONFERENCE ON MACHINE LEARNING AND KNOWLEDGE DISCOVERY IN DATABASES, p. 451-466. Springer, 2013.

[93] SADR, N.; DE CHAZAL, P.. Automatic scoring of non-apnoea arousals using the polysomnogram. In: 2018 COMPUTING IN CARDIOLOGY CONFERENCE (CINC), volumen 45, p. 1-4. IEEE, 2018.

[94] RAO, A.; GHOSH, P. K.; BHATTACHARJEE, T. ; CHOUDHURY, A. D.. Trend statistics network and channel invariant eeg network for sleep arousal study. In: 2019 41ST ANNUAL INTERNATIONAL CONFERENCE OF THE IEEE ENGINEERING IN MEDICINE AND BIOLOGY SOCIETY (EMBC), p. 5716-5722. IEEE, 2019.

[95] SHOEB, A.; SRIDHAR, N.. Evaluating convolutional and recurrent neural network architectures for respiratory-effort related arousal detection during sleep. In: 2018 COMPUTING IN CARDIOLOGY CONFERENCE (CINC), volumen 45, p. 1-4. IEEE, 2018.

[96] LÓPEZ, D. F. A.; VÉLEZ, D. D. C.; SUÁREZ, D. V. J. C.; MARTínEZ, D. J. Á. C.; BUIL, J. C. G.; LÓPEZ, D. M. J.; MATEO, J. L.; ARDOY, 
D. D. N.; CANALS, O. M.; ARIAS, D. I. R. ; OTHERS. Neurociencia, Deporte y Educación. Wanceulen Editorial SL, 2018.

[97] NOGALES-GAETE, J.. Tratado de neurología clínica. Editorial Universitaria, 2005.

[98] HORNYAK, M.; FeIGE, B.; RIEMANN, D. ; VODERHOLZER, U.. Periodic leg movements in sleep and periodic limb movement disorder: prevalence, clinical significance and treatment. Sleep medicine reviews, 10(3):169-177, 2006.

[99] SATEIA, M. J.. International classification of sleep disorders. Chest, 146(5):1387-1394, 2014.

[100] CHOKROVERTY, S.. Medicina de los trastornos del sueño. Elsevier, 2011.

[101] TATUM IV, W. O.. Handbook of EEG interpretation. Demos Medical Publishing, 2014.

[102] SHRIVASTAVA, D.; JUNG, S.; SAADAT, M.; SIROHI, R. ; CREWSON, K.. How to interpret the results of a sleep study. Journal of community hospital internal medicine perspectives, 4(5):24983, 2014. 


\section{Glossário}

- Batch: Subconjunto de observações do conjunto de dados.

- Hipercapnia: Excesso de dióxido de carbono $\left(\mathrm{CO}_{2}\right)$ na corrente sanguínea, O problema decorre da falta de ventilação pulmonar, em que a insuficiência respiratória, faz com que o $\mathrm{CO}_{2}$ não seja exalado de forma suficiente.

- Hipoxia: Estado de deficiência de oxigênio no sangue, células e tecidos do corpo, com comprometimento do sua função.

- Pressão Arterial: É a força exercida pela sangue contras a parede das artérias e expressa em unidades de $\mathrm{mmHg}$.

- Pressão positiva contínua nas vias aéreas (CPAP): Tipo de pressão positiva nas vias aéreas, em que o fluxo de ar é introduzido nas vias aéreas para manter uma pressão contínua para abrir o stent constantemente nas vias aéreas, em pessoas que respiram espontaneamente.

- Quimiorreatividade: Refere-se à alteração da ventilação em resposta a alterações nos estímulos químicos.

- Quimiorresponsividade: Respostas a hipóxia e hipercapnia.

- Ritmo Alpha: Refere-se a atividade mais proeminente nas derivações occipitais que é atenuada pela abertura de olho e aumentada pelo fechamento do olho.

- Saturação de Oxigênio: É a medida da quantidade de oxigênio disponível na corrente sanguínea.

- Tônus muscular: É o estado de tensão elástica que apresenta o músculo em repouso, e que permite iniciar a contração rapidamente após o impulso dos centros nervosos. 